\title{
FISSURAS LÁBIO-PALATAIS: \\ ESTUDO CASO-CONTROLE DE FATORES DE RISCO
}

Leonor de Castro Monteiro Loffredo

Tese apresentada à Faculdade de Saúde Pública da Universidade de São Paulo, Departamento de Epidemiologia, pare obtenção do título de Doutor em Saúde Pública.

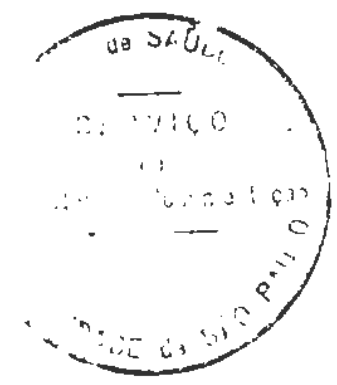

SÃo PAULO

1990 


\section{FISSURAS LÁBIO-PALATAIS:}

ESTUDO CASO-CONTROLE DE FATORES DE RISCO

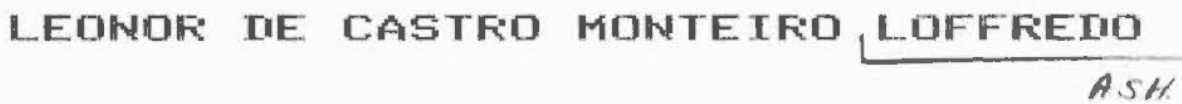

Tese apresentada à Faculdade de Saúde Pública da Universidade de São Paulo, Departamento de Epidemiologia, para obtenção do titulo de Doutor em Sacide Pública

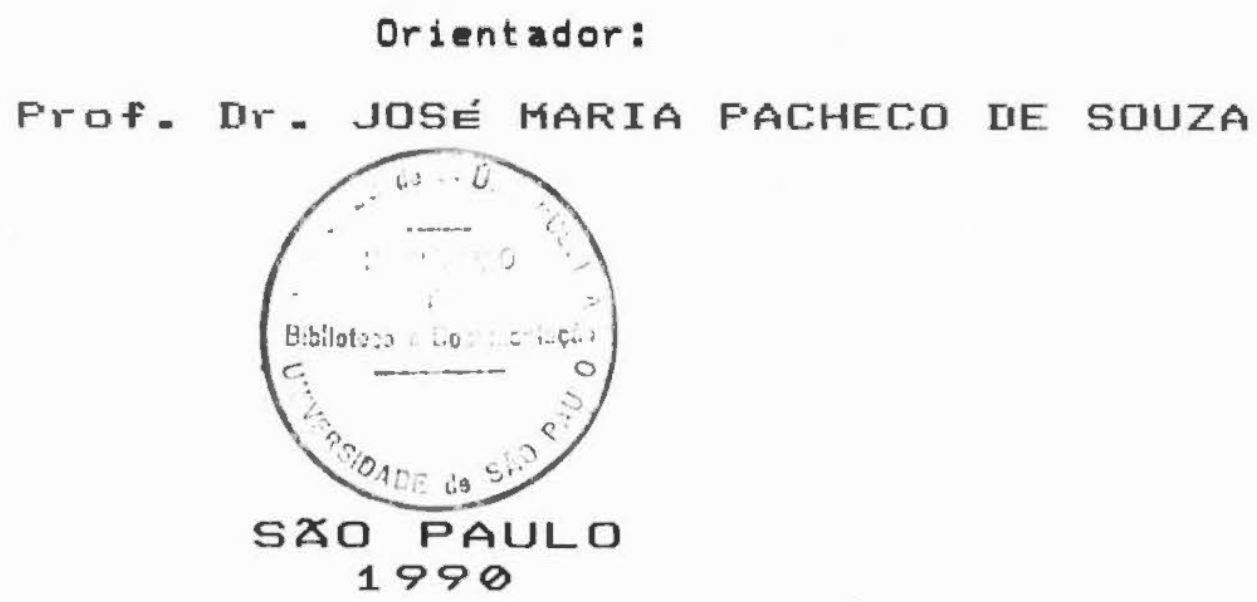


AO FRANCISCO 
Este trabalio foi firuto da conjugacaro de esforcos de varias fessoas, a quem, sinteramente,

\section{AGRADECO:}

Em primeiro lugar, ao Professor JOSá MARIA PACHECD DE SOUZA, meu orientador de tese e, mais que isso, lúcido guia e apoio seguro em todas as minhas fases de estudo nesta Universidade.

Ao Professor Joxo YUNEs, que desempenhou papel decisivo para meu ingresso no curso de Pós-Graduacão, abrigando-me sob sua orientacão, na fase de abtencão de créditos.

Aos Professores ANTONIO RUFFino NETO e SABINA LEA DAUIDSON GOTLIEB, pela participacão na elaboracão do projeto e pela leitura critica deste trabalho.

Ao Professor José ALberto dE souza freitas, Superintendente do Hospital de Pesquisa e Reabilitação de Lesões Lábio-Palatais, da USP, Pela especial atencão no levantamento de casos junto a essa Instituicão. 
Ao Professor EDMUNDo JUAREZ, pelas consideracões feitas quanto à metodologia a ser utilizada e pela indicacão de entrevistadoras para aplicacão de questionários aos controles.

Aos Professores RoOUE MONTELEONE, EUCLIDES AYRES DE CASTILHO, MARIA LúCia dE MOURA SILUA SOBOLl, MARIA DO CARMO COSTA UASCONCELLOS, ELCIO MARCANTONIO, FAUSTO GABRIELLI, VALTER CURI RODRIGUES, HAROLDO WILSON MOREIRA E MARIA JACIRA'SIMÕES, pelas sugestões.

Ao analista de sistemas NIKOLAS LOCHAGIN, pela participacăo em todas as fases do processamento de dados.

Ao engentheiro FRANCISCO LOFFREDO NETO, pela orientação quanto ao procedimento para conversão da moeda.

¿ Professora LÚCIA HELENA DE MOURA NEVES, que muito me ajudou, assumindo as aulas do curso de Bioestatistica e Metodologia Cientifica. 
Ao Professor ANTONIO LUIZ RODRIGUEs JUNIOR, pela colaboracão na revisão.

Às entrevistadoras WILZA CARLA SPIRI, SöNIA MARIA SANTOS SOMENZARI, SILUANA LUPATELLI e MARTA INENAME, que aplicaram os questionários com competência e dedicacão, possibilitando a realizacão dessa pesquisa.

A bibliotecária MARIA HELENA MATSUMOTO KOMASTI pela orientacão dada quanto às referências bibliográficas.

A GISELDA APARECIDA BOTARI, secretária excelente que se dedicou a um trabalho que, para ela, era voluntário. 
Para a realizaหă deste trabalho contribuiram também as seguintes instituieses:

A Faculdade de Odontologia de Araraquara - UNESP, que me ofereceu condicões institucionais para dedicacão à pesquisa, e à qual agradeco nas pessoas de seu Diretor, Professor TATSUKO SAKIMA, de seu Vice-Diretor, Professor LUIS ROBERTO DE TOLEDO RAMALHO e do Chefe de seu Departamento de Odontologia Social, Professor LUIZ ANTONIO SAMPAIO.

A Faculdade de Saúde Pública, que me destinou uma bolsa para obtencão de periódicos de interesse junto à Biblioteca.

Ao Programa Instttucional de Capacitacão Docente (PICD), pela bolsa de estudos oferecida para obtencão de créditos.

A FUNDUNESP (Prac . ne $274 / 88$ ), que financiou o levantamento de campo. 


\section{RESUMD}

As fissuras orais integram dois grupos segundo origens etiológicas distintas, quais sejam, fissuras labiais ou lábio-palatais e fissuras palatais.

Realizou-se um estudo tipo caso-controle, com 450 casos e 450 controles, sendo que, entre os casos, 354 eram portadores de fissura labial ou lábio-palatina e 96 de fissura palatina.

A fin de se estudar a associacão entre fissuras orais e possiveis fatores de risco, foram objeto de análise as variáveis: local de moradia da mãe nos quatro primeiros meses de gestacão (urbana/rural), poluicão, aplicacão de pesticida e herbicida na lavoura, doencas nos pais, doencas na mãe nos quatro primeiros meses de gestacão, ingestão medicamentosa nesse periodo, hereditariedade, tabagismo, consumo de bebida alcoolica e exposicão a raio-X durante a gestação ou um ano antes.

Foram estimados os riscos relativos (RR), segundo cada variavel, por ponto e por intervalo de $95 \%$ de confianca. Empregou-se análise multivariada, adotando-se o. procedimento de máxima verossimilhanca incondicional, para,cada tipo de fissura.

As variáveis hereditariedade (RR $=4,96)$, epilepsia na mãe (RR $=2,39)$ e ingestão de anti-inflamatório (RR = 2,59) são fatores de risco para fissuras lạbiais ou lábio-palatais.

As variáveis hereditariedade $(R R=2,82)$ e poluicลão (RR $=2,58)$ são fatores de risco para fissuras palatinas. 


\section{SUMMARY}

There are two groups of clefts which differ in their etiology, namely the group with cleft lip with or without cleft palate and the group of cleft palate isolated.

This study refers to a case-control analysis, with 450 cases and 450 controls. Among the cases, 354 have cleft 1 ip with or without cleft palate and 96 have cleft palate.

In order to study the association between oral clefts and possible risk factors, the analised variables were: place of mother's residence (urban/rural); pollution, "parents's diseases, mother's diseases during the first four months of pregnancy, intake of drugs related to this period, heredity, smoking habits, alcohol consumption and $X$-ray examinations during pregnancy or X-ray examinations prior to pregnancy.

It was estimated the relative risks (RR), for each variable by point and by $95 \%$ of confidence interval. It was applied multivariate analysis, for unconditional maximum likelihood procedure, according to each type of cleft.

Related to cleft lip with or without cleft palate, the risk factors areheredity $(R R=4,96)$, epilepsy in the mother ( $R R=2,39)$ and drug intake as anti-inflammatory in the first four months of pregnancy $(R R=2,59)$.

Related to cleft palate, the risk factors are heredity $(R R=2,82)$ and pollution $(R R=2,58)$. 
3. MATERIAL E MÉTODO ............................... 21

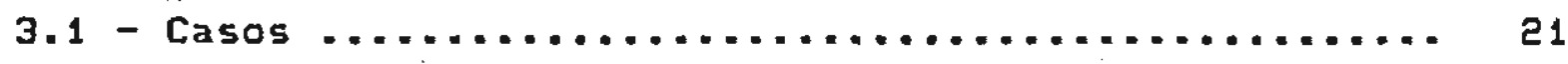

3.2 - Controles $. \ldots \ldots \ldots \ldots \ldots \ldots \ldots \ldots \ldots \ldots \ldots \ldots \ldots \ldots . \ldots \ldots$

3.3 - Formulário.. .......................... 24

3.4 - Variáveis estudadas ..................... 26

3.5 - Análise estatistica $\ldots \ldots \ldots \ldots \ldots \ldots \ldots \ldots \ldots \ldots . .27$

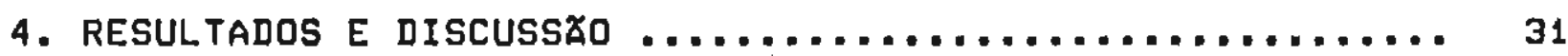

4.1 - Caracterizacão da amostra................... 31

4.2 - Fatores de risco ........................ 41

4.3 - Consideracões gerais ..................... 59 
ANEXOS

- ANEXO I - FORMULÁRIO - FISSURAS LÁBIO-PALATAIS: FATO-

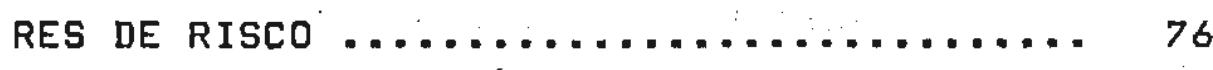

- ANEXo II - Manual para aPLicacxo do formulário ......

- ANEXO III - CONUERSZ̃ DA RENDA PER CAPITA ........... 93

- ANEXo IU - TABELAS de contingência para fissura laBIAL OU LÁBIO-PALATINA ............... 94

- anexo $U$ - tabelas de contingencia para fissura pala- 


\section{FISSURAS LÁBIO-PALATAIS: ESTUDO CASO-CONTROLE DE FATORES DE RISCO}

\section{1 - INTRODUCXO}

As fissuras lábio-palatais são anomalias congênitas que se originam em periodos iniciais do desenvolvimento embrionário 11,40 e podem ocorrer como transtornos isolados ou associados a outras anomalias 39,60 de maior ou menor gravidade.

$$
\text { Morfologicamente } 6 \text { existem três tipos de fissuras: }
$$

de lábio, de lábio e pálato e de pálato, os quais integram dois grupos de fissuras segundo origens etiológicas distintas 63,78 ,

a saber:

- Fissura de lábio ou lábio-palatina, também denominada de fenda de lábio (ou lábio leporino) ou fenda lábio-palatina,que é resultante da falta de fusão dos processos nasais da proeminência frontal com o processo maxilar, por volta da $7^{a}$. semana do desenvolvimento embrionário. As fissuras de lábio podem ser unilaterais ou bilaterais,

- Fissura de pálato, também conhecida por fenda palatina ou pálato fendido, originária da falta da união na linha mediana de processos bilaterais independentes do maxilar, por volta da $12^{a}$. semana de vida intra-uterina.

Estas malformacões, como transtornos isolados, exercem influência na vida do portador, pois o pálato fendido 
provoca defeitos de fonacão e degluticão, o lábio fendido desfigura, sendo que esses fatores levam a efeitos psicológicos e sociais negativos.

Para o entendimento da instaląão das fissuras, é de interesse observar o desenvolvimento do embrião de 10 semanas, em corte frontal (Fig. 1) 38.

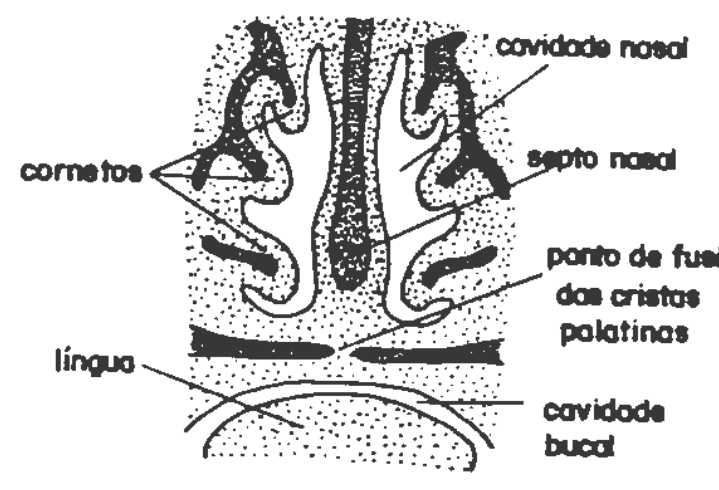

A

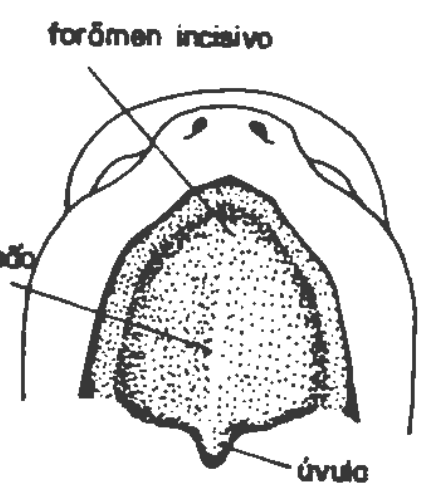

B

Fig. 1 - A, Corte frontal do cobego de um embribo de 1080 monas. As duos cristas palatines fundirom-se entre si - com o septo nosd. B, Teto ventral do palota. 0 forömen incisivo marca o ponto onde ocorreu a fusto entre o paloto primitivo o o secundório.

LANGMAN 38 sugeriu que "o forâmen inclsivo deva ser considerado como um ponto de referência entre as malformacones anteriores e posteriores. Aquelas que ocorressem anteriormente ao forámen incisivo, estariam baseadas na falta de uma invasão adequada de mesoderma no sulco que ocorre entre a crista nasomedial 
e as saliências maxilares, e incluiriam o lábio leporino lateral, - maxilar superior fendido e a fissura entre os pálatos primário e secundário (Fig. 2 B, $C, D$ ). Aquelas anomalias que ficassem posteriormente ao forâmen incisivo, seriam causadas por uma ausência de fusão das cristas palatinas e incluiriam o pálato (secundário) fendido e a úvula fendida (Fig. 2 E). Uma terceira categoria seria formada pela combinacăo de fissuras que ocorrem tanto adiante, como atrás do forâmen incisivo (Fig. E F). "Obtémse a forma mais completa de fissura quando a fenda palatina ocorre em conjunto com o lábio-leporino bilateral.

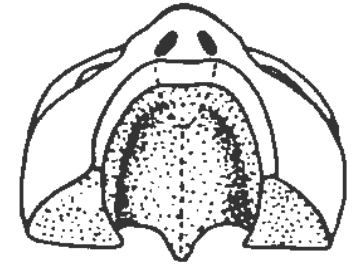

A

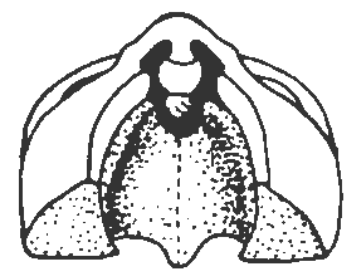

D

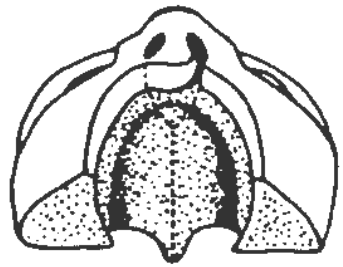

B

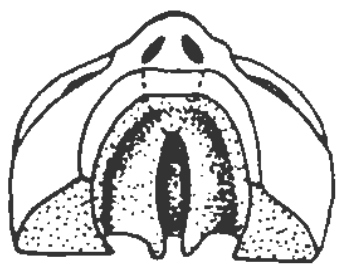

E

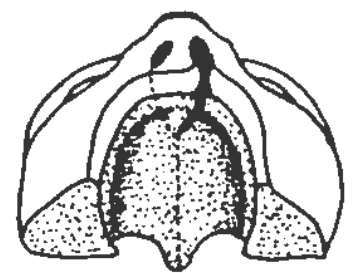

c

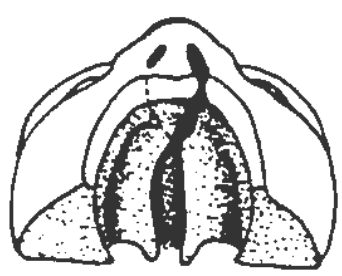

$F$

Fig. 2 - Visto ventral do pálato, gengivos, lóbio e noriz. A, Normal. B, Lábio leporino uniloterol estendendo-se $\infty$ noriz. $C$, lóbio leporino unilateral interessando o lábio, e maxilo $\theta$ estendento-se 00 forâmen incisivo. D, Lébio leporino biloteral interesaando o lóbio a maxila. E, Fendiduro palatina simples. F, Fendidura polotino combinado com lóbio leporino unilaterol. 
A diferenca entre as fissuras de lábio cou lábiopalatina) e de pálato foi primeiramente descrita por FOGH-ANDERSEN, em 1942, citado por SAXÉN 66, que realizou um estudo epidemiológico e verificou que descendentes de pacientes com fissura de lábio ou lábio-palatina tinham uma freqüência maior de fissura de lábio ou lábio-palatina, mas não de fissura palatina, e viceversa.

Mais tardes foi sugerido que as fissuras de lábio e/ou pálato também diferiam em sua etiologia com relacão a fatores genéticos e ambientais 19, 40,50. Assim, observaram uma história familiar positiva de maior freqüência de portadores de fissura de lábio ou lábio-palatina do que de pálato e fizeram referência à hereditariedade da fissura de lábio ou lábio-palatina. Quanto aos fatores ambientais, sugeriram que poderiam desempenhar papel importante. no aparecimento da fissura palatina. Entre os fatores etiológicos para as fissuras, FOGH-ANDERSEN 19 considera a hereditariedade como o mais importante, sendo responsavel por 40 - $50 \%$ das fissuras lábiais ou lábio-palatais e por 20 - 25\% das fissuras palatais.

A maioria dos casos de fissuras tem o padrão de heranca multifatorial, com a interacão de fatores genéticos e ambientais $14,21,43$. Os restantes estão associados a um gene mutante especifico, a aberracões cromossômicas ou a agentes ambientais especificos 21,78 .

Dados sobre a freqüência desta anomalia têm como fontes principais os hospitais e clinicas especializadas no tratamento 1,50 , certidões de nascimento $28,29,30,46,50,80$ e materni- 
dades 10,50,69. Em relacão às certidões de nascimento, uma investigacão indicou que quanto mais severa a lesão, mais completo era - relato e, à medida que as lesŏes eram de menor gravidade, o relato trazia problemas aospesquisador, dada a falta de informacóes completas 46.

o primeiro pesquisador a se preocupar com a prevalência das fissuras orais foi o russo FROBELIUS, citado por FOGHANDERSEN 18, sendo que, para o periodo de 1833 a 1864 , analisou 180000 criancas de um hospital de St. Petersburg e encontrou 118 portadores, o que resultou na relafão afetado: normal de 1:1525 ou numa prevalência de 0,7 por 1000 crianças.

A fim de verificar a tendência da anomalia na Dinamarca, FOGH-ANDERSEN 18 encontrou, para os quinqüênios correspondentes ao nascimento da crianca, 1938-42, 1943-47, 1948-52 e 1953-57, indices de pacientes operados por 1000 nascidos vivos de, respectivamente, $1,31,1,37,1,46$ e 1,64. Assim, para o periodo de estudo, houve um aumento na prevaléncia da doenca $e$ o autor sugeriu que alguns aspectos deveriam ser analisados, tais como a queda da mortalidade pós-natal a a diminuifăo do número de óbitos operatórios. Acrescentou que a acentuada melhora dos resultados operatórios resultariam numa vida normal para o paciente e conseqüente aumento da hereditariedade como fator etiológico. 0 autor menciona que na Dinamarca, em 1939, a proporcão de fissuras para nascimentos foi de 1:665, resultando a prevalência de 1,50 para 1000 nascimentos e de 1,45 para 1000 naseidos vivos. Analisando esporificamente as fissuras palatinas, verificou-se o aumento de sua frequência na Dinamarca no periơo de 1940 a 1971, sen- 
do, respectivamente, 0,28 e 0,51 por 1000 nascimentos 71.

Levantamento da ocorrência das lesões lábio-palatinas, segundo revisão da literatura por SESGIN \& STARK 69, assinalou a maior ocorrência no Hawai, em 1940, numa proporcão de 1:550, ou seja, 1,82 por 1000 e a mais baika ocorrência na Inglaterra, no London Hospital, em 1908, correspondendo a 1:1742, ou seja, 0,57 por 1000 .

KNOX e BRAITHWAITE 36 procuraram avaliar a prevalência das fissuras na Inglaterra, para os condados de Northumberland e Durham, no periodo de 1949 a 1959. Para este periodo, obtiveram os registros hospitalares de 404124 nascimentos, encontrando 574 fissurados, resultando o coeficiente de 1,42 por 1000 nascidos vivos.

LECK 40 realizou estudo em Birmingham - Inglaterra, no periado de 1950 a 1960 e encontrou prevalência de 0,60 por 1000 nascimentos para fissura palatina e de 1,20 por 1000 nascimentos para fissura labial ou lábio-palatina.

GREENE 28 analisou 3578438 certidões de nascimento para a Califórnia, Hawai, Pensilvânia e Wiscosin, referentes ao periodo de 1956 a 1960 e observou o coeficiente de 1,24 por 1000 nascidos vivos, sendo mais alto no Hawai, de 1,50 por 1000 e mais baixo na Pensilvânia, correspondendo a 1,16 por 1000 .

Em Montana, E.U.A., TRESTUEN 79 fez um levantamento de 7461 criancas indigenas no periodo de 1956 a 1961, inclusiVes encontrando 27 portadores de fendas, numa proporcão 1:276, ou seja, 3,62 por 1000, a maior prevalência observada em todo o mun- 
do. Em relacão às criancas não-indigenas, a prevalência foi de 1,72 por 1000, pois entre as 115402 criancas examinadas, 198 eram afetadas. O autor chama a atencão para a necessidade de verificacão de diferencas culturais entre as duas populacões.

MILHAM 48 analisou 79536 criancas nascidas em três hospitais do norte do Estado de Nova York, na década de 1950 a 1960, tendo encontrado 143 casos; resultando uma prevalência de 1,80 por 1000 nascidas vivas, ou seja, $1: 556$.

OLIN 59 obteve, para os anos de.1945, 1951 e 1961, as seguintes prevalências de fendas por numero total de nascimentos, no estado de Iowa - E.U.A., 0,83 por $1000,1,36$ por 1000 e 1,43 por 1000 , respectivamente. 0 autor relata que as discrepâncias nas prevalências não refletem diferenca, mas variacão no método de coleta de dados nos diversos anos.

MOLLER 50 estudou a prevalência de fissuras lábiopalatais segundo diferentes fontes de informacão - certidão de nascimento, prontuários de maternidades e de clínicas especializadas - na Islândia, no periodo de 1956 a 1962, encontrando a taxa de 1,94 por 1000 .

Em 1965, estudo sobre a prevalência de fissurasi na Jamaica, onde $90 \%$ da populacão da ilha é de negros ou de negros miscigenados, revelou uma taxa de 1:18日7 nascimentos, ou seja, 0,53 por 1000 49. Segundo o autor, os fatores contributórios para essa baixa prevalência são infanticidio nas tribos africanas e escolha dos escravos para importacão 49.

$\mathrm{Na}$ Noruega, em 1967, foi introduzido o modelo de registro médico de nascimentos, incluindo malformacões congênitas 
nos nascidos vivos 1. Para o periodo de 1967 a 1974, já estando as fissuras registradas nos prontuários médicos, foi estimada a prevalência destas anomalias, para a Noruega, em 2,08 por 1000 nascidos vivos, assim distribuidas: 1,43 por 1000 para fissura lábio-palatina e 0,65 por 1000 para fissura palatina. Dutro estudo mostrou que, para o periodo de 1967 a 1969 , a prevalência média anual era de 1,8 por 1600 e a partir de 1969 houve um decréscimo gradativo deste coeficiente, atingindo 1,60 por 1000 em 1972, elevando-se para 2,0 por 1000 , em 19735.

Na Franca 6, foram estudados 126087 nascimentos e encontrou-se 104 portadores de fissura lábio-palatina e 44 de fissura palatina, excluidas as malformacŏes sindrômicas, resultando as prevalências de, respectivamente, 0,82 por 1000 e 0,35 por 1000. Ao serem excluidos os nati-mortos, restaran 124356 nascidos-vivos e o número de portadores de fissura lábio-palatina foi de 162, não se alterando o numero de portadores de fenda palatina, tendo as respectivas prevalências permanecido iguais. BONAITI et al 6 comentam que a freqüência de fissuras, particularmente as de lábio elou pálato é menor na Franca do que nos outros paises europeus.

SAXÉN 65, en 1974, analisando resultados de estudos epidemiológicos existentes, encontrou uma prevalência na Finlândia que julgou "alta", variando de 1,66 por 1000 a 1,71 por 1000.

Gombos 26 estudou a prevalência de fissuras em Nápoles, na Itália, no quinquiênio 1975-79 e num total de 177996 nascimentos encontrou 64 fissurados, ou seja 0,36 por 1000 , sendo 
que a incidência anual variou de 0,20 por 1000 (1975) a 0,54 por $1000(1979)$.

A prevalência de fissurados numa revisão de 43649 prontuarios de recém-nascidos numa maternidade de Camaguey, Cuba, para os anos de 1975, 1976, 1977 , 1978 e 1979 foi de, respectivamente, 0,80 por $1000,0,35$ por $1000,0,33$ por $1000,0,33$ por 1000 e 1,14 por 1000 42.

Estudo realizado na populacão negra da África do Sul, com análise retrospectiva de 29633 prontuários médicos de nascimentos ocorridos no Baragwanath Hospital, em Johannesburg, no periodo de janeiro/76 a dezembro/77, encontrou 9 fissurados, ou seja, 0,30 por 1000 37. Este. coeficiente foi similar ao referente à raca negra de Pretoria $(0,10$ por 1000 nascimentos) durante. estudo conduzido por STEUENSON et al 76 em 1966 , que observou, Para Uganda, coeficiente de 1,45 por 1000 nascimentos, mostrando que a situacăo dos grupos negros de região mais ao norte da África não é a mesma.

IREGBULEM 33 examinou 21624 criancas nascidas na Nigéria, no " The University of Nigeria Teaching Hospital"-Enugu, no periodo de 1976 a 1980 e encontrou 8 casos de fissuras lábiopalatinas; resultando numa prevalência de $1: 2703$ nascidos vivos $(0,48$ por 1000$)$. Sugeriu que alguns fatores poderiam estar subestimando o numero de fissurados, assim como a mortalidade perinatal por desnutricãos morbidade e infanticidio. Acrescentou que a incidência de casamentos consangüíneos é bastante baika entre nigerianos e a freqüência maior de fissurados observada entre negros americanos poderia estar associada à maior intensidade de 
casamentos miscigenados, bem como ausência de infanticidios e mortalidade perinatal mais baixa 33. Posteriormente, em 1985, ADEKEYE 2 realizou estudo de fissurados, independentemente da faixa etária dos portadores, e comentou não ser possivel obter a exata prevalência da anomalia na Nigéria, porque nascimentos e óbitos não são registrados de maneira adequada e o fato das lesões mais severas levarem à sobrevida baixa compromete a comparacão das diferencas encontradas em outros paises, quanto a atributos como sexo, etnia, tipo de fissura e outros.

$\mathrm{Na}$ Austrália, as fissuras orais integram o grupo das anomalias mais prevalentes, cuja freqüência é de 1,71 por 1000 nascidos vivos, em 1982 e $1983^{9}$.

A prevalência da anomalia entre os japoneses foi calculada a partir de informacões a respeito de 40304 nascidos vivos durante 1982 , representando $49,2 \%$ do total de nascidos vivos em Aichi Prefecture. O coeficiente observado foi de 2,06 por 1000 nascidos vivos 56.

MORRISON et al 52 encontraram para a populacão de Western Cape-Africa, no ano de 1983, os seguintes coeficientes por 1000 nascimentos, para brancos, "coloureds" e negros: 0,59, 1,40 e 0,32 , respectivamente. Entre negros, a prevalência é baixa e próxima à encontrada para os negros da Nigéria 33 . 0 autor 52 comenta que os brancos da África do Sul apresentam prevalência baixa, quando comparada com a de brancos de qualquer outra parte do mundo.

Quanto ao tipo de fissura, foi feita a tabela 1, tendo como fonte pesquisas anteriormente conduzidas. 
TABELA 1 - DTSTRIRUTLAO DAS FISSURAS SEGUNDO O TIFO E FAT'SES SELECTONADOS.

\begin{tabular}{|c|c|c|c|}
\hline PAIS & $\begin{array}{l}\text { LABBIO OU } \\
\text { LÁBIO E PÁLATO } \\
(\%)\end{array}$ & $\begin{array}{l}\text { PÁLATO } \\
(\%)\end{array}$ & $\begin{array}{c}\text { REFERÊNCIA } \\
\text { BIBLIOGRÁFICA }\end{array}$ \\
\hline DINAMARCA & 79,7 & 20,3 & 27 \\
\hline NIGERIA & 81,0 & 19,0 & 33 \\
\hline NORUEGA & 68,6 & 31,4 & 1 \\
\hline SUÉCIA & 69,1 & 30,9 & 61 \\
\hline ISLÂNDIA & 68,7 & 31,3 & 50 \\
\hline JAPX̃O & 78,8 & 21,2 & 56 \\
\hline FINLÂNDIA & 43,0 & 57,0 & 61 \\
\hline
\end{tabular}

Observa-se, pela tabela 1, que apenas na Finlândia existe maior proporção de fissuras referentes ao pálato (57\%). A esse respeito, SAXEN 67 sugeriu que caracteristicas morfológicas distintas na populacão da Finlândia poderiam estar associadas à susceptibilidade à fissura palatina. RINTALA 61 afirmou que embora as prevalências nos diferentes paises escandinavos sejam semelhantes, variando de 1,76 a 2,16 por 1000 nascidos vivos, existe diferenca nas proporcões de fissura lábio-palatina e palatina, sendo a primeira responsável por mais de $68 \%$ das fissuras na Dinamarca, Suécia, Islândia e Noruega. 
Quanto ao comportamento das fissuras segundo etnia, foi construida a tabela 2 .

TABELA 2 - FREUALENLTA DE FISSURAS LAETO-FALATATS; SEGUNDO ETNTA E PATS.

PREUALÊNCIA

REFERÊNCIA

ETNIA

(POR 1000)

PAIS

DATA BIBLIOGRÁFICA

$\begin{array}{lllll}\text { MONGOL } & 2,68 & \text { Japão } & 1958 & 57 \\ & 2,06 & \text { Japão } & 1982 & 56 \\ \text { CAUCASóIDE } & 1,30 & \text { Inglaterra } & 1953 & 43 \\ & 2,00 & \text { Dinamarca } & 1971 & 21 \\ \text { NEGRóIDE } & 0,23 \text { a } 0,71 & \text { E.U.A. } & 1963 & 3 \\ & 0,53 & \text { Jamaica } & 1965 & 49 \\ & 0,37 & \text { Nigéria } & 1981 & 34 \\ & 0,32 & \text { Africa do sul } & 1985 & 52\end{array}$

A tabela 2 mostra prevalência mais baixa na raca negróide, alta entre os mongóis e intermediária entre os caucasóides. Pesquisa desenvolvida nos E.U.A. - North Carolina, em grupos raciais, relata desconhecer as razões para o número reduzido de fissurados entre os negros, sugerindo que poderiam estar 
relacionadas com o processo de selecão de escravos africanos, sendo que um numero reduzido de pessoas com fissuras atravessaria - Atlântico, resultando, portanto, em menor carga genética para as fissuras 53. Segundo MORRISON et al 52 , as populacões com caracteristicas caucasóides da África do Sul apresentam prevalência de fissura (1:1700) mais baixa do que a citada em pesquisas entre caucasóides de outras partes do mundo 21, 43. Entre os mongóis, fatores relacionados à cultura e a aspectos biológicos poderiam desempentar papel importante no estudo da etiologia das fissuras, tais como:

- consangüinidade - populacão confinada em aldeias, ocorrendo casamento entre parentes e

- radiacão ionizante da bomba atômica, pois o Japão apresenta. a maior prevalência de fissuras e de malformacões em geral.

Quanto à consangüinidade, TANAKA 77 encontrou $2,7 \%$ de casamentos consangiíneos entre pais de fissurados de lábio elou pálato, quando realizou estudo epidemiológico em Hokkaidog Japão. CHUNG \& KAU 12 observaram diferencas raciais quanto a medidas cefalométricas e prevalência de fissuras lábio-palatais, sugerindo atencão para o embasamento morfológico em estudos de fissuras. Quando se distribuem as fissuras segundo tipos, lábio ou lábio/pálato e pálato, o comportamento, segundo etnia, é semelhante ao observado para as fissuras em geral, como mostra a tabela 3 : 
TABELA 3 - FREUALENETA (FOK IGOG NASTIDOS UTWDS DAS FISSURAS DE LABTO OU LABTO-FALATINA E FISSURA FALATINA; SEGUNDO ETNTA.

LÁBIO OU FISSURA
ETNIA LABIO E PALATO REFERENCIA
BIBLIOGRÁFICA

$\begin{array}{llll}\text { MONGOL } & 2,13 & 0,55 & 57 \\ \text { CAUCASÓIDE } & 1,34 & 0,48 & 13 \\ \text { NEGRÓIDE } & 0,41 & 0,41 & 13\end{array}$

Segundo FRASER 22, a fissura palatina é mais rara do que a fissura labial ou lábio-palatina, assumindo a prevalência de 0,36 por 1000 na Califórnia - EUA, 0,49 por 1000 na Dinamarca e 0,43 por 1000 na Inglaterra. Estudo epidemiológico realizado no Canada 81, no periodo de 1964 a 77 encontrou prevalência média anual de 0,46 por 1000 para fissura palatina e 1,05 por 1000 para fissura labial ou lábio-palatal.

Quanto à distribuicão por sexo, existe uma predominância do sexo masculino 6, 43, 61 para as fissuras de lábio e/ou pálato, podendo variar de 60 a $80 \%$ 22. Na Inglaterra, $65,3 \%$ dos portadores eram do sexo masculino e $34,7 \%$ eram do sexo feminino 36. FRASER 22 afirma que desconhece a razão desta ocorrencia, mas poderia corroborar para ela o fato de existirem diferencas no padrão de desenvolvimento da face nos embriões masculinos e femi- 
ninos 22. MESKIN et al 47 comentam que, em um dado momento gestacional, o embrião masculino poderia apresentar morfogênese palatina diferente do feminino. Estudo sobre a diferenca das prevalências nos dois sexos observa que o pálato secundárto no embrião masculino humano se fecha com maior rapidez do que no feminino 7 . $\mathrm{Na}$ Noruega, ao serem analisados 1073 casos de fissuras de lábio e/ou pálato. verificou-se que $59 \%$ eram do sexo masculino e $41 \%$ do sexo feminino 1. A fissura palatina $\dot{e}$ mais freqüente no sexo feminino do que no masculino, na razão $3: 2$ 2P, 43. Para a Inglaterra, $41 \%$ referiu-se ao sexo masculino e $59 \%$ ao feminino 36,43 . Segundo estudo conduzido pelo EUROCAT em 17 centros europeus, a fissura palatina apresentou discreto excesso de proporcão no sexo feminino, sendo de $53 \%$ e a fissura lábio-palatina apresentou $62 \%$ de casos do sexo masculino 16.

Quanto à variacão sazonal, alguns estudos mostraram não existir variacão consistente na freqüência das lesões em relacão às estacões do ano 22, 36, 55, 77 . Estudo conduzido em São Francisco -EUA, mostrou que nos meses de novembro a marco, periodo qualificado pelo autor de verão "quente" ao inverno "moderado", a prevalência de fissurados aumentava em relação à média 80 .

Quanto à classe social, não se verificou diferenca nas frequiencias das fissuras nas diversas elasses sociais, sugerindo que fatores referentes à desnutricão e doencas infecciosas não sejam fatores causais destas anomalias 22.

Quanto à idade dos pais, WOOLF 82 relatou associacão entre fissura lábio-palatina e idade dos pais, sendo esta associacão inexistente para fissura palatina. Estudo realizado na 
Austrália mostrou que a idade materna média de 176 controles foi de 26,96 anos e de 89 casos foi de 25,67 anos, diferenca não-significativa, segundo BURMAN 9.

Dutras possiveis'associacões com as fissuras foram estudadas em relação ao peso ao nascer 3, 15, idade gestacional 17, ingestão de drogas nos quatro primeiros meses de gestação 25 , 64, 72, especialmente de anticonvulsivantes, presenca de outras mal formacõos 1,9,15, 28, procedência 9, ocupacão paterna 9, alcoolismo 9,67 e tabagismo 9,65 .

Em relacão ao peso ao nascer, verificou-se ser similar para criancas fissuradas e controles 3, com excecão para meninas portadoras de fissuras palatina, que foi significantemente menor, observacão feita anteriormente por FRASER \& CALNAN 23. Quanto à idade gestacional, existiu diferenca significativa entre - número de fissurados de pálato e de controles, nascidos antes de 31 semanas de gestacão 17.

Quanto à ingestão de medicamentos, SHAPIRO et al 70 observaram que mães epiléticas apresentam freqüência maior de criancas malformadas do que mães não-epiléticas,com risco relativo de 1,6. Comentaram que a epilepsia e não o medicamento foi responsável pelo risco aumentado, observacão feita também por BONAITI 6 e contestada por FRASER 21. Estudo realizado na Itália estimou o risco relativo de 1,87 , sendo as fissuras e outros defeitos congênitos mais freqüentes do que o esperado entre recém-nascidos de mães epiléticas 4, acrescentando que a epilepsia materna com. ou sem tratamento está associada à frequência de fissuras. Segundo BERTOLINI 1, muitas dificuldades se apresentam em estudos 
da relacão entre epilepsia, drogas anticonvulsivantes a anomalias, tais como:

- o número reduzido de epiléticos $(1,2$ a 7,7 por 1000 mulheres grávidas) e o número raro de anomalias congênitas $(2$ a 3 por 1000 nascimentos), indicando que grandes populacões precisariam ser investigadas

- distincão do papel das drogas e da própria epilepsia e de ou+ tros fatores associados à epilepsia. Além disto, o tratamento inclui mais de uma droga, e a comparacão entre tratamentos é dificultada pela baixa frequência de pacientes tratados e pela diferenca entre tipos de epilepsia.

Nos EUA, pesquisa realizada com 278 mães de criancas malformadas mostrou que a ingestão de "Diazepan" no primeiro trimestre de gestacão foi quatro vezes mais freqüente em mães de portadores de fissuras do que em mães de criancas com outras deformidades 62. Em relacão à ingestão de medicamentos, SLONE et al 72 comentam a complexidade da interpretacão de possivel associaFão mesmo que seja estatisticamente significante. Outro estudo, realizado por GOLDING at al 25, comparou duas drogas anti-eméticas, "Avomine" e "Debendox", encontrando associacão entre esse último medicamento e fissura 23.

Estudos experimentais procuraram contribuir para o entendimento dos mecanismos do desenvolvimento facial e suas falhas, embora seus resultados năo possam ser inferidos diretamente para o ser humano. Investigacão en camundongas verificou que a administracão de cortisona na fase gestacional gerava filhotes portadores de fissura palatina.31. Achados semelhantes acrescen- 
tam que a prevalência de fissura palatina varia de acordo com a constituicão do camundongo, dose de cortisona ministrada e o estágio gestacional correspondente 24,36. Outros teratogênicos que causaram fissuras de pálato em animais foram radiafão 8, 32 e poluentes ambientais 34.

Quanto à procedência, estudo realizado na Austrália mostrou que o coeficiente de fissurados é 2,5 vezes maior na área rural do que na urbana, o que não foi verificado quando se considerou todas as outras anomalias congênitas 9.

Alguns autores têm-se preocupado com o número de fissurados entre filhos de trabalhadores da lavoura 9, 28. Burman comentou que a proporcăo de pais de fissurados que trabalhavam na lavoura era maior do que o esperado, porém não divulgou o respectivo valor 9.

Mal formações congênitas associadas foram encontradas em 52\% dos portadores de fissuras palatinas e em $21 \%$ dos portadores de fissuras de lábio ou lábio-palatina 9.

Quanto ao tabagismo, BURMAN 9 encontrou $34 \%$. de măes fumantes no grupo controle e $35 \%$ no grupo de casos, porém ao se dividir os casos nas categorias, verificou-se que o percentual de mães de portadores de fissura palatina era maior do que o de fissura lábio-palat ına, valendo, respectivamente, $52 \%$ e $27 \%$. Neste mesmo trabalho, encontrou associacăo nula para consumo de álcool e freqüência de fissuras. SAXEN relatou um discreto aumento no hábito de fumar $e$ ingestão de álcool entre mães de casos 65 . No Brasil, são poucas as publicacões sobre o assunto. NAGEM FILHD et al 54 realizaram o primeiro estudo epide- 
miológico que envolveu o levantamento de 13249 escolares da cidade de Bauru, SP, encontrando-se 20 fissurados, ou seja, a prevalência entre escolares foi de 1:650, ou 1,54 por 1000.

CÂNDIDO 10 analisou os prontuários de hospitais. de Porto Alegre-RS, no periodo de 1970 a 1974 , encontrando a prevalência de $1: 1136(0,88$ por 1000$)$.

souza et al 75 estudaram anomalias congênitas em sete maternidades de São Paulo, uma do Rio de Janeiro e uma de Santa Catarina, no periodo de 1981-1982, sendo que as fissuras lábio-palatinas isoladas contribuiram com $2,4 \%$ do total de anomalias. A prevalência foi de $0 ; 47$ por 1000 , pois entre 12782 recém-nascidos vivos, o apresentaram fissura.

JANERICH e POLEDNAK 34 comentam que a epidemiologia das anomalias congênitas está consideravelmente menos desenvolvida em relacão a outras doencas crônicas. Pode-se supor que se está ainda em fase exploratória na busca de fatores de risco Assim, julgou-se de interesse estudar alguns agentes, procurando colaborar na investigafão de efeitos teratogênicos, genéticos e ambientais, no aparecimento das fissuras.

Considerando a escassez de trabalhos referentes à epidemiologia de fissuras orais no Brasil e a multi-causalidade a elas atribuida, estudaram-se os fatores de risco para estas anomalias, considerando-as integrantes de dois grupos distintos, quais sejam, fissura de lábio ou lábio-palatina e fissura de pálato, sem outras malformacões associadas. 
0 objetivo do presente trabalho é o estudo epidemiológico de associacão entre fissuras orais e possiveis fatores de risco:

- morar na zona rural, nos quatro primeiros meses de gestacão,

- exposicão à poluicãos nos quatro primeiros meses de gestacão;

- aplicacão de. pesticida e herbicida na lavoura pelos pais,

- história de parentesco entre os pais,

- história familiar de fissura,

- história de epilepsia nos pais,

- história de hanseniase nos pais,

- ocorrência de doencas, nos quatro primeiros meses de gestacão: rubéola, hipertensão, convulsão e diabetes,

- ingestão de medicamentos, nos quatro primeiros meses de gestacão: anti-inflamatórios, anti-eméticos, anti-convulsivantes, anti-hipertensivos, anti-alérgicos, anovulatórios, complexos vitaminicos, tratamento de hanseniase, abortivos, analgésicos e antibióticos,

- exposicão da mãe a raio-X nos quatro primeiros meses de gestacão ou exposicão dos pais a raio-X no periodo de um ano antes da gestacão da mãe,

- ocorrência do consumo de bebidas alcoólicas pela mãe e

- ocorrência do hábito de fumar pelos pais. 
3 - MATERIAL E MÉTODD

Adotou-se a abordagem tipo caso-controle 68.

3.1 - CASOS

Foram considerados casos os portadores de fissuras orais, num total de 450 .

- CRITÉRIO DIAGNóstico: Foi considerado "caso" o portador de fissura palatina ou fissura lábio-palatina, sem malformacão associada, menor de 1 ano de idade.

- FONTE: Hospital de Pesquisa e Reabilitafão de Lesões Lábio-Palatais de Bauru, da USP, hospital especializado em reabilitar portadores de deformidades orais.

- .CRITÉRIO DE SELECAO: Foram selecionados todos os casos novos, até atingir 450 casos, no período de agosto de 88 a agosto de 89.

Conforme rotina do Hospital, os casos novos eram previamente agendados e recebiam, na primeira consulta, o atendimento de uma Enfermeira, que preenchia uma ficha integrante do prontuário, com perguntas de carater geral e especifico. 
Esta enfermeira selecionava os casos assindrônicos, menores de 1 ano de idade, e ela própria aplicava o formulario referente a esta pesquisa, tomando o cuidado para não prejudicar o atendimento do paciente'nas diferentes especialidades.

\section{2 - CONTKOLES}

O grupo controle foi formado por 450 individuos.

- CRITERIO DIAGNóStICO: Foi considerado "controle", o não-portador de fissuras orais ou de quaisquer anomalias, menor de 1 ano de idade.

- FONTES:

- Araraquara-SP:

- Servico Especial de Saúde de Araraquara, da USP.

- Hospitais: - Santa Casa de Misericórdia, Hospital São Paulo, Santa Casa de Misericórdia.N.S. Fátima e Beneficencia Portuguesa e Maternidade Gota de Leite de Araraquara

- Bauru-SP:

- Santa Casa de Misericórdia.

- São Paulo-SP:

- Hospital Infantil Menino Jesus

- Hospital das Clinicas

- Londrina-PR:

- Centro de Saude 
- CRITERIO DE SELECÃO: Os controles foram selecionados até ser atingido o tamanho da amostra desejado, de 450 , no periodo de janeiro 1989 a agosto de 1989.

APlicou-se os formulários aos controles, selecionados em Maternidades e Centros de Sacide.

Nas Maternidades, todas as mães que deram à luz foram entrevistadas, dentro dos critérios adotados, ou sejam, de que as criancas năo fossem portadoras de anomalias congênitas e de que as mães estivessem dispostas a colaborar com a pesquisa.

Nos Centros de Sacide, foram incluidas criancas menores de 1 ano agendadas para consulta, com a informacão prévia de que năo apresentavam anormalidades, segundo a ficha clinica.

Decidiu-se que Maternidades e/ou Centros de Saude de diferentes localidades seriam visitados, a fim de se controlar a situacăo dos casos serem tomados na mesma localidade, porém de procedência diversa.

Assim, em Bauru e em São Paulo, os controles foram tomados em hospitais, em Araraquara, em hospitais e Centro de Saúde e em Londrina, no Centro de Saúde.

Considerando-se que a fonte dos casos foi Bauru, esta cidade foi incluida para obtencão de controles por possibilitar que a mesma entrevistadora aplicasse o formulário a casos e controles. Dbservou-se ainda que grande número de casos procediam de São Paulo e decidiu-se tomar controles naquela cidade. Araraquara fez parte do grupo de cidades por facilidade de levantamento, visto que é o local de moradia da autora da pesquisa e Lon- 
drina integrou este rol por ter sido identificado com frequência pacientes de lá procedentes e por ser de fácil acesso.

A tabela a seguir dá os valores aproximados dos menores riscos relativos detectáveis para amostras de tamanho 450, com $\alpha=0,05$ e poder do teste igual a 0,80 e 0,90 .

TABELA 4 - MALOKES AFROXTHADOS DOS HENORES RTSCOS RELATTUOS DETECTAUETS FARA AHOSTRA DE TAHANHO $456^{7}$, COH $\alpha=6.65 E$ $B=6,1 \theta^{3} E \quad B=6, E \theta^{3}$

\begin{tabular}{|c|c|c|c|}
\hline Po & $n$ & 0,10 & 0,20 \\
\hline 0,50 & 450 & 1,6 & 1,5 \\
\hline 0,30 & 450 & 1,6 & 1,5 \\
\hline 0,10 & 450 & 1,9 & 1,8 \\
\hline 0,05 & 450 & 2,5 & 2,0 \\
\hline
\end{tabular}

\section{3 - FORMULARIO}

Para a comparacão da proporcão de expostos aos fatores de risco, entre os casos e os controles, foi aplicado um formulário que envolve perguntas referentes à idade dos pais na 
época do nascimento da erianca, informacăo sóciomeconômica da família, hábito da mãe de ingerir bebida alcoólica, história de doencas na măe e no pai, exposicão materna a medicamentos durante os quatro primeiros meses de gestacão, entre outras. o formulário foi pré-testado para uma amostra de tamanho 20 e a forma definitiva tem um desenho que possibilitou a transferência direta dos dados para o computador (ANEXO I).

A fim de se garantir uma padronizacão na aplicacão dos formulários, as entrevistadoras foram treinadas, adotando-se um manual explicativo (ANEXO II).

Como, na maioria das vezes, era impossivel o mesmo entrevistador entrevistar os casos e os controles, foi feito um estudo de validade de uma amostra de 20 casos e de 20.controles, entrevistados anteriormente. Foi aplicado o formulário 5 meses após a primeira entrevista, estudando-se a. capacidade da entrevistadora obter respostas idênticas às que a entrevistadora padrão (autora da pesquisa) obteve, referentes à ocorrência das seguintes variáveis: exposicão à poluicão, história.de hereditariedade, história de doencas na mãe, como, epilepsia, rubéola, hipertensão, diabetes e convulsão, ingestão de drogas e exposicão à irradiacăo. Para casos e controles, houve $100 \%$ de coopositividade e coonegatividade, verificando-se que as respostas dadas à entrevistadora eram as mesmas dadas à pesquisadora.

Para o processamento das informacões, foi criado um banco de dados, euja estrutura favorecesse a consulta. 


\title{
3.4 - VARIÁVEIS ESTUDADAS
}

\author{
As variáveis de estudo foram:
}

- Local de moradia da mãe nos quatro primeiros meses de gestacão: zona rural e urbana.

- Poluicão ambiental: sim ou não.

- Ocupacão dos pais: especificamente voltada para lavoura e em caso positivo, analisou-se exposicão a pesticida e/ou herbicida na lavoura.

- Parentesco entre os pais: sim ou não.

- Hereditariedade: estudou-se a história familiar de fissura, positiva ou negativa.

- Doencas nos pais (sim ou não): epilepsia e hanseniase.

- Doencas na gestante nos quatro primeiros meses de gestacão (sim ou não): rubéola, hipertensão, convulsão e diabetes.

- Ingestão de drogas nos quatro primeiros meses de gestacão (sim ou não): anti-inflamatório, anti-emético, anti-convulsivante; anti-hipertensivo, anti-alérgico, anovulatório, complexo vitaminico, tratamento de mal de Hansens abortivo, analgésico e antibiótico.

- Exposicão da mãe a raio $X$ nos quatro primeiros meses de gestaఢ ão (sim ou não).

- Exposicão dos pais a raio $X$, um ano antes da gestacão (sim ou กลัo).

- Ingestão de bebida alcoólica pela mãe (sim ou não).

- Tabagismo (sim ou não). 


\section{5 - ANÁLISE ESTATISTICA}

As condicões de trabalho impuseram a escolha dos casos num local e a escolha dos controles em local diferentes todavia, como a origem de váriosicasos e controles era o municipio de São Paulos decidiu-se fazer um análise estratificada, onde "morar em São Paulo" seria possivel fator de modificacão a ser considerado.

As comparacões dos resultados obtidos para os casos com os obtidos para os controles foram realizadas nas seguintes condicões:

a. os casos portadores de fissura labial ou lábio-palatal foram comparados com todos os controles, num total de 354 casos e 450 controles;

b. análise em a.s segundo local de moradia da mãe, ou seja, residentes no Municipio de São Paulo (SP) e fora do Municipio de São Paulo (NSP), Para verificar se morar em São Paulo é fator de modificacão de efeito;

c. os casos portadores de fissura palatina foram comparados com todos os controles, num total de 96 casos e 450 controles;

d. análise de c.s considerando o local de moradia da mãe, MuniciPio de São Paulo (SP) e fora do Municipio de São Paulo (NSP), Para verificar se morar, em São Paulo é fator de modificacão de efeito. 
Para a análise dos resultados, usou-se os "softwa$\operatorname{res}^{\prime \prime}(*):$

- DBASE III - PLUS - permitiu a análise descritiva da exposicão a cada um dos "possiveis" fatores de risco entre casos e controles;

- WORKS - para as planilhas de cálculo;

- HARUARD GRAPHICS - para representacão gráfica e

- MULTLR - para análise multivariada dos fatores em conjunto.

Preliminarmente foi realizada análise de cada variável em separado, empregando-se o "ODDS RATIO", por ponto, como estimativa do risco relativo (RR), ou razão de prevalências 70. Para cada variável, foi construida uma tabela de associacão conforme o modelo genérico:

(*)

GARCIA, J.H.P.P.L. \& NOGUEIRA, A.R.R. - DBASE TOTAL. Säo Paulo, Livros Técni$\cos$ e Cientificos Editora S.A., 1987.

MICROSOFT WORKS - HANUAL DE REFERÊNCIA. HICROTEC SISTEMAS INDÚSTRIA E COMÉRCIO S.A. - SÃO PAULO, 1989.

HARUARD GRAFHICS - Software Publishing Corporation, USA, 1987.

HULTLR USER'S HANUAL - LUDWIG INSTITUTE FOR CANCER RESEARCH - SÃO PAULO, 1988. 


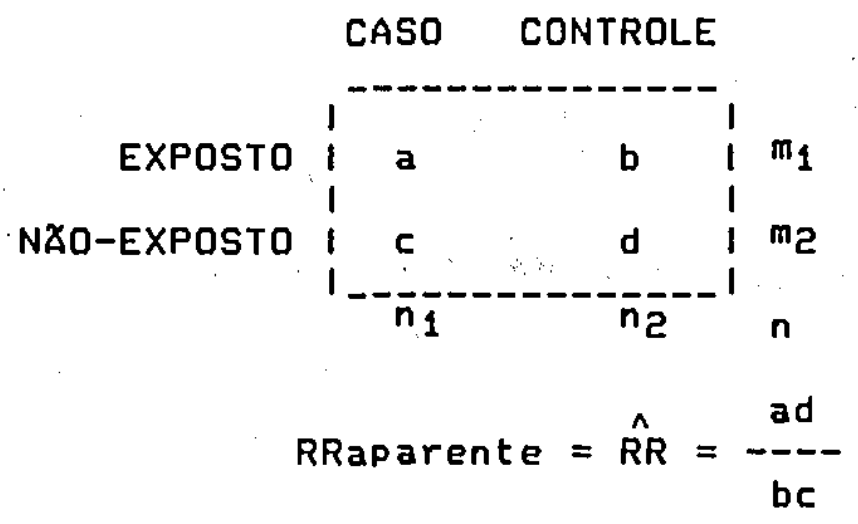

Para cada tabela de associacão, referente à variável de estudo, verificou-se a existência (ou não) de associacão entre exposicão e doenca, adotando-se como critério o qui-quadrado segundo Mantel- Haenszel:

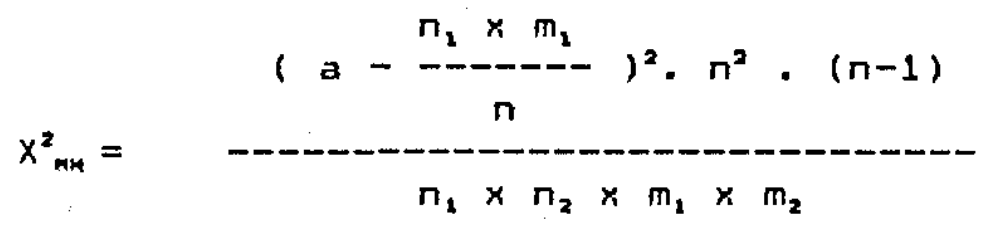

As variáveis que apresentaram associacão com significância estatística, ou apresentaram risco relativo maior do que 2 (ou menor do que 0,5 ), ou, ainda, apresentaram riscos relativos em sentidos opostos segundo local de moradia da mãe, foram selecionadas para análise multivariadas possibilitando conhecer a forca da associacão de uma variável em presenca de outras 74, ajustando-se simultâneamente para possiveis variáveis de confusão. Para as variáveis em que a interacão com moradia em SP/NSP 
foi significativa na análise univariada, o modelo incluiu o fator de interacão.

0 modelo de análise multivariada para as variáveis selecionadas e os termos de interacão foi o de regressão logistica não condicional 69,74 .

$$
\ln \left(p_{2} / q_{1}\right)=\beta_{1}+\sum_{i / \ell} \beta_{i} x_{i}+\sum_{i \neq j} \beta_{i j} x_{i} x_{j}
$$

onde:

In $\left(p_{x} / q_{x}\right)=$ logaritmo natural do "odds".

$$
\begin{aligned}
B_{0}= & \text { constante sem interesse em caso-controle } \\
\beta_{i}= & \text { coeficiente de regressão, tal que, } \beta_{i} \text { represente o } \\
& \text { RR aparente para o fator de risco } x_{i}=1 \text {, ou seja, } \\
& \text { Presente } \\
x_{i}= & \text { fator de risco, } i=0 \text { ausente, } i=1 \text { presente } \\
\beta_{i j}= & \text { coeficiente de regressão correspondente a inte- } \\
& \text { racão } x_{i} x_{j}, \text { para alguns } i, j
\end{aligned}
$$

Além da estimativa por ponto do risco relativo aparente, foram também obtidos os intervalos de $95 \%$ de confianca, utilizando-se as estatisticas do programa MULTLR.

0. nivel de significância adotado foi de $5 \%$ para a tomada de decisão. 


\section{4 - RESUltados E DISCUSSXO}

\section{1 - CARACTERIZACXO DA AMOSTRA}

A amostra foi constituida por 450 criancas sadias que formaram o grupo controle e 450 casos, entre os quais verificou-se predominio de portadores de fissuras de lábio ou de lábiopálato, correspondendo a $78,6 \%$, sendo que $19,3 \%$ se referiu ao 1 ábio e $59,3 \%$ ao lábio e pálato, conforme tabela 4.

TABELA 5 - DTSTRIBUTEAO DOS CASOS, SEGUNDO TFFO DE FISSUAA DAAL.

$\begin{array}{lcc}\text { TIPO DE FISSURA } & \text { Ne } & \% \\ \text { Lábio } & 87 & 19,3 \\ \text { Lábio e pálato } & 267 & 21,3 \\ \text { Pálato } & 96 & 99,9 \\ & & \end{array}$

A maioria dos trabalhos, que envolveu o estudo do tipo de fissura prevalente entre os fissurados, observou a excesso da fissura de lábio e de Iábio-pálato em relação à fissura de pálato 18, 33, 56 com excecão da Finlândia 53. 
A tabela 6 refere-se à distribuicãode casos e controles, segundo sexo, mostrando o predominio de sexo masculino entre os portadores de fissura de lábio e de lábio-pálato e o predominio do sexo feminino entre os portadores de fissura de pálato.

TAEELA 6 - DISTRIEUTGAO DE CASOS E CONTROLES. SEGUNDO SEXO

\section{SEXO}

CATEGORIA

M F

TOTAL

Fissura de Lábio

50

37

87

Fissura dé Lábio e pálato

161

106

267

Fissura de Pálato

36

80

96

Controle

245

205

450

Tot a 1

492

$40 B$

900

A importância relativa dos dois sexos, entre fissurados, consta das figuras 3 e 4 . 


\section{Figura 3- Casos de fissura labio- -palatina, segundo sexo (\%).}

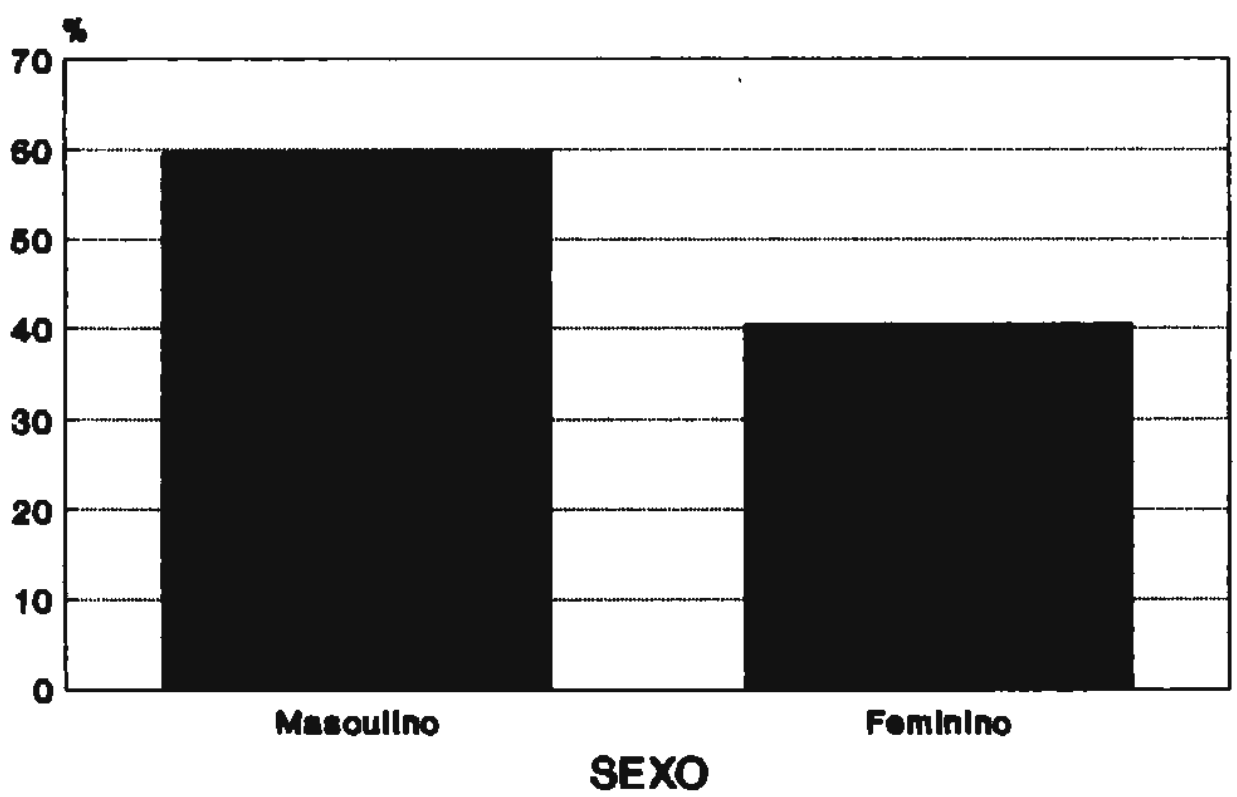

\section{Figura 4 - Casos de fissura palatina segundo sexo (\%).}

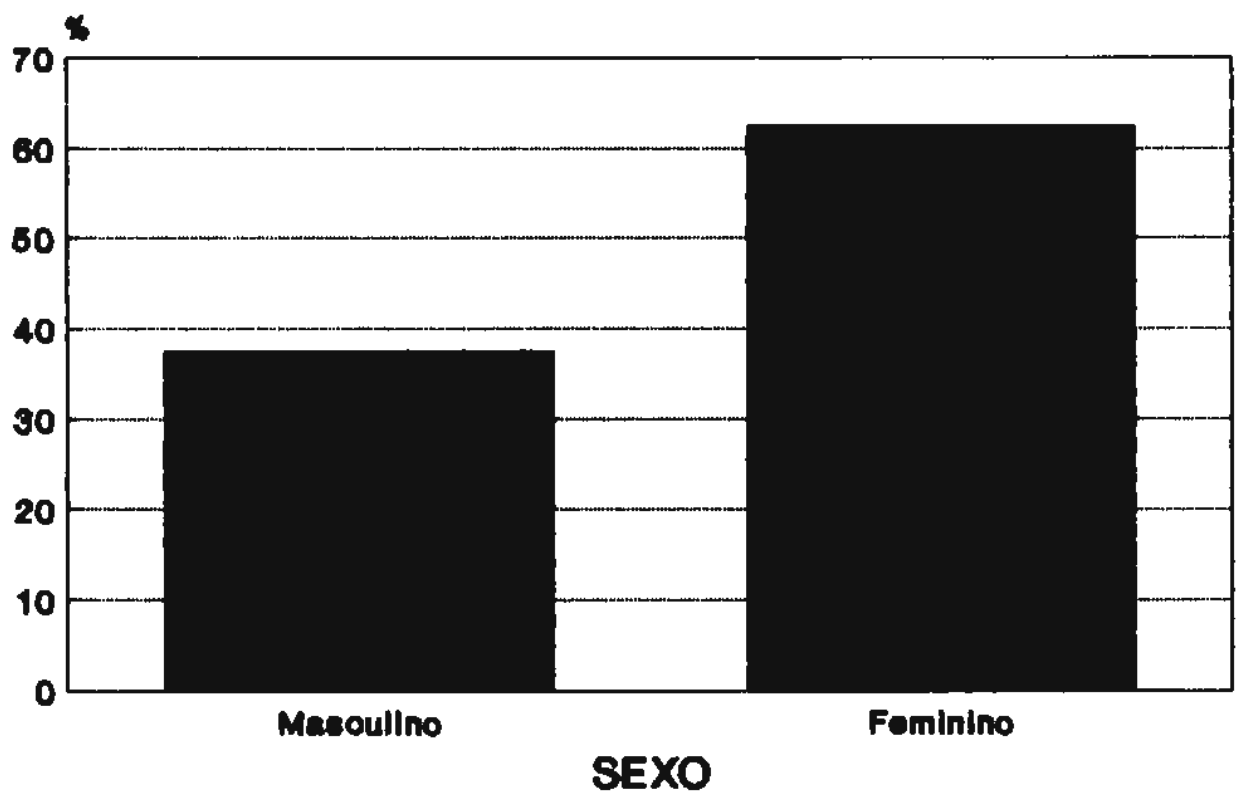


Trabalho realizado na Finlândia, em 599 fissurados, encontrou maior proporcão de criancas do sexo feminino com fissura palatina e de criancas do sexo masculino com fissura lábio-palatina 65 .

A idade média dos fissurados foi de 121 dias e dos controles foi de 39 dias. Justifica-se esta diferenca em funcão dos casos estarem sujeitos a agendamento préviog em época compatível com a provável primeira cirurgia edos controles serem tomados, em sua maioria, em maternidades ( $80 \%$ ). Observou-se que a idade média dos portadores de fissura lábio-palatina foi de 112 dias, menor do que à verificada para a fissura de lábio e fissura Palatina, sendo, respectivamente, 134 e 135 dias supondo-se que a gravidade da lesão tenha colaborado para que isto ocorresse.

As idades médias dos pais dos casos e controles foram iguais entre si, sendo 29 anos. As idades médias das mães dos casos e controles foram de 26 e 25 anos, respectivamente. Estudo realizado na. Inglaterra 43 mostrou que a fissura palatina seria independente da idade materna, porém a fissura labial cou lábio-palatal) aumentava sua prevalência com a idade materna, sendo 0,37 por 1000 em recém-nascidos de mães com menos de 23 anos de idade e 1,41 por 1000 para idades de 38 anos e mais.

Quanto à procedência dos casos e dos controles, construiu-se a tabela 7 , onde foi incluido o local de moradia nos quatro primeiros meses de gestação. 
TABELA 7 - DTSTRIEUTEKO DOS LASOS E CONTROLES SEGUNDO FRUCEDENCTA E LOCAL DE HORADTA NOS A FRTHETROS HESES DE GESTAGSO DA MABE.

\begin{tabular}{|c|c|c|c|c|}
\hline \multirow{2}{*}{ ESTADO } & \multicolumn{2}{|c|}{ CASO } & \multicolumn{2}{|c|}{ CONTROLE } \\
\hline & PROC. & MOR. & PROC. & MOR. \\
\hline Acre & - & - & - & - \\
\hline Alagoas & - & - & - & - \\
\hline Amapá & - & - & - & 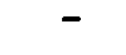 \\
\hline Bahia & 4 & 4 & 1 & - \\
\hline Ceará & - & - & - & - \\
\hline Distrito Federal & 11 & 11 & - & - \\
\hline Espirito Santo & 3 & 3 & - & - \\
\hline Fernando Noronha & - & - & - & - \\
\hline Goiás & 6 & 7 & - & - \\
\hline Maranhão & 2 & 2 & - & - \\
\hline Minas Gerais & 34 & $3 \overline{2}$ & - & 1 \\
\hline Mato Grosso & 2 & 2 & 1 & 1 \\
\hline Mato Grosso Sul & 8 & 8 & 1 & 1 \\
\hline Pará & 1 & 1 & - & - \\
\hline Paraiba & - & 1 & - & - \\
\hline Pernambuco & - & - & 1 & 1 \\
\hline Piaui & 1 & 2 & - & - \\
\hline Paraná & 85 & 83 & 6 & 11 \\
\hline Rio de Janeiro & 10 & 10 & - & - \\
\hline R. Grande Norte & 2 & 1 & - & 3 \\
\hline Rondônia & - & - & - & - \\
\hline Roraima & - & - & - & - \\
\hline R. Grande Sul & 1 & 1 & - & - \\
\hline Santa Catarina & 11 & 11 & - & - \\
\hline Sergipe & $=$ & & & 2 \\
\hline São Paulo & 267 & 269 & 440 & 430. \\
\hline Tocantins & 2 & 2 & $\therefore$ & - \\
\hline
\end{tabular}

Observa-se a maioria dos casos e controles proce. dentes do Estado de São Paulo. Em relacão aos casos, isto se de. veu ao fato deste estado contar com o Hospital de Pesquisa e Rea. bilitacão de Lesões Lábio-Palatais, da USP, localizado em Bauru favorecendo o atendimento dos fissurados residentes neste estad ou próximos a ele. Destaque-se que o referido hospital é o únic 
no pais que atua com uma equipe integrada de profissionais das áreas de Medicina, Odontologia, Fonoaudiologia, Enfermagem, Psicologia, Fisioterapia, Recreacão e Educacão, favorecendo o trabalho de reabilitacão do fissurado da comunidade nacional e internacional. Em relacão aos controles, procurou-se obter o maior número possivel de criancas do Estado de São Paulo, por facilidade de se contar com as mesmas entrevistadoras, reduzir custos, favorecendo a exequibilidade do projeto.

A renda per capita, para casos, foi US\$ 84,42 e para controles, US\$48,78, mostrando que a situacão econômica dos casos é melhor do que a dos controles. Convém acrescentar que a projecão foi feita em dolar por parecer mais adequada do que projecões similares em OTN, BTN, etc., pois as sucessivas mudancas na nossa economia ainda são passiveis de disputas legais nos tribunais competentes (Anexo III).

Quanto à paridade, o número médio de gestacões foi - mesmo para mães de casos e de controles e igual a 2 . 0 número de mães de casos que tiveram filhos nati-mortos foi igual ao de controles, sendo $16(3,6 \%)$. Quanto à frequêencia de abortos, observou-se que 61 mães de casos $(13,5 \%)$ abortaram, sendo esse número superado pelo verificado para mães de controles, 77 (17\%).

Em relacão ao peso ao nascer, construiu-se a tabela 8, para o teste de diferenca de médias. 
TABELA 8 - MEDTA E MARTSNCTA DE PESO AO NASLER (g).

\begin{tabular}{lrr} 
MEDIDAS & CASO & CONTROLE \\
MÉDIA & 3147,00 & 3126,00 \\
UARIÂNCIA & 348401,84 & 559790,40 \\
DESUIO-PADRX̃O & 590,26 & 509,70 \\
\hline t-Student $=0,5712 \quad P>0,05$ &
\end{tabular}

Verificou-se que o peso ao nascer de criancas fissuradas foi, em média, semelhante ao peso ao nascer dos controles. Achado análogo foi o do estudo reálizado na Islândia, encontrando diferenca não-significativa nos pesos ao nascer entre casos e controles 51 .

Qs graus de instrucão que predominaram, para os pais dos fissurados foram primário completo, secundário incompleto, secundário completo e técnico completo e para as mães dos casos foram primário completo, secundário incompleto, secundário completo, superior incompleto e superior completo, sendo que para pais e mães dos controles predominou primário incompleto (figu$\operatorname{ras} 5$ e 6 ). 


\section{Figura 5 - Grau de instrucáo dos pais dos casos e controles.}

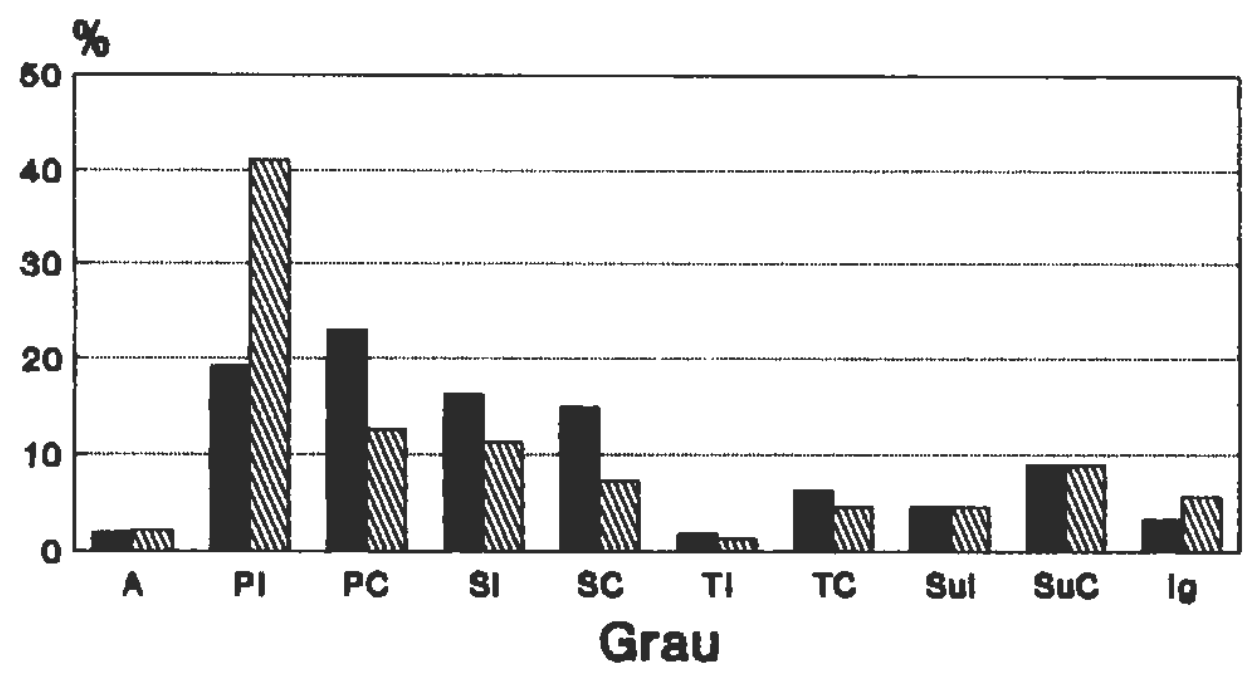

CASO MIIV CONTAOLE

Legenda :
A - analfaboto
$\pi$-técnico incompleto
PI -primário Incompleto
TC -técnico complato
PC -primário completo
Sul -superlor Incompleto
\$ -eecundário Incomploto
suc - euperior completo
SC -ecundário completo
Ig -ignorada 
Figura 6 - Grau de instruçáo das maes dos casos e dos controles.

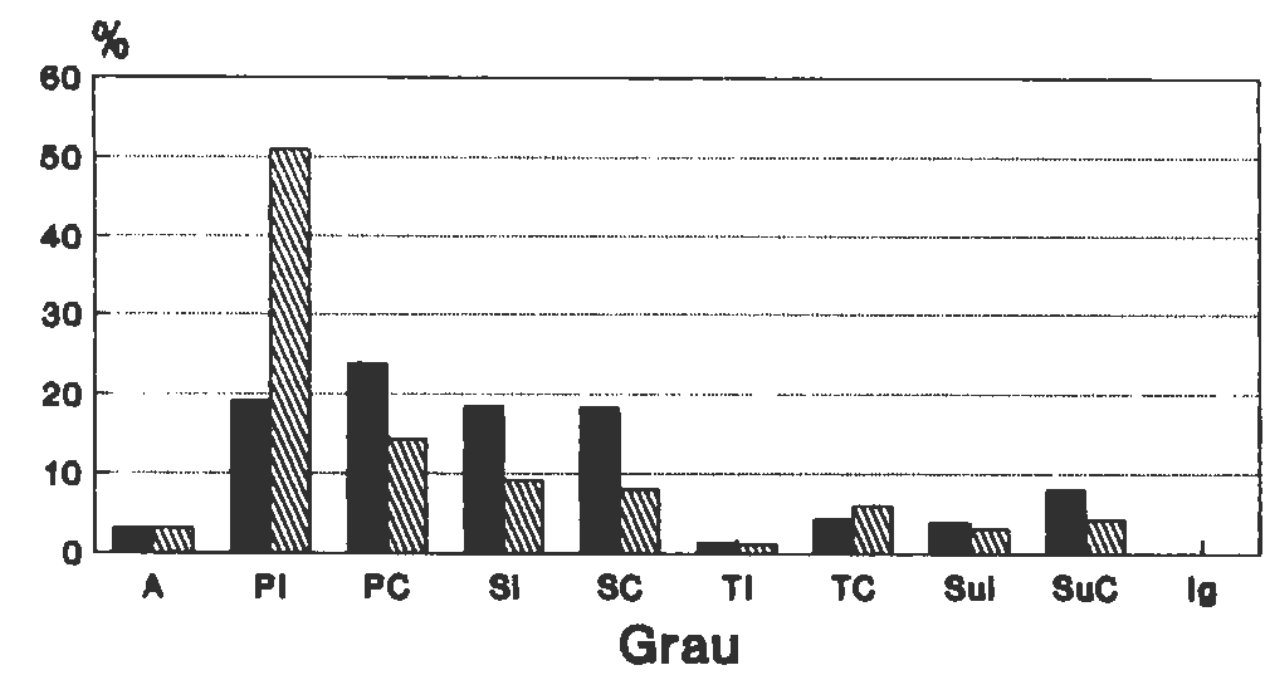

- caso MU⿴囗十⺝木 controle

\section{Legenda :}
A - analfabeto
TI -técnico incompleto
PI -primárlo incompleto
TC -técnico completo
PC -primárlo completo
Sul -ouperlor Incompleto
SI -secundário Incompleto
SuC - superior completo
sC -secundérlo completo
Ig -Ionorada 
Analisando o grau de instrucão em conjunto com a renda "per capita", nota-se que as condicões sócio-econômicas dos casos são diferentes dos controles. Este fato poderia ser explicado, sabendo-se que as pessoas que vieram de mais longe cos.casos) em geral são provenientes de familia mais aquinhoadas econônomicamente e com nivel de escolaridade melhor. Desta maneira; isto poderia levar à facilidade de acesso ao conhecimento da existência do Hospital de Pesquisa e Reabilitacão de Lesões Lábio-palatais de Bauru, bem como ao atendimento propriamente dito. 


\section{2 - FatoRES DE RISCO}

\subsection{1 - FISSURA LABIAL OU LÁBIO PALATINA}

A análise incluiu 354 cásos e 450 controles.

Julgou-se importante que os casos e controles fossem distribuídos por "local de moradia da mãe" porque verificouse que esta variável poderia ser fator de modificacão (tabela 1 Anexo IV).

Foram elaboradas três tabelas de contingência segundo cada variável de análise, para os resultados obtidos para amostra total (AT), municipio de São Paulo (SP) e não - municipio de São Paulo (NSP) e calculados os riscos relativos para cada variável (Anexo IU).

A tabela 9 dá a relacão das categorias de referência de cada variável, riscos relativos e referencia à significâncias dos mesmos, segundo resultadas do Anexo IV. Quando não foi possivel determinar a magnitude do risco relativo itendendo a infinita ou divisão de 0 por $\theta$ ), denotou-se por -. 
TABELA 9 - FISCO RELATINO SEGUNDO GATEGORTA DE REFERENETA DE CADA VASTAVEL E LOCAL DE HORADTA DA MIE. FISSURA LABTAL OU LABIO-FALATINA.

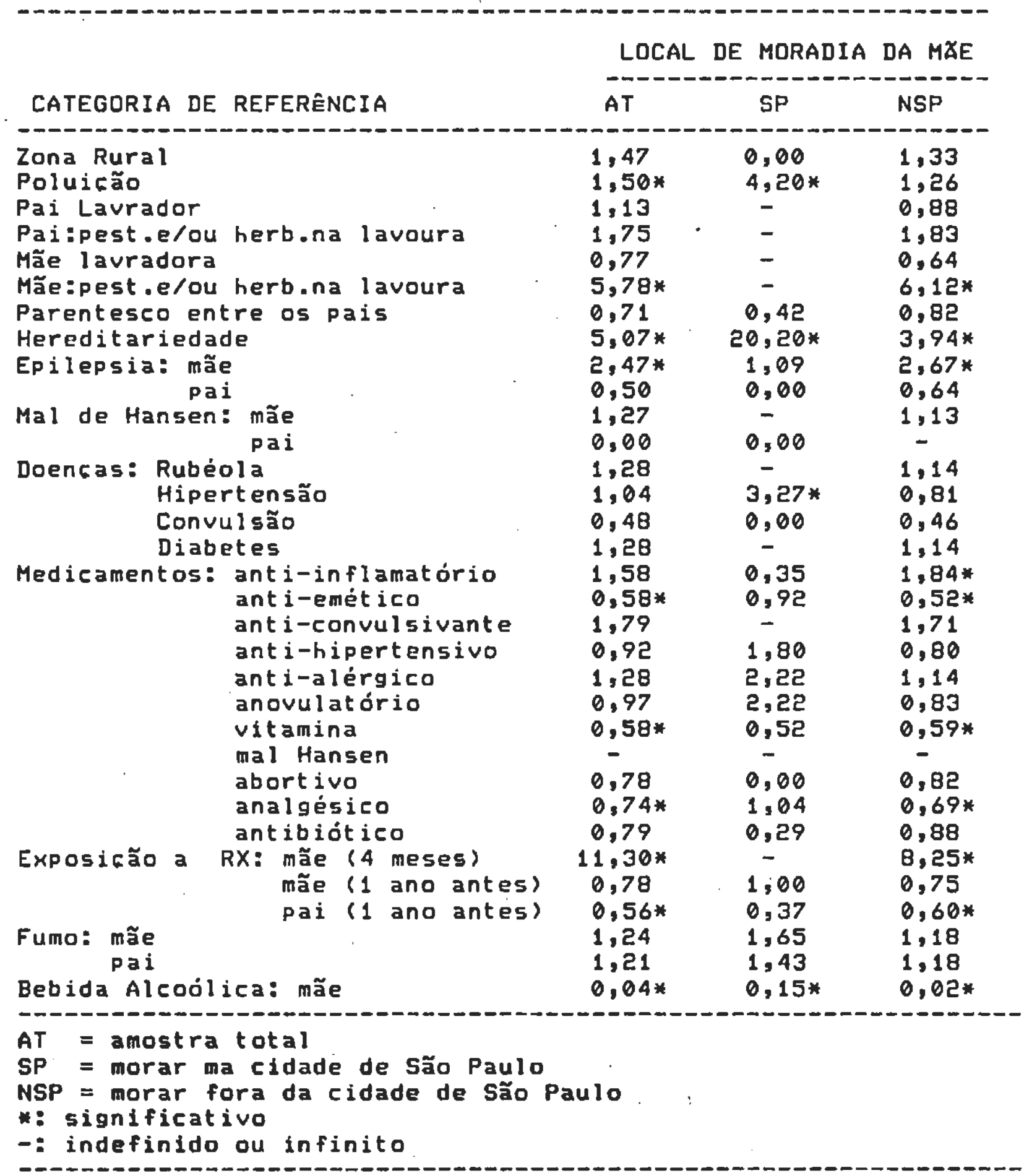


Segundo a tabela 9, algumas variáveis apresentaram riscos relativos com significância estatistica, podendo ser divididas em três grupos, segundo o potencial de ser fator de risco: - variáveis com riscos significantes para a amostra total e para apenas um dos estratos: poluicão, aplicacão de pesticida e/ou herbicida na lavoura pela mãe, epilepsia na mãe e exposicão da mãe a raio $X$, nos quatro primeiros meses de gestacão,

- variável com risco significante para a amostra total e para os dois estratos: hereditariedade e

- variáveis com riscos significantes apenas para um dos estratos: hipertensão na mãe (SP) e ingestão de anti-inflamatório (NSP)

A fim de prosseguir com a análise, separadamente para SP e NSP, ainda univariadas, adotou-se os seguintes critérios de selecão:

a) Risco relativo global significante (*), independentemente da magnitude;

b) Risco relativo global, 2, independentemente de ser significativo ou não;

c) Risco relativo global $(0,5$, independentemente de ser significativo ou não e

d) em situacão diferente das anteriores, porém com riscos relativos em sentidos opostos, quando observados para SP e NSP (pois sugere fator de modificacão).

Assim foram selecionadas as variáveis:

- Ocorrência de poluicão

- Aplicacão de pesticida e/ou herbicida na lavoura pela mãe

- História de hereditariedade 
- Ocorrência de epilepsia, hipertensão e convulsão, na mãe

- Uso de drogas: anti-inflamatório, anti-emético, anti-hipertensivo, anovulatório, complexo vitamínico e analgésico.

- Submeter-se a raio X: mãe (nos quatro primeiros meses de gestaఢão) e pai (um ano antes da gestacão da mãe)

- Uso de bebida alcoólica pela mãe

$$
\text { 4.2.1.1 - Análise Univariada }
$$

Aplicando-se análise univariada aos dados relativos a SP e NSP, obteve-se a tabela 10 ,

TABELA 10 - ANALISE UNTUARIADA - SF E NSF. FISSURA LABTAL UU LABTO-PALATIKA.

RR

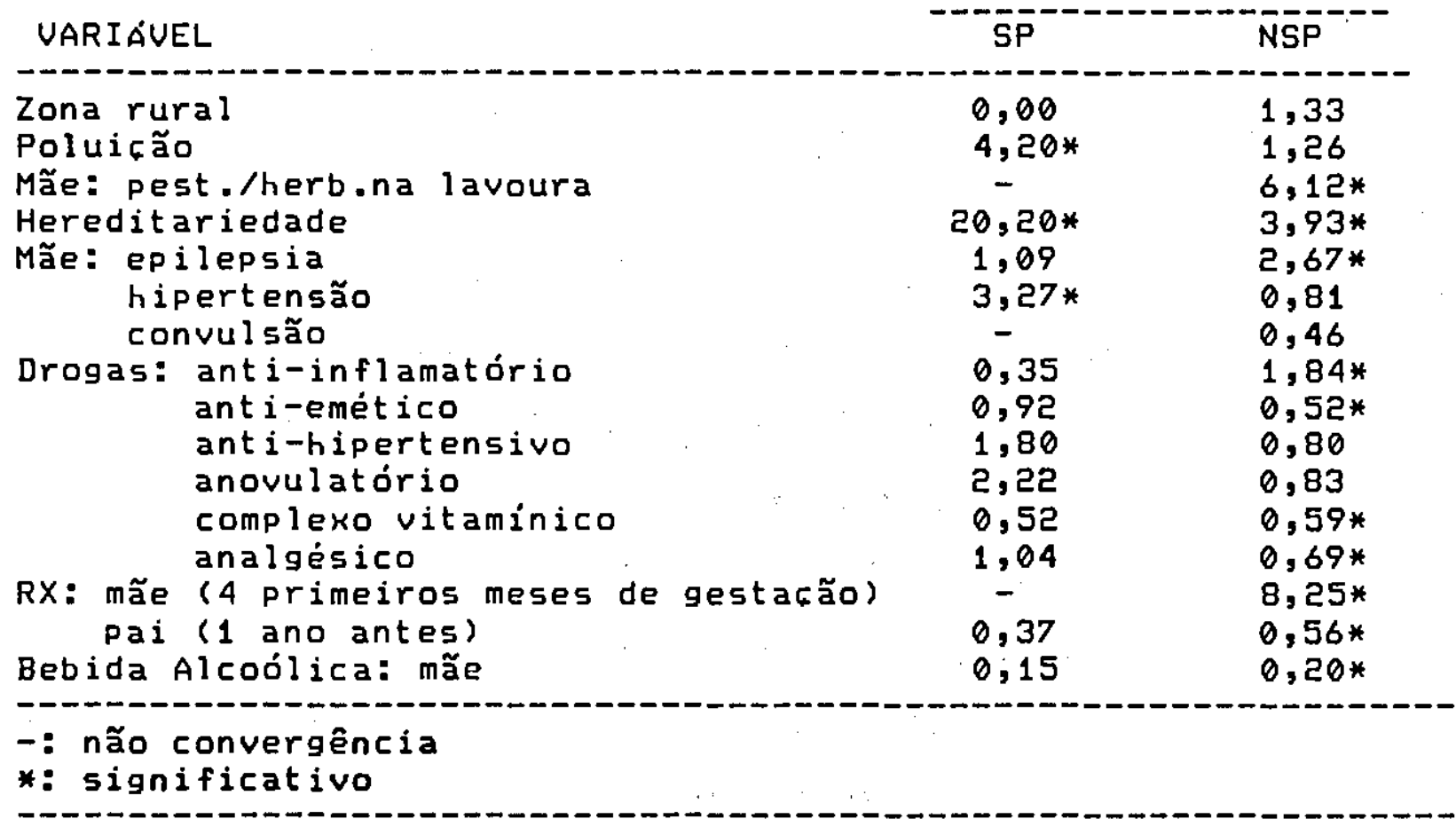


As variáveis hereditariedade, poluicão e hipertenso apresentaram riscos relativos significantes, para moradores do Município de São Paulo.

Para moradores de fora do Municipio de São Paulos as seguintes variáveis apresentaram-se como fator de risco: aplicacão de pesticida e/ou herbicida na lavoura pela mãe, hereditariedade, epilepsia na mãe, ingestão de anti-inflamatório e exposicăo da măe a rajo $X$ nos quatro primeiros meses de gestacto.

Observa-se que heredttariedade foi o único fator de risco comum para moradores do Municipio de São Paulo e de fora dele.

Por outro lado, algumas variáveis apresentaram-se como "fator de protecão" para não moradores do Municipio de Săo Paulo, quais sejam, ingestão de medicamentos como de anti-emético, vitamina e analgésico e hábito da mãe de beber bebida alcoólica.

Todas as variáveis que constan da tabela 10 para as quais foram possiveis estimar os riscos relativos em SP e NSP deveriam compor a análise multivariada para fissuras lábio-palatais. Assim sendo, foram eliminadas as variáveis: aplicacão de pesticida/herbicida na lavoura pela mães convulsăo na mãe e exposicão da mãe a raio $X$ nos quatro primeiros meses de gestacão, por terem apresentado risco relativo indefinido em um dos estratose morar na zona rural, pelo fato de ter-se observado apenas 1 exposto no estrato de São Paulo (1 controle). Convém acrescentar que morar em São Paulo (SP) foi incluida como variável bem como as interacões que resultaram significantes estatisticamente, 
quais sejam, poluicão e SP, hereditariedade e SP e hipertensão e SP.

\subsubsection{2 - And11so Multivariada}

Foram selecionadas as variáveis:

- exposição à poluiçãos

- história de hereditariedade,

- ocorrência de epilepsia e hipertensão na mãe,

- ingestão de drogas (anti-inflamatório, anti-emético, anti-hipertensivo, anovulatório, complexo vitaminico e analgésico),

- hábito da mãe de beber bebida alcoólica,

- ocorrência de raio X no pai um ano antes da gestacão da mãe e

- morar em São Paulo, bem como as interacões, poluicão \& São Pau10, hereditariedade \& São Paulo e hipertensão \& São Paulo. 
TABELA 11 - ANALISE GULTIMARIADA. FISSURA LABIAL DU LABTO-FALATINA.

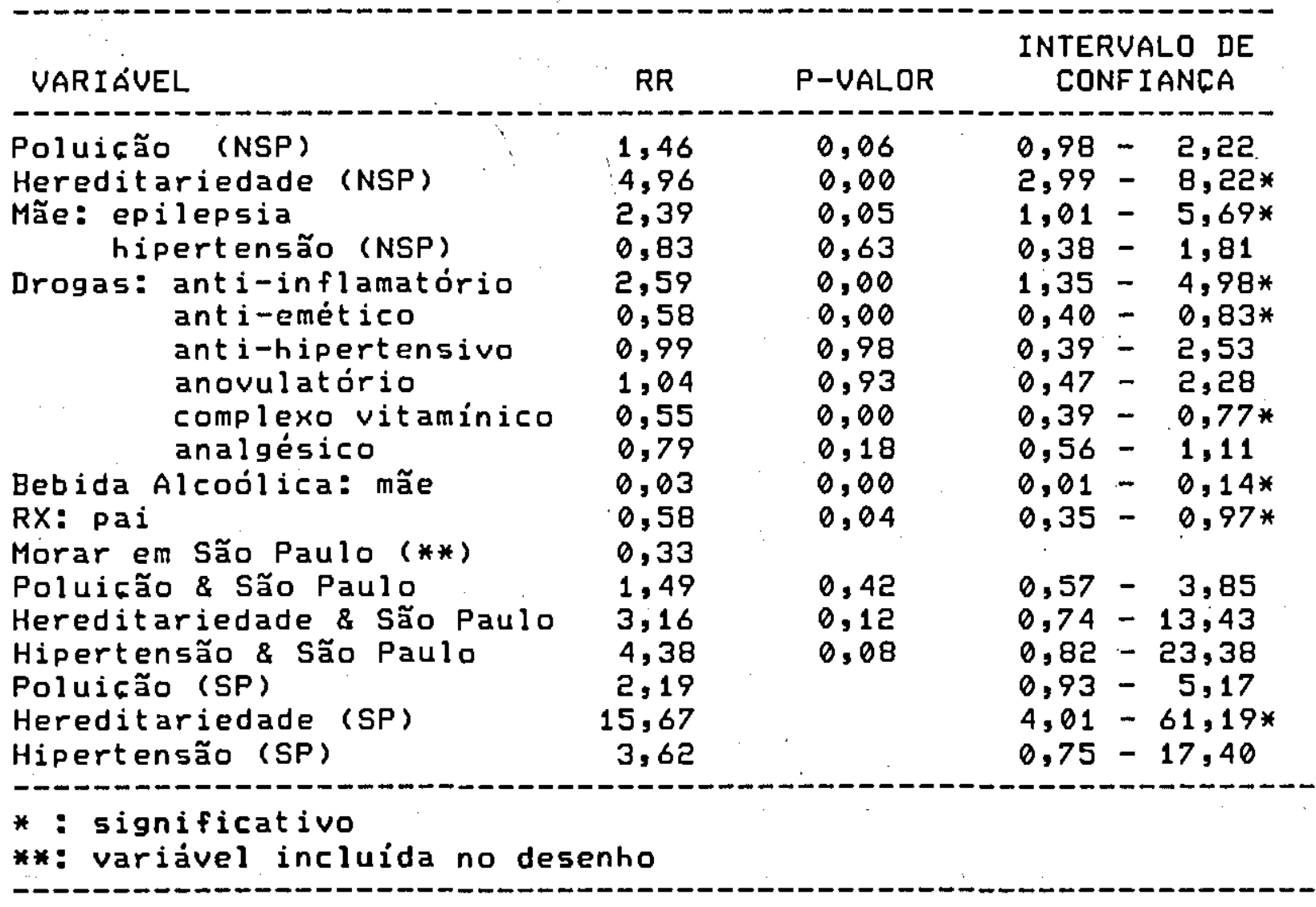

A análise da tabela 11 permite detectar os seguintes fatores de risco para fissuras labio-palatais:

- hereditariedades com riscos relativos de 4,96 e 15,67, respectivamente para NSP e SP,

- epilepsia na mãe, com $R R=2,39 \mathrm{e}$

- ingestão de anti-inflamatório, com $R R=2,59$.

Em relacão à hereditariedade, observou-se que todos os casos de fissura labial ou lábio-palatina que apresentaram história familiar positiva de fissuras, referiram-se a antecedentes de fissura labial ou lábio-palatina e nunca de fissura palatina isolada. 
Considerando os resultados prévios do possivel efeito modificador que morar em SP exerceria, estimou-se os riscos relativos, segundo a moradia da măes para as variáveis poluicão, hereditariedade e hipertensão, embora as interacões não tenham sido estatisticamente significantes.

Para hipertensão observou-se, na análise univariada, que o risco relativo, para o municipio de São Paulo, foi de 3,27 e significativo. Ao ser realizada a análise multivariada, a hipertensăo, agora controlada por outras variáveis, apresentou risco กão*significativo, não sendo fator de risco.

Convém lembrar que as variáveis ocorrência de raio $x$ na mãe nos quatro primeiros meses de gestaç̃o e aplicacão de pesticida elou herbicida na lavoura pela măe se apresentaram como fatores de risco para as fissuras labiais ou lábio-palatais. Quando analisadas para a amostra total, os valores dos riscos relativos foram de, respectivamente, 11,30 e 5,78, não sendo possivel a análise para um dos estratos, o Municipio de são Paulo, estando, portanto, a amostra total representada por moradores de fora de São Paulo.

Em relacão aos fatores genéticos e ambientais, vários autores têm-se preocupado em explicar essas associacŏes com as fissuras:

MOLLER 50 comenta que as informacões a respeito das causas das fissuras são meramente sugestivas, sendo que o único ponto para o qual existe un consenso é a importância da hereditariedade como um fator na ocorrência dessas anomalias. MELNICK et al 45 sugerem que existe a susceptibilidade genética para 
agentes ambientais de forma que, durante o periodo critico, a exposicão a esses agentes levaria a um efeito teratogênico, se se tratasse de um ser geneticamente predisposto.

SHAPIRO et al 70 e BONAITI 6 estudaram o efeito da epilepsia na mãe e ingestão de anti-convulsivantes no desenvolvimento de malformacões, levantando a hipótese de que o dano fetal, anteriormente atribuido às drogas, deveria estar associado à doenca, ou seja, à epilepsia. Outro pesquisador, MEADOW 44 verificou que mães epilépticas apresentavam prevalência maior de fis_ suras lábio-palatais e ressaltou o papel do anti-convulsivante no aparecimento dessas lesões, pois os niveis de infiltracão na pla_ centa eram altos. SMITHELLS 73 comenta que a prevalência de fissura lábio-palatina em gestantes tratadas com anti-convulsivantes é 12 vezes maior em relacão às não tratadas.

FOGH-ANDERSEN 18 chama atencão para que se adote uma conduta contrária à ingestão de qualquer droga, com excecão de complexos vitamínicos, durante os primeiros meses de gestacão. Observa-se que, neste trabalho, a ingestão de complexo vitamínico resultou fator de protecão $(R R=0,55)$ na análise multivariada. BRIGGS, citado por NIEBYL et al 58, levanta a hipótese de que suplementacão vitaminica poderia diminuir o risco de fissura lábiopalatina. RINTALA 61 afirma que deficiências nutricionais seriam fatores de risco para fissuras. MEADOW 14 comenta a necessidade de experimentos em animais para se verificar se a adicão de ácido fólico na alimentacão controlaria o efeito do anti-convulsivante na formacão das fissuras. 
BURDI et al 8 citam a irradiacão como agente de destruicão das células e de efeito teratogênico para as fissuras. SAXÉN 64 relata a significância etiológica da exposicão a raio $x$ para as fissuras e a dificuldade para analisála, pois a condicão patológica para a indicacão desse exame poderia estar associada à lesão.

GREENE et al 28 observaram freqüência maior de filhos de trabalhadores rurais portadores de fissuras orais, sendo essa diferenca estatisticamente significativa e comentam a necessidade de estudos mais acurados de fissuras segundo ocupacão dos pais, nos quais sejam identificadas as exposicões a agente quimicos e também radioativos. 


\section{2 .2 - FISSURA PALATINA}

A análise incluiu 96 casos e 450 controles,distribuindorse casos e controles segundo local de moradia da mãe, pois morar na cidade de são Paulo poderia ser fator de modificacão (tabela 1 - Anero $U)$.

Foram construidas tabelas de contingência para cada variável de análise, segundo as situações: amostra total (AT) morar na cidade de São Paulo (SP) e morar fora de São Paulo (NSP) calculandorse os riscos relativos para cada situação (Anexo U)

A tabela 12 apresenta os valores de riscos relativos obtidos paracada categoria de referência de variável e significância dos mesmos. 
TABELA 12 - RTSLO RELATTUO SEGUNDO CATEGOATA DE REFERERLIA DE LADA VAGTAVEL E LOGAL DE MDGADIA DA HAE - FTSSURA FALATINA

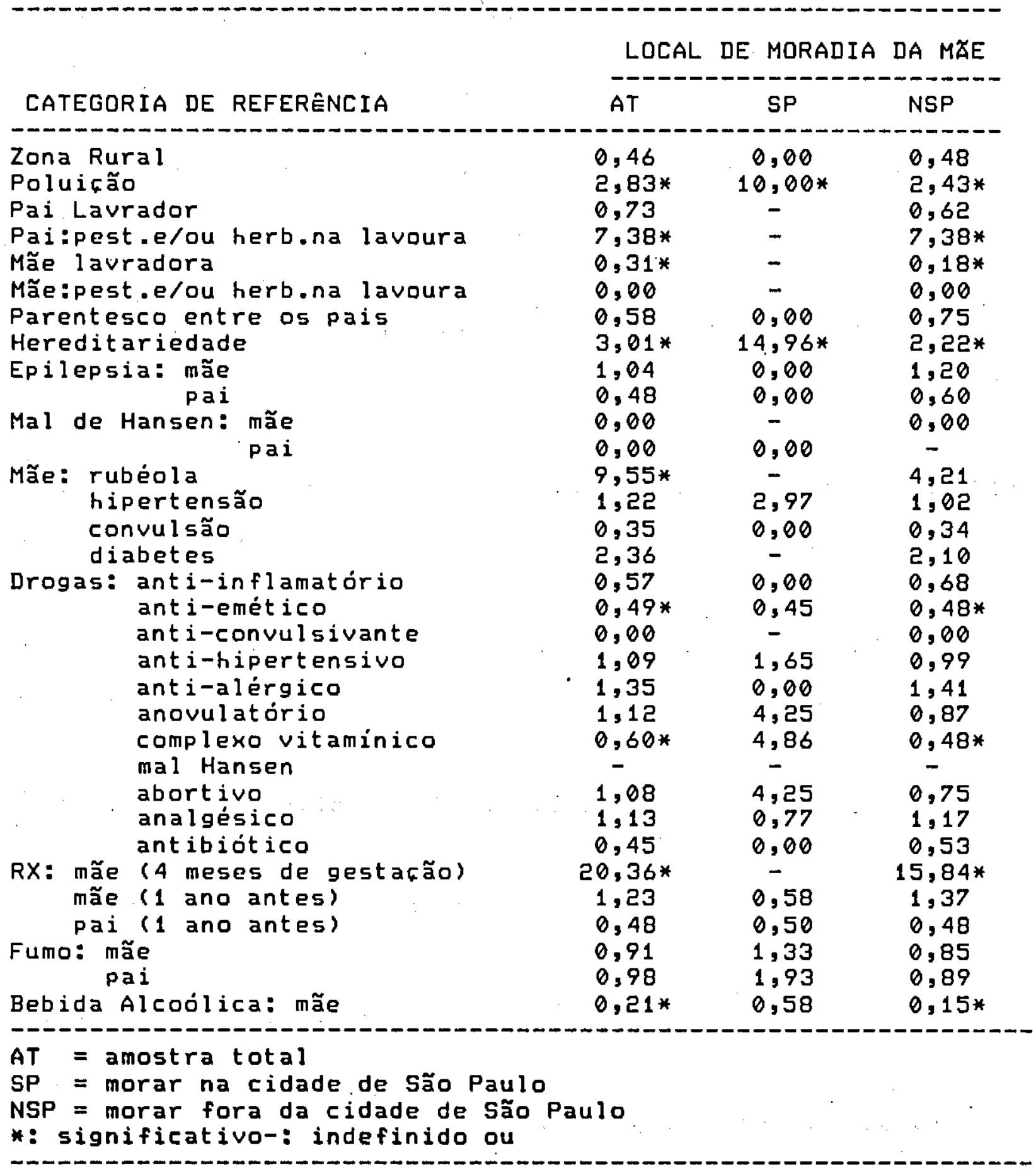


A selecăo das variáveis para comporem a análise univariada para SP e NSP foi efetuada de acordo com os critérios definidos, referentes às situacões:

a) Risco relativo global significante $(*)$, independentemente da magnitude;

b) Risco relativo global )2, independentemente de ser significativo ou năo;

c) Risco relativo global $(0,5$, independentemente de ser significativo ou não $e$

d) Em situacão diferente das anteriores, porém com riscos relativos em sentidos opostos ao serem analisados para SP e NSP.

Assim, foram selecionadas as variáveis:

- Presenfa de poluicão

- Aplicacão de pesticida e/ou herbicida na lavoura pelo pai

- Atividade na lavoura pela mãe

- História de hereditariedade

- Ocorrência de doencas, como: rubéola, hipertensão, convulsão e diabetes, na mãe 
- Ingestão de drogas: - anti-emético

- antibiótico

- anovulatório

- complexo vitamínico

- abortivo

- Exposiqão da mãe a raio X, nos quatro primeiros meses de gestacão e do pai um ano antes da gestacão da mãe

- Ingestão de bebida alcoólica pela mãe

- História paterna de epilepsia

- Morar na zona rural

Dado o número reduzido de expostos para o estrato SP, as seguintes variáveis foram excluidas: morar na zona rural, história paterna de epilepsia, ingestão de antibiótico pela mãe e ocorrencia de raio $X$ no pai. 


\subsubsection{Análise Univariada}

Aplicando-se análise univariada aos dados relativos a SP e NSP, obteve-se a tabela 13.

TABELA 13 - ANALTSE UNTCARTADA - SF E KSP - FISSURA FALATINA.

\begin{tabular}{|c|c|c|}
\hline & \multicolumn{2}{|c|}{ RR } \\
\hline UARIÁUEL & SP & NSP \\
\hline Poluicão & $10,00 *$ & $2,43 *$ \\
\hline Aplicacão de Pest./Herb.na lavoura, pelo & & \\
\hline pai & - & $7,38 *$ \\
\hline Atividade da mãe na lavoura & - & $0,18 *$ \\
\hline Hereditariedade & -- & $2,22 *$ \\
\hline Doencas na Mãe: rubéola & - & 4,21 \\
\hline hipertensão & 2,97 & 1,02 \\
\hline convulsão & - & 0,34 \\
\hline diabetes & $-\infty$ & 2,10 \\
\hline Ingestão de drogas: anti-emético & 0,45 & $0,48 *$ \\
\hline anovulatório & 4,25 & 0,87 \\
\hline complexo vitaminico & 4,86 & $0,48 *$ \\
\hline abortivo & 4,25 & 0,75 \\
\hline
\end{tabular}

Ocorrência de RX na mãe nos 4 primeiros meses de gestação

Uso de bebida alcoólica pela mãe

0,58

$0,15 *$ 
Para moradores de São Paulog verificou-ses pela tabela 13, que a poluicão se apresentou como fator de risco para fissura palatina. Outras variáveis apresentaram risco relativo de grande magnitude, como hipertensão, ingestão de anovulatório, complexo vitaminico e abortivo, porém sem significancia estatistica. Em relacão à hereditariedade, a tabela 12 mostrou um risco relativo de 14,96, significativo estatisticamente.

As variáveis ocorrência de raio X na mãe, aplicacão de pesticida elou herbicida na lavoura pelo pai, poluicão e hereditariedade são fatores de risco para fissura palatina, em individuos que moram fora do municipio de São Paulo.

Todas as variáveis que constaram da tabela 13 deveriam ser incluidas na análise multivariada, porém as variáveis atividade da mãe na lavoura, aplicacão de pesticida e/ou herbicida na lavoura pelo pai, doencas como rubéola, convulsão e diabetes e exposicão da mãe a raio $x$ nos quatro primeiros meses de gestacão, foram excluidas, em funcão das duas primeiras comprometerem o tamanho da amostra a ser analisada multivariadamente e as outras por apresentarem problemas relativos à inversão das matrizes. 


\subsubsection{2 - Análise Multivariada}

Aplicando-se análise multivariada às variáveis selecionadas bem como morar em São Paulo e a interacão poluicão. \& São Paulo, obteve-se:

TABELA 14 - ANALISE HULLTIUARTADA - FISSURA FALATINA.

\begin{tabular}{|c|c|c|c|c|}
\hline VAR IÁVEL & RR & P-VALOR & $\begin{array}{r}\text { INTEF } \\
\text { CON }\end{array}$ & $\begin{array}{l}\text { RUALO DE } \\
\text { VF IANCA }\end{array}$ \\
\hline $\begin{array}{l}\text { Poluicão (NSP) } \\
\text { Hereditariedade } \\
\text { Hipertensão } \\
\text { Drogas: antiemético } \\
\text { anovulatório } \\
\text { complexo vitaminico } \\
\quad \text { abortivo } \\
\text { Bebida Alcoólica: mãe } \\
\text { Morar em São Paulo (**) } \\
\text { Poluicão \& São Paulo } \\
\text { Poluicão (SP) }\end{array}$ & $\begin{array}{l}2,58 \\
2,82 \\
1,32 \\
0,48 \\
1,11 \\
0,67 \\
1,03 \\
0,19 \\
0,22 \\
3,66 \\
9,42\end{array}$ & $\begin{array}{l}0,00 \\
0,00 \\
0,47 \\
0,01 \\
0,85 \\
0,10 \\
0,96 \\
0,01 \\
0,09\end{array}$ & $\begin{array}{l}1,51 \\
1,45 \\
0,62 \\
0,27 \\
0,34 \\
0,41 \\
0,27 \\
0,06 \\
0,82 \\
2,34\end{array}$ & $\begin{array}{l}-\quad 4,41 * \\
-\quad 5,50 * \\
-\quad 2,83 \\
=\quad 0,84 * \\
-\quad 3,26 \\
=\quad 1,09 \\
-\quad 3,93 \\
-\quad 0,65 * \\
-16,31 \\
-\quad 37,94\end{array}$ \\
\hline
\end{tabular}

As seguintes variáveis se mostraram como fatores de risco para as fissuras palatinas:

- hereditariedade, com risco relativo de 2,82 e

- poluicão, com riscos relativos de 9,42 e 2,58, respectivamente para SP e NSP. 
Em relacão à hereditariedade, os portadores de fissura palatina, que apresentaram história familiar positiva de fissura, referiram-se a antecedente de fissura palatina e nunca de fissura labial ou lábio-palatina.

Outras variáveis, quando analisadas univariadamente, apresentaram-se como fatores de risco, porém não foi possível inclui-las na análise multivariada, quais sejam, raio $X$ na mãe, nos 4 primeiros meses de gestacão e aplicação de pesticida e/ou herbicida na lavoura pelo pai.

o Papel de fatores genéticos e ambientais, na inducão: de fissura palatina em animais, foi discutido num estudo de KALTER 35 no qual o tratamento com cortisona a duas linhagens resultou em $100 \%$ de todos os embriões de uma das linhagens com fissura palatina e apenas $12 \%$ da.outra linhagem com essa fissura. 0 autor atribuiu esse achado à diferenca intrinseca do padrão de desenvolvimento do embrião.

BURDI e SILVEY 7, em. 1969, estudaram embriões abortados e sugeriram que o padrão de desenvolvimento deveria ser estudado a fim de se determinar a susceptibilidade hereditária para fissura palatina também no homem.

LECK. 40 considera que a fissura palatina apresenta maior variabilidade do que a fissura lábio-palatina em cada grupo de populacões de mesma etnia, sugerindo que o meio ambiente esteja mais envolvido na sua etiologia do que o genótipo. 


\title{
4.3 - CONSIDERACõES GERAIS
}

\begin{abstract}
Tendo emi mente a possivel multicausalidade das fissuras orais, realizou-se um estudo de fatores de risco para essas anomalias, considerando-as integrantes de dois grupos distintos, fissuras labiais ou lábiomalatais e fissuras palatinas, com abordagem caso-controle..
\end{abstract}

Os fatores de risco identificados para fissura labial ou lábio-palatina foram hereditariedade, epilepsia na mãe e ingestão de anti-1nflamatórlo e para fissura palatina foram ferraditariedade e foluifác.

Alguns problemas que poderiam interferir em estudos epidemiológicos deste tipo, mas julgados controlados, são expostos a seguir:

- comparabilidade das informacões pertinentes aos casos $e$ aos controles: suponha-se que os controles fossem casos e perguntase se iriam para Bauru, no Hospital de Pesquisa e Reabilitacão de Lesões Lábio-Palatais? Possivelmente sim, dependendo de um conjunto de circunstâncias, entre elas, o conhecimento da existência do Hospital,

- em relacão à exposicãos considera-se que as informações da mãe poderiam mascarar uma real diferencas principalmente se for mãe do caso. No entanto, exposicão: do pai ao Raio $X$, quando analisada univariadamente, foi fator de protecão para fissura labial ou lábio-palatina (tabela 9), sendo que a mãe do caso poderia ser levada à dar informacão contrária e 
- quanto à aplicacão dos formulários, a disponibilidade dos casos. e controles não permitiu que os entrevistadores que entrevistaram casos, entrevistassem controles. A fim de evitar uma possivel tendenciosidade, houve a preocupacão de se fazer um estudo de validade. Este estudo referiu-se as variáveis: poluiGẫo, hereditariedades doencas nos quatro primeiros meses de gestacão (convulsão, rubéola, hipertensão e diabetes), epilepsias irradiacão e drogas ingeridas nos quatroprimeiros meses de gestacão, referentes ao uso de anti-inflamatório, anti-emético, anti-convulsivante, anti-hipertensivo, anti-alérgico, anovulatório, complexo vitaminico, abortivo, analgésico e antibiótico. Encontrou-se $100 \%$ de coopositividade e $100 \%$ de coonegatividade.

Segundo estudo realizado pela OMS em 16 paises, a mortalidade entre fissurados é mais precoce, principalmente se outras malformacões estão associadas, o que torna a população de estudo limitada aos sobreviventes 76 . MOLLER 50 ressalta que a maioria dos estudos analisa dados de prontuários de clínicas de tratamento, excluindo, portanto, natimortos e casos que morram antes da intervencão, sendo que a exclusão desse grupo pode criar uma tendenciosidade na amostra de pacientes a ser estudada. Isto poderia explicar o resultado referente à ingestão de bebida alcoólica, como fator de protecão. Por outro lado, poderia mascarar - real valor do risco de uma variável para a fissurag pois não se teria a informacão desejada para as criancas nati-mortas ou que tenham falecido precocemente. 
Algumas variáveis apresentaram risco relativo menor do que 1 com significância estatistica, quais sejam, ingestão dé anti-emético e bebida alcoólica para os dois tipos de fissuras: e ingestão de complexo vitaminico para fissura lábio-palatina. Enquanto que complexo vitaminico como fator de protecão seja aceitável, é dificil entender o fato para ingestão de antiemético e de bebida alcoólica.

Anti-emético possivelmente é um achado espurio. Em relação à bebida alcoólica, dadas as consideracões já apontadas sobre as perdas antes do nascimento vivo, julga-se que este fator deveria ser analisado de outra forma mais especifica, com abordagem, por exemplo, do tipo coorte.É bem possivel que o efeito da ingestão do álcool seja subestimado num estudo caso-controle, em que se trabalhe apenas com "fissuras simples", pois, a ingestão de álcool não provoca apenas a fissura mas sim a sindrome materno alcoólico-fetal acompanhada de outras malformacões. 


\section{5 - CONCLUSÕES}

Os fatores de risco para as fissuras orais, com as respectivas estimativas de risco relativo, por ponto e por intervalo de $95 \%$ de confianca, são apresentados a seguir, segundo a análise multivariada:

5.1 - FISSURA LABIAL DU LABIO-PALATINA

$\begin{array}{ccc}\text { FATOR } & \text { POR PONTO } & \text { POR INTERUALO } \\ \text { Hereditariedade (NSP) } & 4,96 & 2,99-8,22 \\ \text { (SP) } & 15,67 & 4,01-61,19 \\ \text { Epilepsia na mãe } & 2,39 & 1,01-5,69 \\ \text { Ingestão de anti-inflamatório } & 2,59 & 1,35-4,98\end{array}$

5.2 - FISSUFA PALATINA

\begin{tabular}{ccc} 
FATOR & POR PONTO & POR INTERUALO \\
\hline Hereditariedade & 2,82 & $1,45-5,50$ \\
Poluicão (NSP) & 2,58 & $1,51-4,41$ \\
(SP) & 9,42 & $2,34-37,94$
\end{tabular}




\section{6 - REFERENCIAS BIBLIOGRAFICAS}

01 - ABYHOLM, F.E. Cleft lip and palate in Norway. I. Registration, incidence and early mortality of infants with CLP. Scand. J. Plast. Reconstr. Surg., 12: 29-34, 1978.

Q2 - ADEKEYE, E.O. et al. Cleft lip and palate in Nigerian children and adults: a comparative study. Br.J.Oral_\& Maxillofac. Surg., 23: 398-403, 1985.

03 - ALtemuS, L.A. The incidence of cleft lip and palate among North American Negroes. Cleft Palate J., 正: 357-61, 1966.

O4 - geRTOLLINI, R. et al. Maternal epilepsy and birth defects: a case-control study in the Italian Multicentric Registry of Birth Defects (IPIMC). Eur. J. Epidemiol., 1: 67-72, 1985.

05 - BJERKEDAL, T. \& BAKKETEIG, L.S. Surveillance of congenital malformations and other conditions of the Newborn. Int. J. Epidemiol., 4: 31-6, 1975.

O6 - gONAITI, C. et al. An epidemiological and genetic study of facial clefting in France. I. Epidemiology and frequency in relatives. J. Med. Genet., 19: 8-15, 1982. 
07 - BURDI, A.R. \& SILUEY, R.G. Sexual differences in closure of the human palatal shelves. Cleft Palate J.s $6:$ : 1-7, 1969.

O8 - BURDI, A. et al. Etiology and pathogenesis of congenital cleft lip and cleft palate, on NIDR state of the art report. Teratology, 으: $255-68,1972$.

O9 - BURMAN, N.T.C. et al: A case: control study of oro-facial clefts in Western Australia. Aust. Dent. J., 30: 423-9, 1985.

10 - CÂNDIDO, I.T. Epidemiologia das fendas de lábio e/ou ealato: estudo de recém-nascidos em dois hospitais de Porto Alegre, no periodo de 1970 a 1974 . Porto Alegre, , 1978. [Dissertacão de Mestrado - UFRS].

11 - Chaves, M.M. Qdontologia social. 2a. ed. Rio de Janeiro, Ed. Labor do Brasil, 1977 .

12 - CHUNG, C.S. \& KAU, M.C.W. Racial differences in cephalometric measurements and incidence of cleft lip with or without cleft palate. J. Craniofacial Genet. Dev. Biol. s 5 : $341-49,1985$. 
13 - CHUNG, C.S. \& MYRIANTHOPOULOS, N.C. Racial and prenatal factors in major congenital malformations. Amer. L. Hum. Genet. 20: 44-60, 1968.

14 - CHUNG, C.S. et al. Segregation analysis of cleft lip with or without cleft palate: a comparison of Danish and Japanese Date. Am, 1. Hum, Genet., 39: 603-11, 1986.

15 - CONWAY, H. \& WAGNER, K.J.: Incidence of clefts in New York City. Cleft Palate J., 3: 384-90, 1966.

16 - DE WALLS, P. \& LECHAT, M.F.s ed. surveillance of congenital anomalies: years 1980-1983. Bruxelles, Catholic University of Louvain - Department of Epidemiology, 1986. (EUROCAT report 1 ).

17 - DONAHUE, R.F. - Birth variables and the incidence of cleft Palate: Part II. Cleft Palate J., 4: 234-9, 1967.

18 - FOGH-ANDERSEN. P. Vital Statistics of cleft lip and palate - Past, present, future. Actachir.Plast. 5: 169-74, 1963.

19 - FOGH-ANDERSEN, $P$. Genetic and non-genetic factors in the etiology of facial clefts. Scand. J. Plast. Reconstr. Surg., 1: 22-9, 1967 . 
20 - FOGH-ANDERSEN, P. Epidemiology and etiology of clefts. Birth Defects Orig. Artic. Ser., I (7): 50-3, 1971.

21 - FRASER, F.C. The genetics of cleft lip and cleft palate (review). Amer. J. Hum: Genet., 22: 336-52, 1970.

22 - FRASER, F.C. Etiology of cleft lip and palate. In: GRABB, w.C. et al.s ed. General aspects of cleft lip and palate. Boston, Little, Brown and Company, 1971. P. $54-65$.

23 - FRASER, G.R. \& CALNAN, J.S.: Cleft lip and palate: seasonal incidence, birthweight, birth rank, sex, site, associated malformations and parental age. Arch. Dis. Child., 36: $420-3,1961$.

24 - FRASER, F.C. \& FAINSTAT, T.D. Production of congenital defects in the offspring of pregnant mice treated with cortisone. Pediatrics, 8: 527-33, 1951.

-25 - GOLDING, J. et al: Maternal anti-nauseants and clefts of lip and palate. Hum. Toxicol., 2: $63-73,1983$.

26 - gombos, F. et al. Studio epidemiologico sulle schisi del labbro e del palato nel la città di Napoli. Arch. Stomatol., 21: 179-92, 1980 . 
27 - GREENE, J.C. Epidemiology of congenital clefts of the lip and palate. Public Health Rep., 78: 589-602, 1963.

28 - GREENE, J.c. et al. Epidemiologic study of cleft lip and cleft palate in four states. L.Amer. Dental Assoc.s 68: $73-90,1964$.

29 - GREENE, J.C. et al. Utilization of birth certificates in epidemiologic studies of cleft lip and palate. cleft Palate ل., 20: 141-56, 1965.

30 - HAY, S. Incidence of clefts and parental age. Cleft Palate ل., 4: 205-13, 1967.

31 - HAY, S. Variables in under-reporting of clefts on birth certificates. Public. Health Ree., 旦: 985-93, 1967.

32 - heitz, F. \& MARTINet, M. Dualité des stades sensibles dans le développement du palais chez la souris mise en évidence par les rayons X. C.R. Soc. Biol., Paris, 155: $707-9,1961$.

33 - IREGGULEM, L.M. The incidence of $\mathrm{cleft}$ lip and palate in Nigeria. Cleft Palate J., 19: 201-5, 1982.

34 - JANERICH, D.T. \& POLEDNAK, A.P. Epidemiology of birth defects. Epidemiol. Rev., ㅍ: 16-37, 1983. 
35 - KALTER, H. The inheritance of susceptibility to the teratogenic action of cortisone in mice. Genetics, 39 : $185-96,1954$.

36 - KNOX, G. \& BRAITHWAITE, F. Cleft lips and palates in Northumberland and Durbam. Arch. Dis. Child., 39: $66-70,1963$.

37 - KROMBERG, J.G.R. \& JENKINS, T. Common birth defects in South African Blacks S. Afr. Med. Jl., 69: 599-602, 1986.

38 - LANGMAN, J. - Embriologia médica. $2^{a}$ ed. São Paulos Atheneu, 1970.

39 - Leavell, H.R. \& ClaRk, E.G. Medicina preventiva. São Paulo, Me Graw-Hill do Brasil, 1976.

40 - LECK, I. The etiology of human malformations: insights from epidemiology. Teratology, 5: 303-14, 1972.

41 - LENZ, W. Malformations caused by drugs in pregnancy. Amer. ل, Dis. Child., 112:99-106, 1966. 
42 - LUNA ALFONSO, R.\& ZALDIUAR, E.R. Incidencia de fisuras labiopalatinas en niños nacidos en. el Hospital Maternoinfantil de Camaguey. Años 1975-1979. Rev. Cub. Estomatol., 23: $9-14,1986$.

43 - MAC MAHON, B. \& MCKEOWN, T. The incidence of harelip and cleft palate related to birth rank and maternal age. Amer. J. Hum. Genet., ㅍ: $176-83,1953$.

44 - MEADOW, S.R. Congenital abnormalities and anticonvulsant drugs. Proc. R. Soc. Med., 63: $48-9,1970$.

45 - MELNICK, M. et al. Cleft lip cleft palate: an overview of the literature and an Analysis of danish cases born between 1941 and 1968. Am. J. Med. Genet.s 6 : 83-97, 1980.

46 - MESKIN, L.H. \& PRUZANSKY, S. Validity of the birth certificate in the epidemiologic assessment of facial clefts.. J. Dent. Res., 46: 1456-9, 1967.

47 - MESKIN, L.H. et al. An epidemiologic investigation of factors related to the extent of facial clefts. I. Sex of patient.Cleft Palate J., 5: 23-9, 1968. 
48 - MILHAM Jr:g S. Underreporting of incidence of cleft lip and cleft palate. Amer.J. Dis. Child., 106: 185-8, 1963.

49 - MILLARD, D.R. \& MCNEIL, K.A. The incidence of cleft lip and palate in Jamaica. Cleft Palate J., ㄹ: 384-8, 1965.

50 - MOLLER, P. Cleft lip and cleft palate in Iceland. Arch. Oral Biol., 10: $407-20,1965$.

51 - MOLLER, P. Epidemiologic and genetic study of cleft lip and palate in Iceland. Ala J. Med. Sci., q: 119-36, 1972.

52 - MORRISON, G. et al. The incidence of cleft. lip and palate in the Western Cape. S. Afr. Med. J., 68: 576-7, 1985.

53 - MYERS, R.A. et al. Cleft lip and cleft palate in. North Carolina. MCMJ, 38: 707-12, 1977.

54 - NAGEM Fog H. et al. Contribuicão para o estudo da prevalência das más formacões congênitas lábio-palatais na populacão escolar de Bauru. Rev. Fac. Odont. Univ. São Paulo, 6: $111-28,1968$. 
55 - NATSUME, N. 8 KAWAI, T. Incidence of cleft lip and cleft palate in 39,696 Japanese babies born during 1983. Int. J. Oral Maxillofac. Surg., 15: 565-8, 1986.

56 - NATSUME, N. et al. The prevalence of cleft lip and palate in the Japanese: their birth prevalence in 40.304 infants born during 1982. Dral Surg. Oral Med. Oral Pathol., 63: $421-3,1987$.

57 - NEEL, J.V. A study of major congenital defects in Japanese infants. Amer. J. Hum. Genet., 10: $398-445,1958$.

58 - NIEBYL, J.R. et al. Lack of maternal metabolic, endocrine, and environmental influences en the etiology of cleft lip with or withour cleft palate. Cleft Palate J., 르: $20-8,1985$.

59 - OLIN, W.H. Incidence of cleft lips and palates in Iowa, 1941-1961. Cleft Palate Bull., 13: 10, 1963.

60 - PANNBACKER, M. : Congenital malformations and cleft $l$ ip and palate. Cleft Palate J., 5: $334-9,1968$.

61 - RINTALA, A.E. Epidemiology of orofacial clefts in Finland: a review. Ann. Plast. Surg., 17: 456-9, 1987. 
62 - SAFRA, M.J. \& OAKLEY Jr.s G.P. Association between cleft lip with or without cleft palate and prenatal exposure to Diazepan. Lancet (7933): 478-80, 1975.

63 - SAXÉN, I. Cleft lip and palate in Finland: parental histories, Course of Pregnancy and Selected Environmental factors. Int. J. Epidemiol., 3: 263-70, 1974.

64 - SAXÉN, I. Associations between oral clefts an drugs taken during pregnancy. : Int. J. Epidemiol.; 4: 37-44, 1975.

65 - SAXÉN, I. Epidemiology of cleft lip and palate. An attempt to rule out chance correlations. Brit.J. Prev. Soc. Med., 29: $103-10,1975$.

66 - SAXÉN, I. Etiological variables in oral clefts. Proci Finn. Dent. Soc., 71 (Suppl. 3): 1-40, 1975.

67 - SAXÉN, I \& LAHTI, A. Cleft lip and palate in Finland: incidence, secular, seasonal and geographical variations. Teratology, ㅇ: 217-23, 1974 .

68 - SCHLESSELMAN, J.J. Case-control studies: design, conduct, analysis. Oxford, University Press, 1982.

69 - SESGIN, M.Z. \& STARK. The incidence of congenital defects. Plast. Reconstr. Surg., 27: 261-6, 1961. 
70 - SHAPIRO, S. et al - Anticonvulsants and parental epilepsy in the development of birth defects. Lancet (feb.): 272-5, 1976.

71 - SHIELDS, E.D. et al. Cleft palate: a genetic and epidemiologic investigation. Clin. Genet., 20: 13-24, 1981.

72 - SLONE, D. et al. Maternal drug exposure and fetal abnormalities. Material and Methods. Clin. Pharmacol. Iher., 14: $648-53,1973$.

73 - SMITHELLS, R.W. Environmental teratogens in man. Brit. Med. Eu11., 32: 27-33, 1976.

74 - SOUZA, J.M.P. de \& EENICIO, M.H.D'A. Analise multivariada: um exemplo usando modelo log-linear. Rev, Saúde públ., S. Paulo, 19: 263-9, 1985.

75 - Souza, J.M.P. et al. Estudo da morbidade e da mortalidade perinatal em maternidades. III - anomalias congênitas em nascidos vivos. Rev. Saúde públ., S.Paulo, 르: 5-12, 1987.

76 - STEUENSON, A.C. et al. Congenital malformations. A report of a study of series of consecutive births in 24 centres. Bull..W.H.O., 34 (Suppl.): 1-127, 1966. 
77 - TANAKA, T. A clinical, genetic and epidemiologic study on cleft lip and/or cleft palate. Jpn. J. Hum. Genet., 16: $278-308,1972$.

78 - THOMPSON, J.5. \& THOMPSON, M.W. Genética Médica. 2a. ed. Rio de Janeiro, Atheneu, 1976.

79 - TREstVen, E.V. Incidence of cleft lip and palate in Montana Indians. J. Speech Hear. Disord., 28: 52-7, Washington, 1963.

80 - WEHRUNG, D.A. \& HAY, S. A study of seasonal incidence of congenital malformations in the United States. Brit J. Prev. Soc. Med., 24: 24-32, 1970.

81 - WELCH, J. \& HUNTER, A.G.W. - An epidemiological study of facial clefting in Manitoba. J. Med. Genet.s 17: 127-32, 1980 .

82 - WOOLF, C.M. Paternal age effect for cleft lip and palate. Amer. J. Hum. Genet., 15: 389, 1963 
$A N E \times D S$ 
ANEXO I

FORMULÁRIO

FISSURAS LÁBIO-PALATAIS: FATORES DE RISCO

IDENT IFICACAO: ---

1. Nome:

2. Atributo: (1) Caso ()

(2) Controle ()

3. Tipo da fissura: (1) labial

(2) palatina

(3) lábio-palatina

(4) sem fissura

4. Instituicão:
(1) Araraquara
(2) Bauru
(3) São Paulo
(4) Londrina
$(2)$
()
( )

5. Procedência: Cidade:

Endereco:..

\section{INFORMACXES GERAIS}

6. Sexo: (1) Masculino (?)

(2) Feminino ( )

7. Qual a idade de seu filho? ..... meses

8. Qual a idade dos pais na época do nascimento?

A. Pai:.... anos

B. Mãe..... anos 
9. Onde a familia morava nos 4 primeiros meses de gestacão? Cidade:.................. Estado:.."

10. Era zona rural ou zona urbana? (1) urbana

(2) rural

(9) ignora

11. Nesse local havia poluifão?
(0) กล̃o
(1) $\mathrm{sim}$
(9) ignora

12. Se positivo, qual o tipo de poluifão ou nome da empresa poluidora:

Tipo:............... Nome:

13. Qual o grau de instrucão do pai?

(0) anal fabeto

(1) primário incompleto

(2) primário completo

(3) secundário incompleto

(4) secundário completo

(5) téenico incompleto

(6) técnico completo

(7) superior incompleto

(8) superior completo

(9) ignora

14. Qual o grau de instrucão da mãe?

(0) anal fabeta

(1) primário incompleto

(2) primário completo

(3) secundário incompleto

(4) secundário completo

(5) técnico incompleto.

(6) técnico completo

(7) superior incompleto

(8) superior completo

(9) ignora 
HISTÓRIA OCUPACIONAL NO PERIODO DE 1 ANO ANTES DA MXE FICAR GRAUIDA DESSA CRIANCA ATÉ OS 4 MESES DE GESTACXO

15. Atividades principais dos pais:

A. Pai:...

B. Mãe: .

16. Nesse periodo, o pai trabalhou como lavrador?
(0) não
(1) 5 im
()
(9) ignora ( )

17. O pai costumava pessoalmente aplicar pesticidas ou herbicidas na lavoura?
(0) กão
(1) 5 im
$($ )
(8) กão se aplica (:)
(9) ignora

18. O pai teve intoxicacão causada por esses produtos?
(0) não
(1) 5 in
(8) não se aplica
(9) ignora

19. Nesse periodo, a mãe trabalhou como lavradora?

(0) กão

(1) 5 im

(9) ignora

()

20. A mãe costumava pessoalmente aplicar pesticidas ou herbicidas na lavoura?
(0) não
(1) 5 im
()
(8) não se aplica ( )
(9) ignora

21. A mãe teve intoxicafão causada por esses produtos?
(0) não
(1) 5 in
)
(8) não se aplica
(9). ignora
$1)$
$(1)$
$1)$ 
22. Renda familiar atual: CZ\$........ OTN.......

23. Número de moradores na casa:.......

24. Nưmero de gestacões da mãe incluindo o náscimento dessa crianca:

$\begin{array}{ll}(1) 1 & (?) \\ (2) 2 & (?) \\ (3) 3 & (?) \\ (4) 4 & (?) \\ (5) 5 & (?) \\ (6) 6 & (?) \\ (7) 7 & (?\end{array}$

25. Quantos nascidos vivos, incluindo essa crianca:

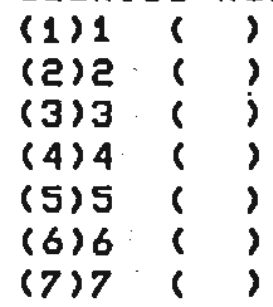

26. Quantos nati-mortos:

$\begin{array}{ll}(0) 0 & (?) \\ (1) 1 & (?) \\ (2) 2 & (?) \\ (3) 3 & (?) \\ (4) 4 & (?) \\ (5) 5 & (?) \\ (6) 6 & (?) \\ (7) 7 & (?\end{array}$

27. Quantos abortos:

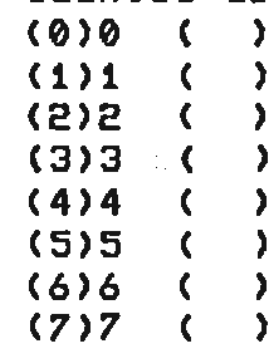


28. Qual o peso dessa crianca ao nascimento (kg):

\author{
HISTÓRIA FAMILIAR
}

29. Existe parentesco entre os pais?

(0) năo

(1) 5 im

$($ )

(9) ignora

qual: ........

30. Os pais e avós desta crianca são fissurados?

A. Fissura labial:

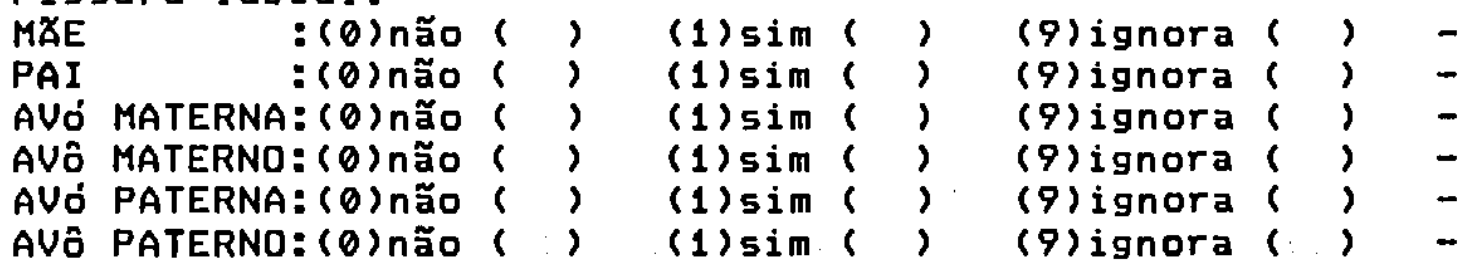

B. Fissura palatina:

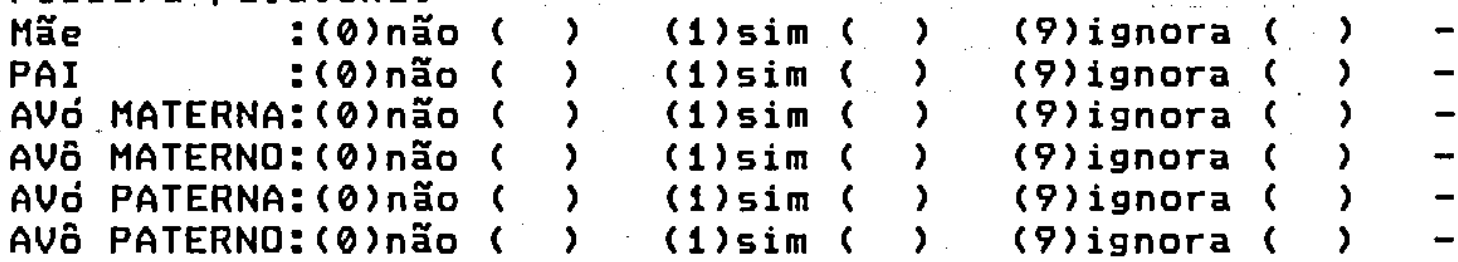

C. Fissura lábio-palatina:

-(Q)não ( )

PAI : $(\theta)$ não $(2)$

AVó MATERNA: $(\theta)$ não ( )

AVó MATERNo: $(\theta)$ กão: ( )

AVó PATERNA: $(\theta)$ กล̃o ( )

(1) $\operatorname{sim}($ )

(9)ignora ( ) -

(1) $\operatorname{sim}($ )

(1) sim ( ) )

(1) $\sin (;)$

(1) $\sin ($ )

(9)ignora $($ ) -

AVó PATERNO: $(\theta)$ năo ( )

(1) $\sin ($ )

(9)ignora ( ) -

(9)ignora $($ ) -

(9)ignora ( ) -

(9)ignora $($ ) -

31. Número de irmãos (vivos, mortos ou nati-mortos) crianca que tém ou tiveram as fissuras do tipo:

A. labial:

$\begin{array}{ll}(0) 0 & (?) \\ (1) 1 & (?) \\ (2) 2 & (?) \\ (3) 3 & (?) \\ (4) 4 & (8) \text { ) } \\ \text { (9)ignora se aplica }\end{array}$


B. palatina

$(0) 0$

(1) 1

$(2) 5$

(3) 3

(4) 4

(8) não se aplica

(9) ignora

C. lábio-palatina

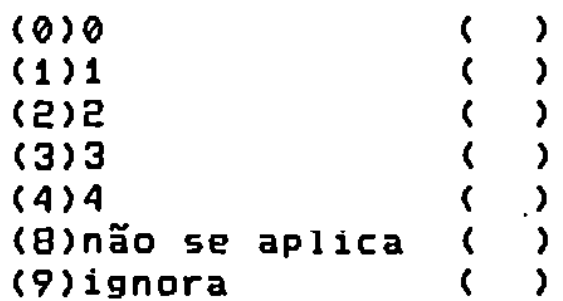

32. A senhora sabe se alguém mais de sua familia teve o problema de seu filho? (para o controle _-_-_ usar o termo fissura).

(0) กão

(1) $\mathrm{sim}$

(9) ignora. ( )

33. Em caso afirmativo, especificar o grau de parentesco com essa crianca e o tipo da fissura:
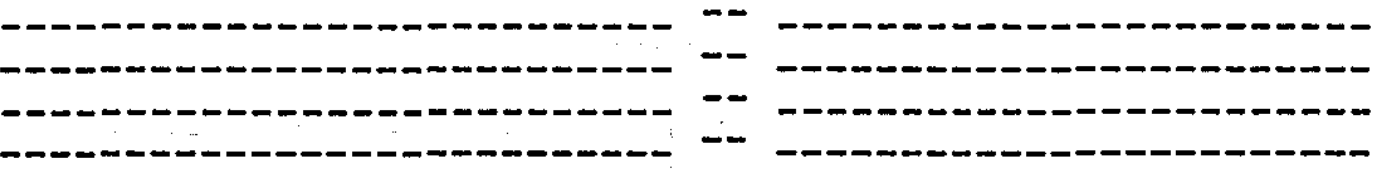

34. Ds pais desta crianca têm ou tiveram epilepsia?

A. MZE:

(0) กล̃o

(1) 5 im

(9) ignora

B. PAI :

(0) กล̃o

(1) 5 im

(9) ignora

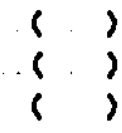

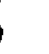


36. Que doencas a senhora teve?
A. Rubéola:
(0) กล̃o
(1) $\mathrm{sim}$
(?)
B. Pressão alta:
(9) ignora
(0) กล̃o
(1) $\operatorname{sim}$
(9) ignora
()
c. Convulsão:
(0) กão
(1) sim
(9) ignora
(?)
D. Diabetes:
(0) กล̃o
(1) sim
(9) ignora

()

37. A senhora teve alguma doenca que levou-a ao médico?

$\begin{array}{ll}\text { (0) não } & \text { (1) } \\ \text { (1) im ignora ( ) }\end{array}$

38. Que remédios a senhora tomou?
A. anti-inflamatórios:
(0) กล̃o
(1) 5 im
(9) ignora ( )
$(1)$
Em caso afirmativo, dar o nome e a dose:

B. anti-eméticos:

(0) กล̃o

(1) $\mathrm{sin}$

(9) ignora

Em caso afirmativo, dar o nome e a dose:

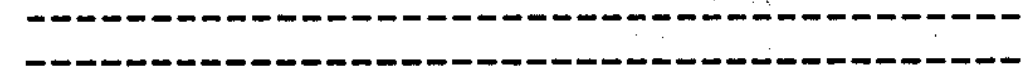

C. anti-convulsivantes: (0) não

(1) 5 im

(9) ignora

( )

- Em caso afirmativo, dar o nome a dose:

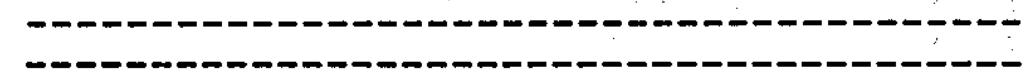


$\begin{array}{ll}\text { D. anti-hipertensivos:: } & \text { (0) não } \\ & \text { (1) sim } \\ & \text { (9) ignora () }\end{array}$ Em caso afirmativo, dar o nome e a dose:

E. anti-alérgicos:

(0) กão

(1) 5 im

(9) ignora

()

Em caso afirmativo, dar o nome e a dose:

F. anovulatórios: :

(0) กล̃o

(1) 5 im

(9) ignora

$($ )

()

Em caso afirmativo, dar o nome $a$ a dose:

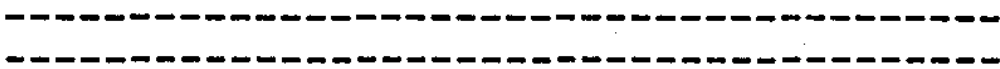

G. complexos vitaminicos: ( $(1)$ não

(1) $\mathrm{sim}$

(9) ignora ( )

Em caso afirmativo, dar o nome e a dose:

H. tratamento lepra:

(0) กล̃o

(1) 5 im

(9) ignora

Em caso afirmativo, dar o nome a a dose:

I. provocar aborto:

(0) กล̃o

(1) 5 im

(9) ignora

(1)

Em caso afirmativo, dar o nome e a dose:

Em caso afirmativo, dar o nome e a dose:

J. analgésicos:

(0) กล̃o

(1) 5 im

(9) ignora

Em $\cos 0$ En caso afirmativo, dar o nome e a dose:

K. antibióticos:

(ø) กลัo

(1) 5 im

(9) ignora

()

$($ )

Em caso afirmativo, dar o nome e a dose: 
39. Quantas vezes a senhora se submeteu a raio-X?

$\begin{array}{ll}(0) 0 & (1) \\ (1) 1 & (1) \\ (2) 2 & (?) \\ (3) 3 & (?) \\ (4) 4 & (?)\end{array}$

40. Quantos cigarros por dia a senhora fumou?

41. O marido da senhora fumava nesse período?
(0) กล̃o
(1) $\operatorname{sim}$
(9) ignora

$(1)$
$(1)$

42. A senhora bebia bebida alcoólica nesse periodo?
(0) กล̃o
(1) $\operatorname{sim}$
$($ )
(9) ignora
$(3)$
$(1)$

43. En caso afirmativo, dar o tipo e a dose de ingestão:

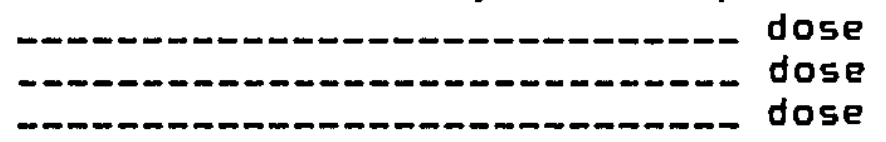

$$
\begin{aligned}
& \text { dose } \\
& \text { dose } \\
& \text { dose }
\end{aligned}
$$

44. A senhora se submeteu a raio-X no periodo de 1 ano antes da gravidez desse filho?
(0) não
(1) sim
(9) ignora

$$
\text { () }
$$$$
(1)
$$

45. O pai dessa crianca se submeteu a raio-X no periodo de 1 ano antes da senhora ficar grávida dessa crianca?
(O) não
(1) 5 im
(9) ignora

1
1




\section{PARA O ENTREUISTADOR}

46. Dê uma nota para a entrevista de 0 a $10: \ldots .$.

47. Data da entrevista:

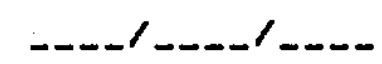

48. Duracão, em minutos: .....

49. Entrevistador:

50. Comentários do entrevistador: 


\section{ANEXO I I \\ MANUAL \\ FORMULÁRIO}

\section{FISSURAS LÁBIO-PALATAIS - FATORES DE RISCO}

1. O principal objetivo do formulário é obter informacões sobre variáveis que estejam associadas com a ocorrência de fissuras labio-palatais.

2. 05 formulários serão preenchidos por entrevistadores e as técnicas de entrevista e os problemas mais freqüentes durante o preenchimento serão discutidos a priori:

3. O entrevistador deverá rever todos os formulários que preencheu antes de entregá-105, com especial atencão para que estejam legiveis e que todas as questões sejam respondidas. No caso de serem identificadas questões com mais de 1 resposta assinalada ou sem resposta, deverá ser realizada nova entrevista.

Recomenda-se revisão sistemática ao final de cada entrevista.

4. Colocar um $X$ nas caselas () que correspondem à resposta da questão.

Se a resposta exigir que se escreva alguma coisa, deverá ser feita de forma legivel, em letra de forma.

SUCES50 


\section{FISSURAS LABBIO-PALATAIS: FATORES DE RISCO}

o formulário deverá ser aplicado a todos os participantes desse inquérito. Seguem abaixo algumas recomendacões para o seu preenchimento, identificadas pelo numero da questão.

1. NOME :

Escrever, por extenso, o nome do entrevistado.

2. ATRIBUTO:

Assinalar, com um "X" na casela (), para a resposta adequada.

(1) Caso (x) _- todo entrevistado portador de fissura-lá

(2) Controle (X) _... todo entrevistado são, não portador de quaisquer anormalidades.

3. TIPO DE FISSURA:

Assinalar com um " $X "$ a resposta adequada:

(1)labial( $X)$ : fissura no lábio

(2)palatina( $X)$ : fissura no pálato

(3) lábio-palatina(X): fissura no lábio e no pálato

(4)sem fissura(X): no caso do entrevistado ser controle

4. INSTITUICX̃:

Assinalar com um " $X "$ a resposta adequada, ou seja, se o entre vistado for de:

(1) Araraquara $(x)$

(2) Bauru : $(X)$

(3) S.Paulo (X)

(4) Londrina. ( $x$ )

5. PROCEDÊNCIA:

Escrever, por extenso, o nome da cidade e o respectivo estado de onde o entrevistado veio.

\section{INFORMACõES GERAIS}

6. SEXO:

Assinalar com um " $X$ " a resposta certa.

7. QUAL A IDADE DE SEU FILHO?

Escrever, por extenso, a idade, que poderá variar de 00 (re cém-nascido) a 12 meses exclusive. 
8. IDADE DOS PAIS NA ÉPOCA DO NASCIMENTO DA CRIANCA:

Escrever, por extenso, a idade em anos.

9. LOCAL DE MORADIA DA FAMILIA:

Escrever, por extenso, o nome da cidade e o respectivo estado em que a familia do entrevistado morava nos 4 primeiros meses de gestacão.

10. ERA ZONA RURAL OU URBANA?

Assinalar com um " $X$ " a resposta adequada:

URBANA: relativo à cidade.

RURAL : relativo ao campo.

11. POLUICXO:

Assinalar com um " $X$ " a resposta adequada.

Entende-se por POLUICXO, para a finalidade deste trabalho:

- gás de escapamento dos automóveis a motor Diesel;

- fuligens de usinas de álcool;

- fumacas de aquecedores e de caldeiras;

- residuos de lavagens de tanques industriais lancados na água dos rios;

- dejetos de usinas nas águas dos rios e riachos;

- indústria automobilistica.

12. TIPO DE POLUICXO OU NOME DA EMPRESA POLUIDORA:

Anotar o tipo ou o nome da empresa que provoca a poluicão.

13. e 14. GRAU DE INSTRUCXO:

No caso da mãe (ou do pai) da crianca haver frequentado algum curso, especificar com um " $x$ " discriminando se completou ou กล̃o.

A codificafão será feita, conforme o seguinte código:
$(0)$-anal fabeto
$(x)$
(1)-primário incompleto
$(x)$
(2)-primário completo
(3)-colegial incompleto
$(x)$
$(x)$
(4)-colegial completo
$(x)$
(5)-técnico incompleto
$(x)$
(6)-técnico completo
(7)-superior incompleto
$(x)$
(B)-superior completo
$(x)$
(9)-ignora
$(x)$
$(x)$

HISTÓRIA OCUPACIONAL

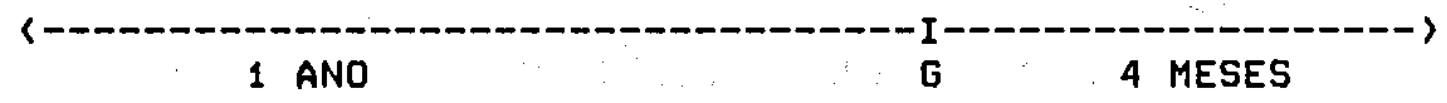

15. ATIUIDADES PRINCIPAIS DOS PAIS:

Escrever, por extenso, as atividades principais do pai e da mãe. 
16. NESSE PERIODO, O PAI TRABALHOU COMO LAURADOR?

Assinalar, com um " $X$ " a resposta adequada

17. O PAI COSTUMAUA PESSOALMENTE APLICAR PESTICIDAS OU HERBICIDAS NA LAVOURA?

Assinalar, comi um "X" a resposta adequada.

18. O PAI TEVE INTOXICACXO CAUSADA POR ESSES PRODUTOS?

Assinalar, com um " $X "$ " a resposta adequada.

19. 20. e 21. - análogas às questões 16, 17 e 18, referentes à. mãe.

22. RENDA FAMILIAR ATUAL:

Anotar, em cruzados, a renda familiar atual.

A conversão em OTN será feita após a aplicacão de cada questionário.

23. NÚMERO DE MORADORES NA CASA:

Anotar esse número.

24. NÚMERO DE GESTACõES DA MXE, INCLUINDO ESSA CRIANCA:

Anotar, com um " $X$ ", a resposta adequada.

25. QUANTOS NASCIDOS UIVOS, INCLUINDO ESSA CRIANCA:

Anotar, com um " $X$ ", a resposta adequada

26. QUANTOS NATI-MORTOS?

Anotar, com um " $X$ ", a resposta adequada.

NATI-MORTO: definicão - é a morte do produto da concepcão ocorrida antes de sua expulsão ou extracão completa do corpo da mãe no periodo de 28 semanas de gestafão e mais. A morte está indicada pelo fato de que depois dessa separacão o feto nem respira nem manifesta nenhum sinal de vida.

27. QUANTOS ABORTOS?

Anotar, com um " $X$ ", a resposta adequada.

ABORTO: definicão - é a morte do produto da concepcão antes da sua expulsão. ou extracão completa do corpo da mãe, no periodo de 27 semanas de gestacão ou menos.

28. QUAL O PESO DESSA CRIANCA AO NASCIMENTO?

Anotar o peso em gramas.

\section{HISTÓRIA FAMILIAR}

29. EXISTE PARENTESCO ENTRE OS PAIS?

Assinalar, com um " $X$ ", a alternativa certa.

Em caso afirmativo, anotar o tipo de parentesco em letra de forma. 
30. OS PAIS E AUÓS DESSA CRIANCA SXO FISSURADOS?

Assinalar, com um " $X$ ", a alternativa certa, para os itens $A$, B e C.

31. NÚMERO DE IRMZOS (UIUDS, MORTOS DU NATI-MORTOS) DESTA CRIANCA QUE TEM OU TIUERAM AS FISSURAS DO TIPO: A.LABIAL; B.PALATINA E C.LÁBIO-PALATINA:

Assinalar, com Um " $X$ ", a alternativa certa, para os itens $A$, B e C.

32. A Senhora sabe se alguém MaIs de sua família teve o problema DE SEU FILHO? (PARA O CONTROLE, USAR D TERMO FISSURA).

Assinalar, com um " $X$ ", a resposta certa.

Para o CONTROLE oeverá ser explicado o que é FISSURA.

33. EM CASO AFIRMATIUO, ESPECIFICAR O GRAU DE PARENTESCO COM ESSA CRIANCA E O TIPO DE FISSURA.

Anotar, com letra de forma, o grau de parentesco e o tipo de fissura do qual é portador.

34. DS PAIS DESSA CRIANCA TEM OU TIUERAM EPILEPSIA?

Perguntar, para os itens $A$. 2 B., 5 e existe história de ofsmaio, at aque ou epilepsia.

35. OS PAIS DESSA CRIANCA TEM OU TIUERAM LEPRA?

Perguntar aos pais sobre essa doenfa de pele - lepra e anotar a alternativa certa, para os itens $A$. E B..

\section{EXPOSICXO NOS a PRIMEIROS MESES DE GESTACXO}

36. e 37. DOENCAS:

Assinalar, com um " $X$ ", a resposta certa.

38. QUE REMÉDIOS A SENHORA TOMOU?

Assinalar, para todos os itens a alternativa certa, conforme a lista de medicamentos a seguir:

ANTI-INFLAMATÓRIOS

Algitanderil

Benflogin

Butazolidina

Cataflan

Feldene

Indocid

Indometacina

Parenzime

Piroxene

Piroxican

Profenid

Tanderil

Tandrilak

voltaren
ANTI-EMÉTICOS

Dramamine

Dramin B6

Emepride

Eucil

Fenergan

Neozine

Plasil

Vogalene 
ANTI-CONUULSIVANTE

Comital L

Depakene

Diazepina

Dienpax

Fenobarbital

Gardenal

Hidantal

Noan

Rivotril

Tegretol

valium
ANT I-ALÉRG ICOS

Alergon

Benadryl

Caladryl

Celestamine

Celest one

Clistin

Descon

Polaramine

Profenid
ANT I-HIPERTENSIVOS

Adelfan Esidrex

Aldomet

Atenol

Capoten

Cat apresan

Corgard

Furosemide

Hidralazina

Higroton

Hydromet

Met ildopa

Minipress

Moduret ic

Nifedipina

Pressuren

Propanolol

Reserpina
COMPLEXOS UITAMINICOS

Aprovit

Benerva

Cebion

Citrovit

Cluvisol

Combiron

Elevit Prenatal

Gestativ com fluor

Nartense

Natalins com fluor

Pré-Natal R

Rarical com vitaminas

Redoxon

Sustacal

Terragram $M$

Vitamina $A$

VitaminaB1 
ANALGÉSICOS E ANTI-PIRÉTICOS

AAS

Algafan

Ac.Acetil Salicilico

Anador

Atroveran

Baralgin

Belacodid

Buscopan

Buferin

Cibalena

Commel

Dipirona

Dorflex

Doril

Ecasil

Espasmo Cibalena

Espasmo Plus

Indocid

Lisador

Magnopirol

Ronal

Sedalene

Tylenol
ANOUULATÓRIOS

Anfertil

Anovlar

Diane

Microvlar

Nordette

Primovlar

Trinordiol

TRATAMENTO LEPRA

Talidomida

39. QUANTAS VEZES A SENHORA SE SUBMETEU A RAIO-X?

Assinalar a casela correspondente ao numero correspondente.

40. QUANTOS CIGARROS POR DIA A SENHORA FUMOU?

Anotar esse número

41. O MARIdo DA SENHORA FUMAUA NESSE PERÍODO?

Assinalar a alternativa adequada.

42. A SENHORA BEBIA BEBIDA ALCÓ́LICA?

Assinalar a alternativa adequada.

43. EM CASO AFIRMATIVO, DAR O TIPO E A DOSE DA INGESTKO:

Escrever o tipo de bebida $e$ a dose diária ou semanal ou mensal.

44. A SENHORA SE SUBMETEU A RAIO-X NO PERIODO DE 1 ANO ANTES DA GRAUIDEZ DESSE FILHO?

Assinalar, com um " $X "$, a alternativa adequada.

45. O PAI DEsSa CRIANCA SE SUBMETEU a RAIO-X NO PERÍDD de 1 anO ANTES DA SENHORA FICAR GRÁVIDA DESSA CRIANCA? Assinalar, com um " $X$ ", a alternativa adequada. 


\section{CONUERSXO DA RENDA PER CAPITA}

Para o cálculo da renda per capita, tomou-se a renda familiar da seguinte forma: como o levantamento se referiu ao periodo agosto/1988 a agosto/1989 e considerando que as medidas governamentais na área econômica alteraram o sistema monetário do pais, procedeu-se à conversão das rendas declaradas em do lar (US\$). Pará a citada transformacão, utilizou-se o valor médio, entre compra e venda, das cotacões oficiais da moeda americana publicadas pelo Banco Central do Brasil, para o dia 15 de cada mês do periodo (Quadro I), visto que os salários mensais, na moeda brasileira, são fixos.

QUADRO I - CUTAEAO DO DOLAR (US\$)* SEGUNDO ANO, MEES E MOEDA BAASILEIAA WIGENTE.

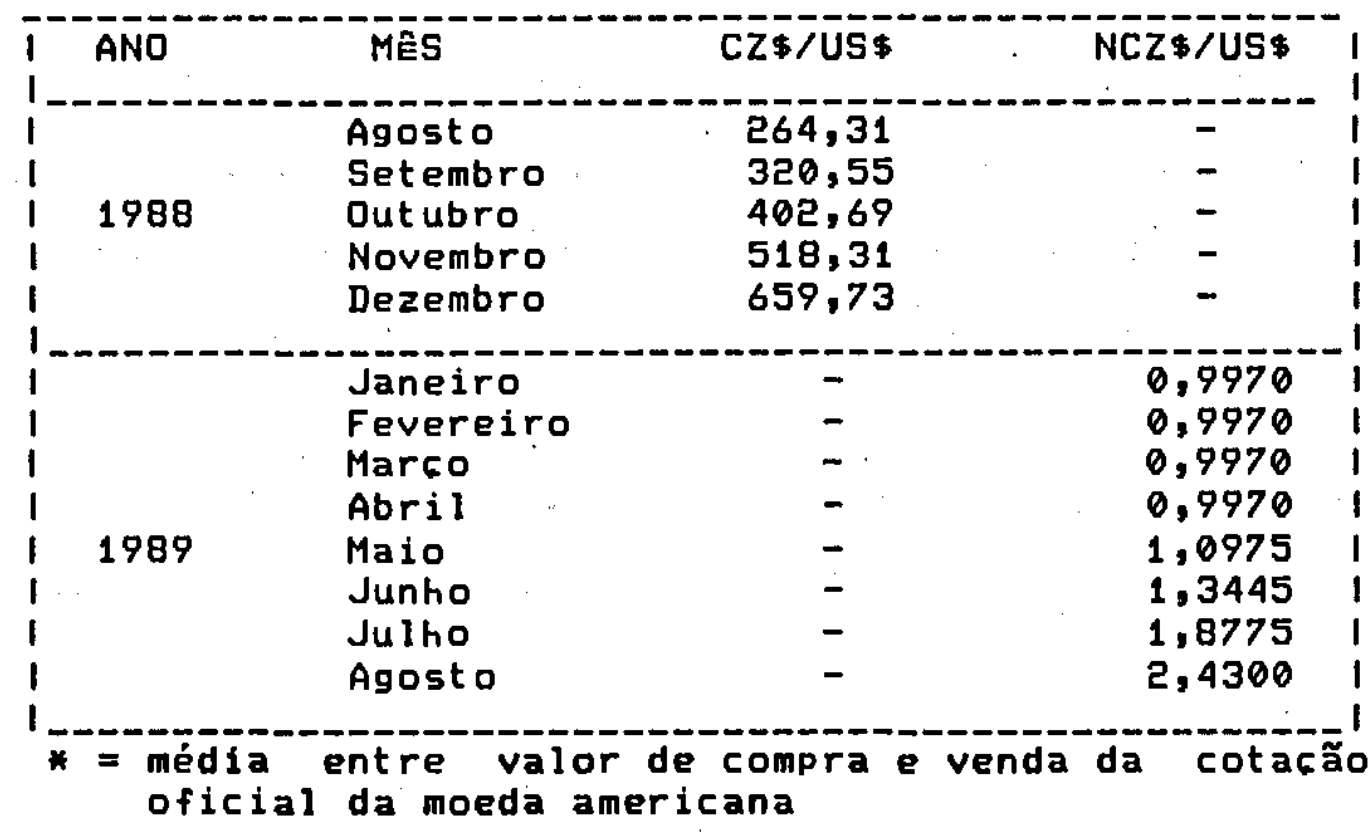




\section{ANEXO IU}

\section{FISSURA LABIAL OU LÁBIO-PALATINA}

As tabelas de contingência a seguir referem-se aos atributos de estudo, quais sejam, caso (Ca) e controle (Co), dado que foram expostos (EXP) ou não-expostos (NEXP) aos possiveis fatores de risco.

Estes atributos foram analisados segundo o local de moradia da mãe do caso ou do controle nos 4 primeiros meses de gestacão e categorizados por : - amostra total (AT), quando o local de moradia se referia ao pais todo; - municipio de São Paulo (SP), quando o local era o municipio de São Paulo; - não-municipio de São Paulo (NSP), quando o local era formado por municipios deste pais, com excecão do municipio de São Paulo.

Foi calculado o risco relativo (RR) para cada tabela de contingência. Não houve preocupacão em ajustes do risco relativo segundo os estratos porque prétendeu-se verificar se. a cidade de São Paulo modificaria o comportamento da variável de análise.

Construiu-se a tabela a seguir para casos e controles da cidade de São Paulo e de fora dela e encontrou-se: 
tabela $f$ - Casos e controles de sło paulo e de fora de sło paUlo.

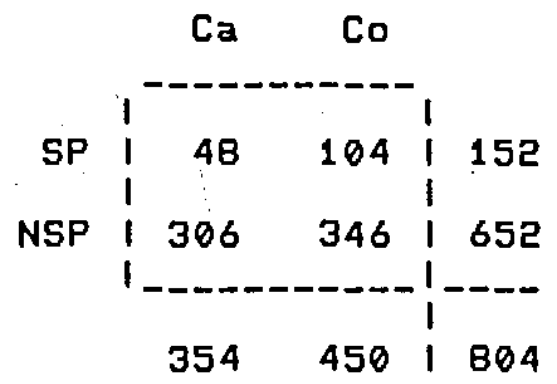

$S P \times C a: O R=0,52$

NSP $\times C a: O R=1 / 0,52=1,92$

TABELA $z$ - NúMERO DE CASOS DE FISSURA LABIAL OU LÁBIO-PALATINA E DE CONTROLES SEgUNDO "ZONA RURAL".
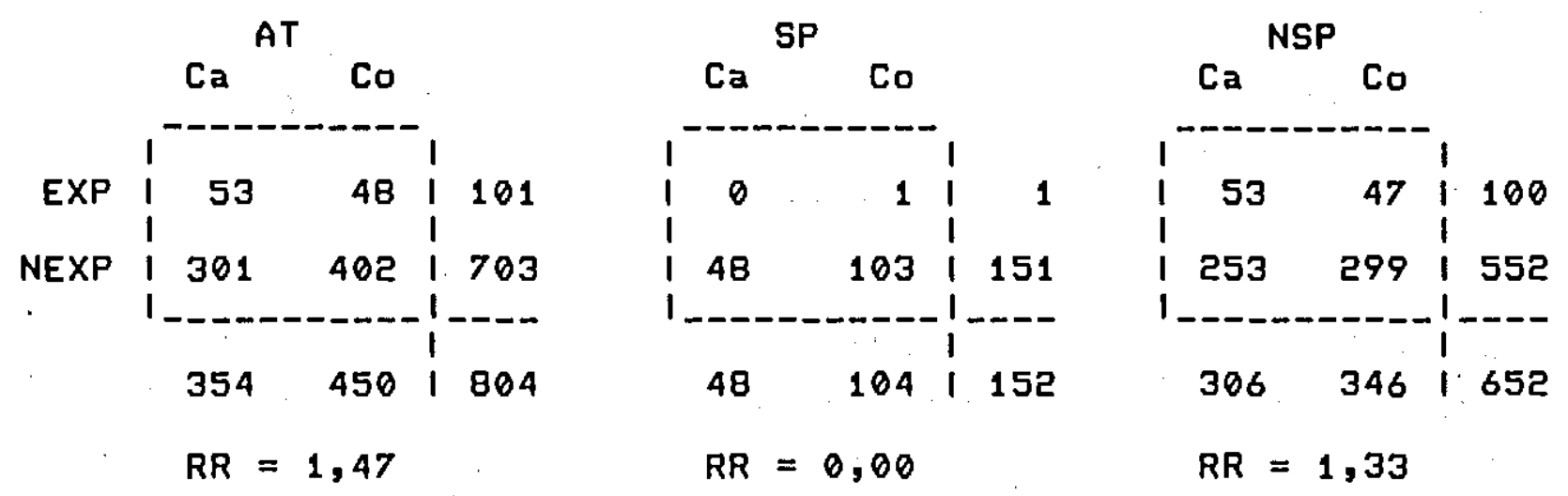
TABELA - NÚMERO DE CASOS DE FISSURA LABIAL OU LÁBIO-PALATINA E de CONTROLES SEGUNDO "POLUICX̃o"
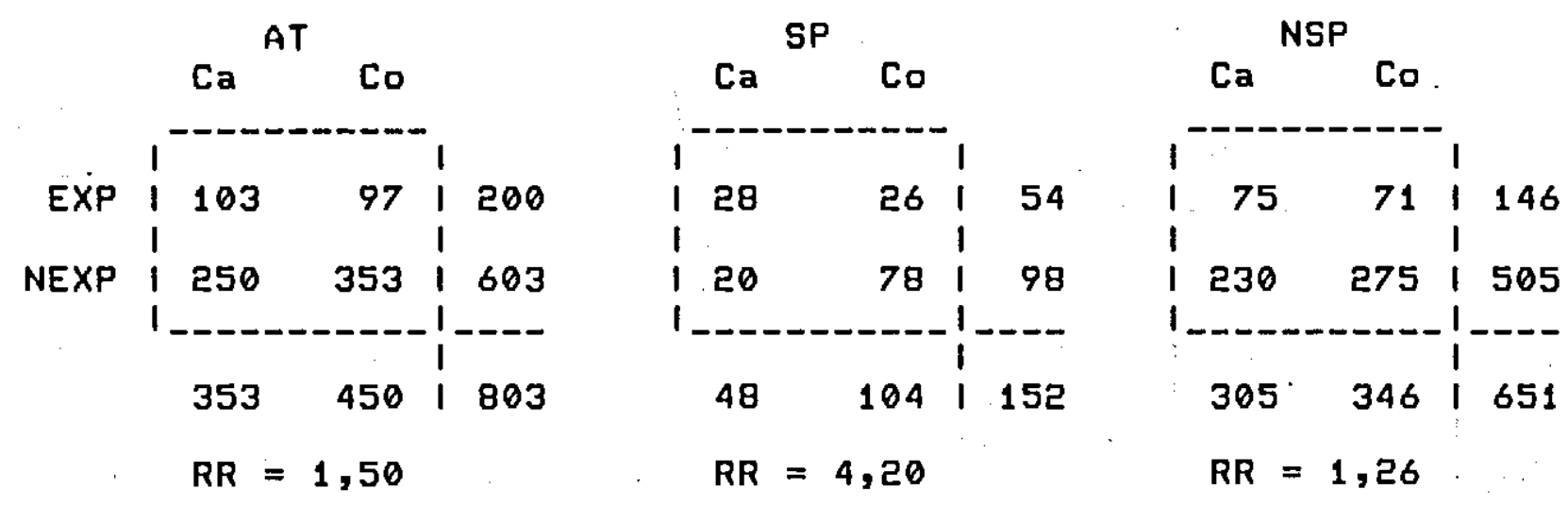

TABELA 4 - NÚMERO DE CASOS DE FISSURA LABIAL OU LABIO-PALATINA E DE CONTROLES SEGUNDO "PAI-LAURADOR".
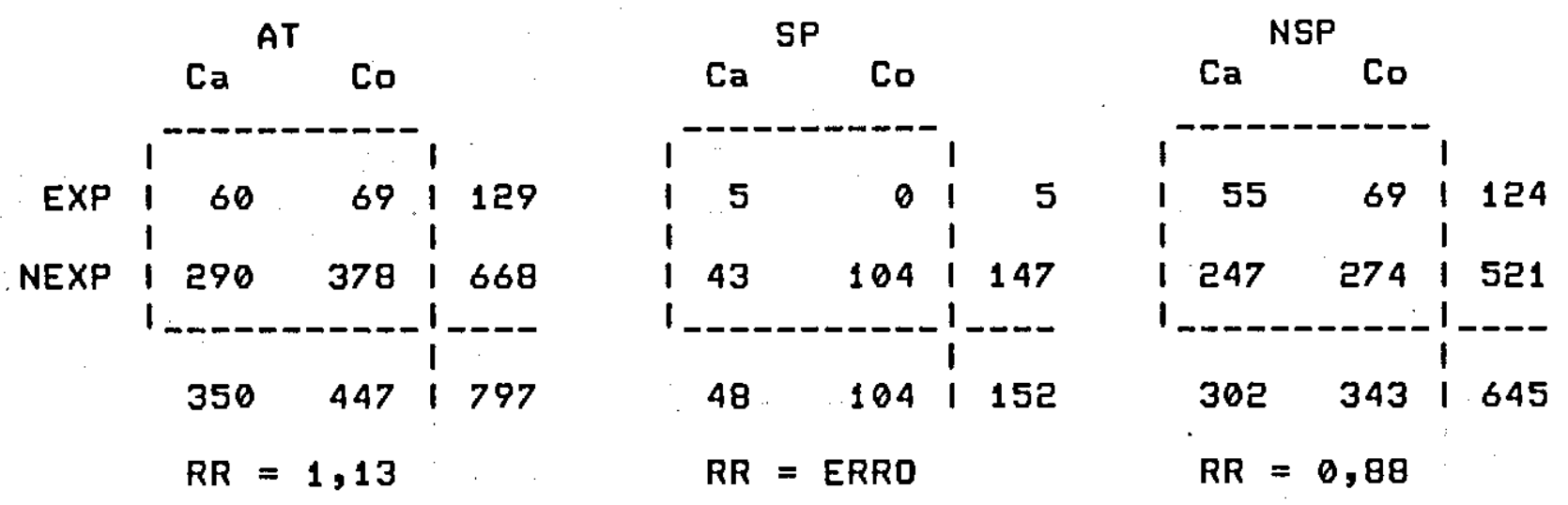
TABELA 5 - NUMERO DE CASOS DE FISSURA LABIAL OU LÁBIO-PALATINA E

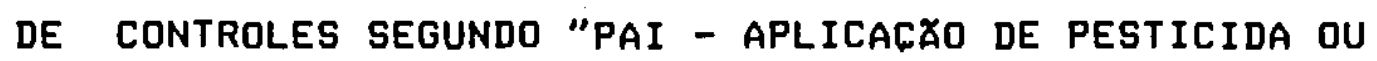
HERBICIDA NA LAVOURA".
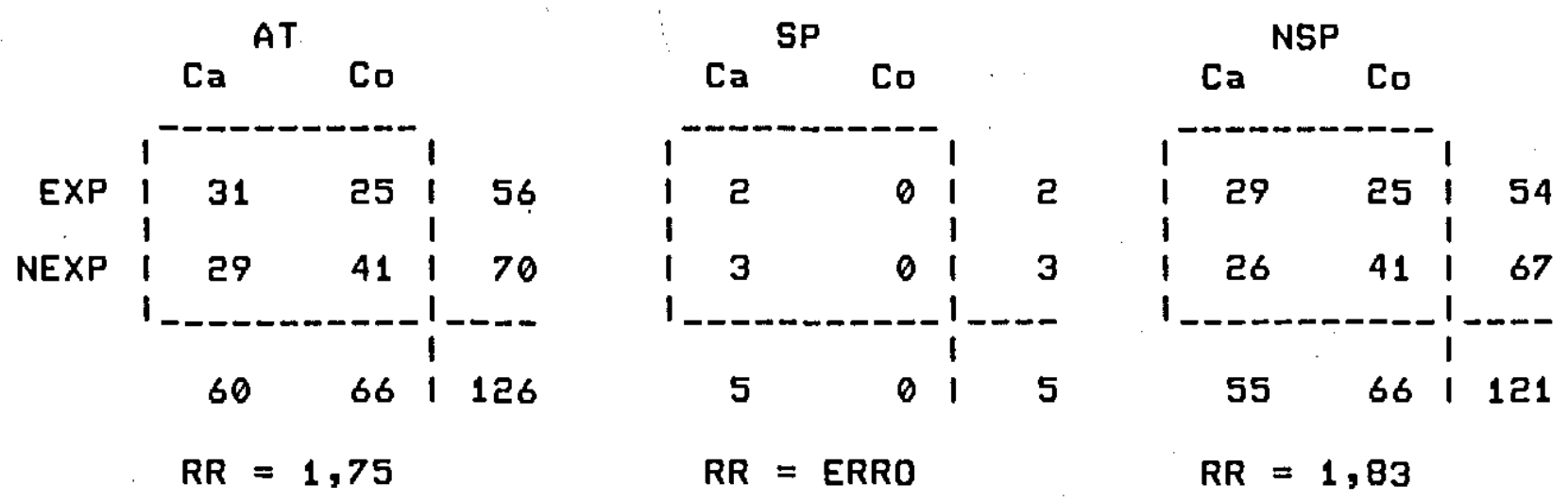

TABELA 6 - NÚMERO DE CASOS DE FISSURA LABIAL OU LÁBIO-PALATINA E de controles segundo "mXe - lavoura".
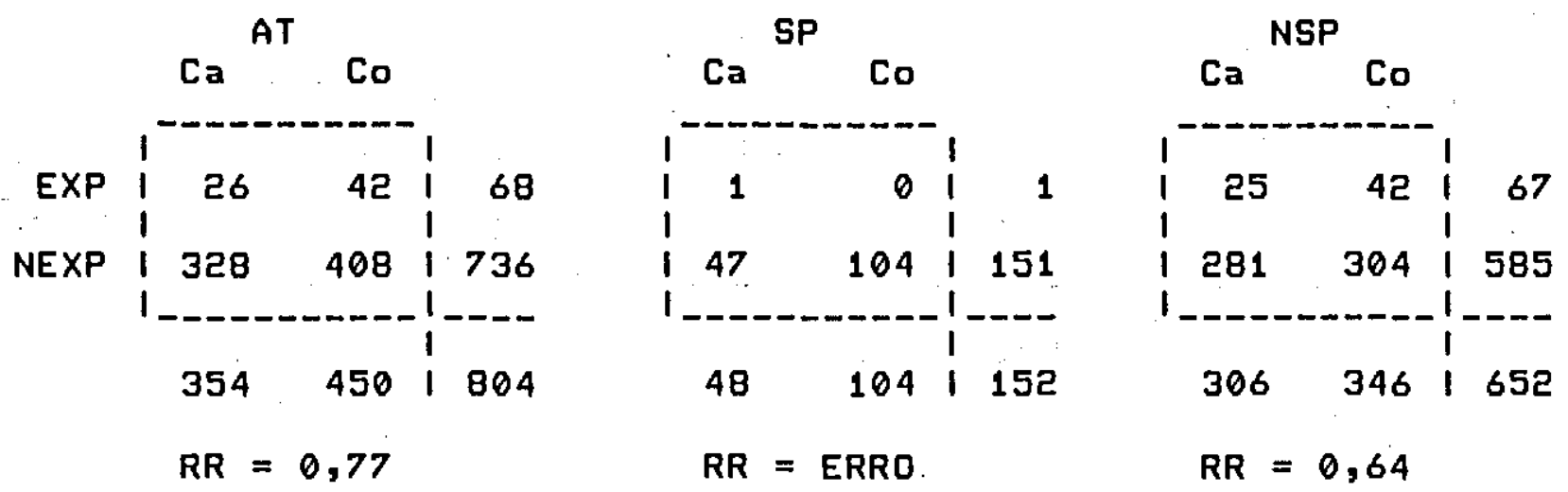
TABELA - NÚMERO DE CASOS DE FISSURA LABIAL OU LÁBIO-PALATINA E DE CONTROLES SEgundo "MðE - APLicACX̃ dE PESTICIDA OU HERBICIDA NA LAVOURA".
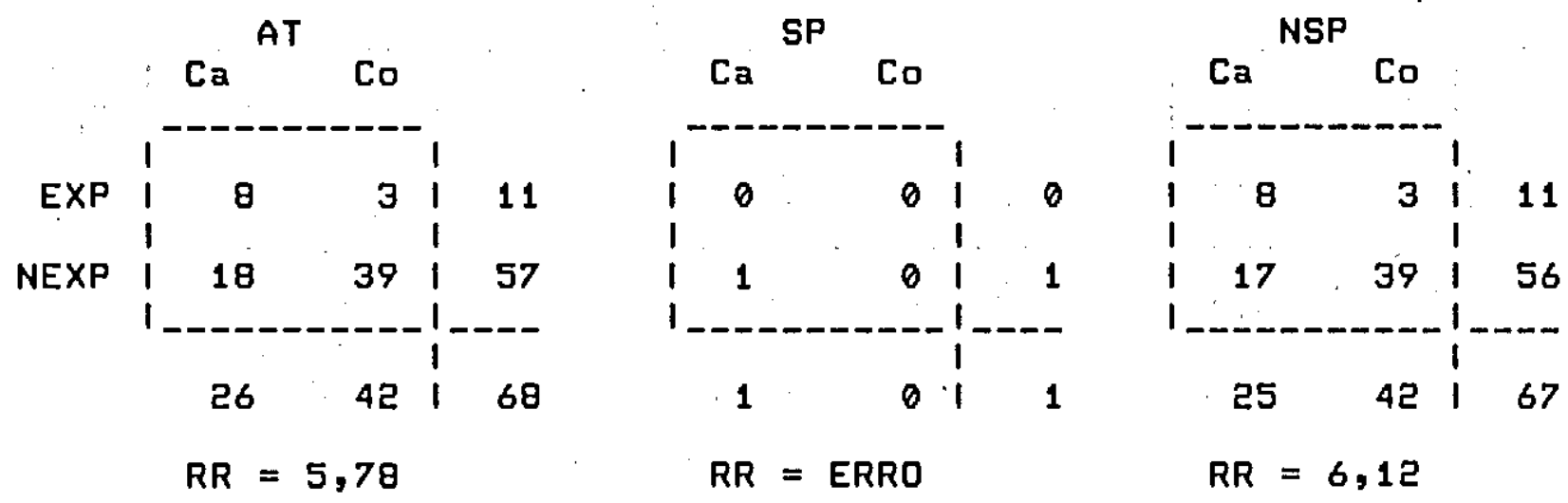

TABELA - NUMMERO DE CASOS DE FISSURA LABIAL OU LÁBIO-PALATINA E de CONTROLES SEgundo "PARENTESCo ENTRE OS PAIS".
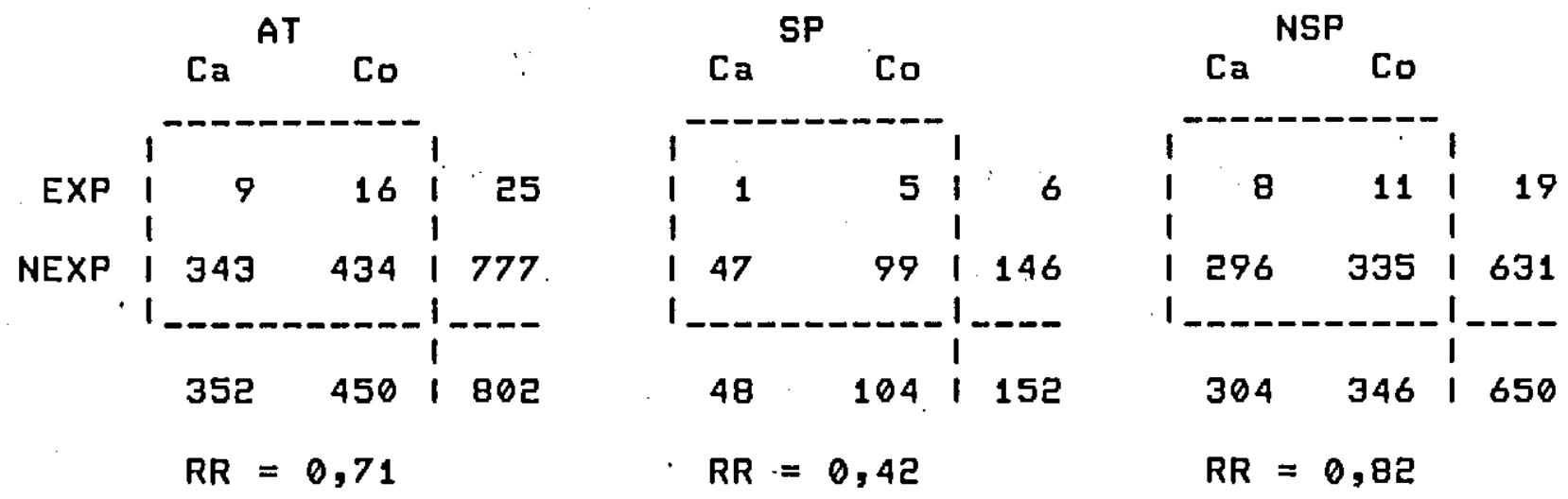
TABELA - NÚMERD DE CASOS DE FISSURA LABIAL OU LÁBIO-PALATINA E de CONTRDLEs SEgundo "TER PARENTE fissurado".
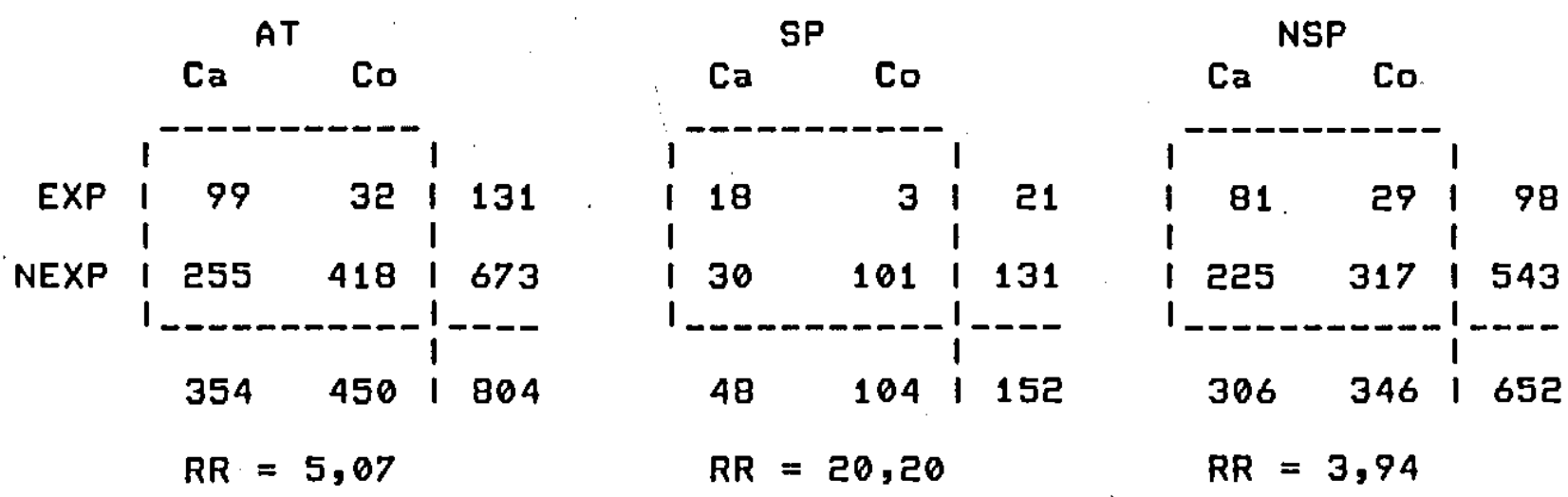

TABELA IO - NúMERO DE CASOS DE FISSURA LABIAL OU LÁBIO-PALATINA E DE CDNTROLES SEgundo "Mãe COM ePIlepsia".
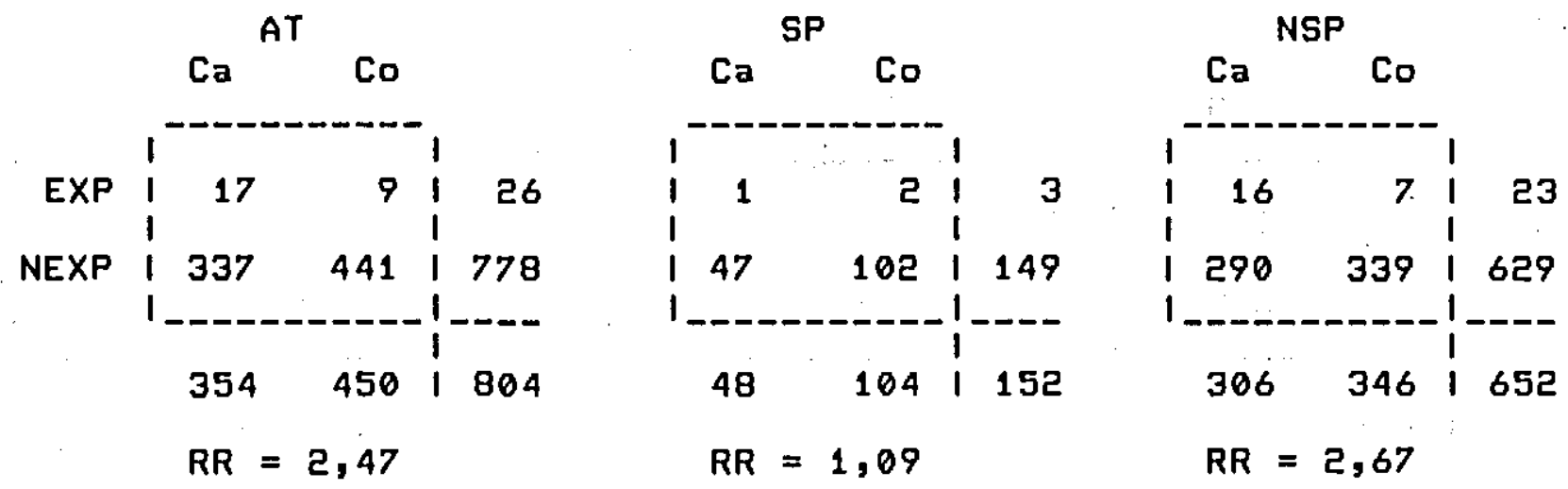
TABELA LA - NÚMERO DE CASOS DE FISSURA LABIAL OU LÁBIO-PALATINA E DE CONTROLES SEgUNDO "PAI COM EPILEPSIA".
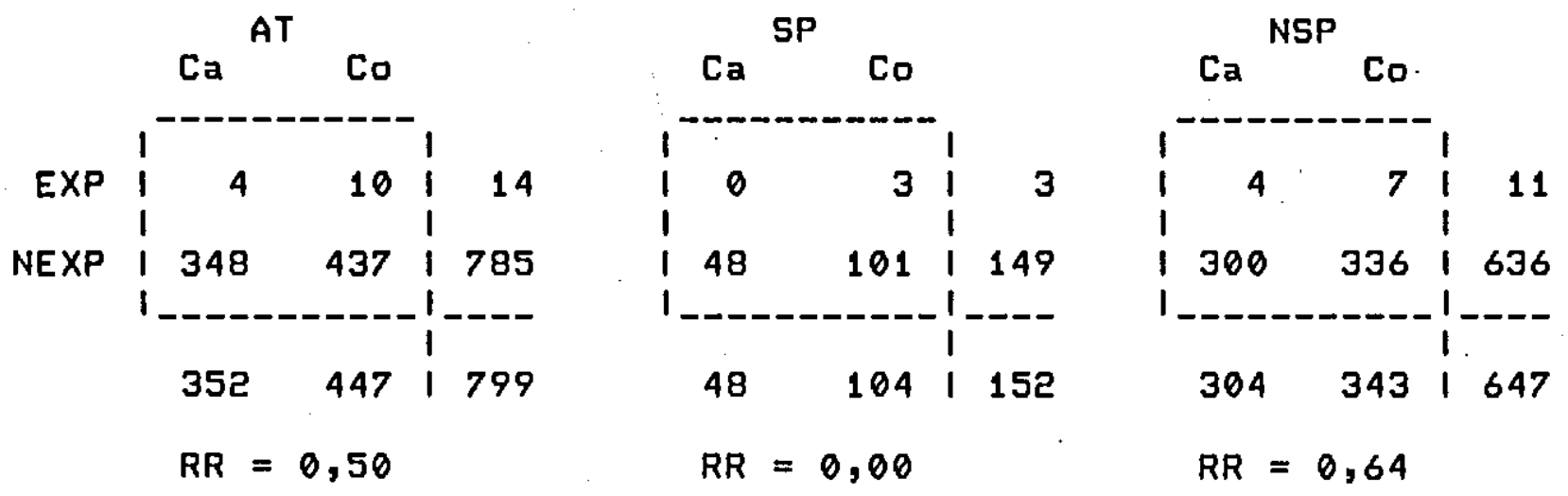

TABELA IZ - NÚMERO DE CASOS DE FISSURA LABIAL OU LÁBIO-PALATINA E de CONTROles SEgundo "Mae com hanseniase".
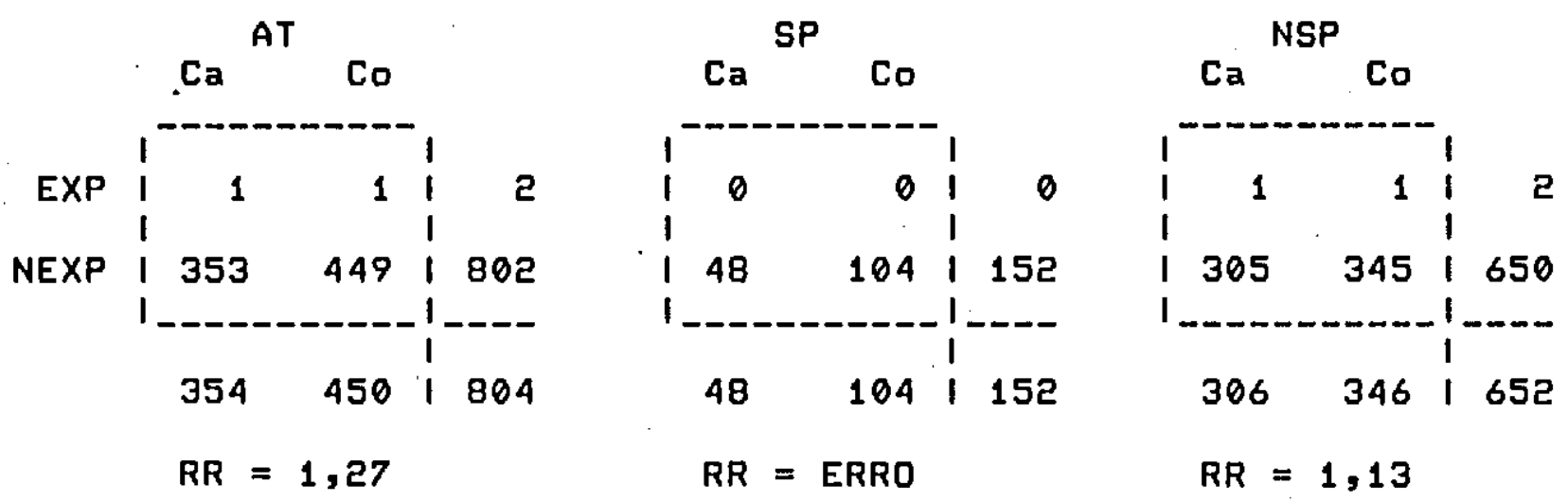
TABELA .6.3 - NÚMERO DE CASOS DE FISSURA LABIAL OU LÁBIO-PALATINA E de controles segundo "Pai com hanseniase".
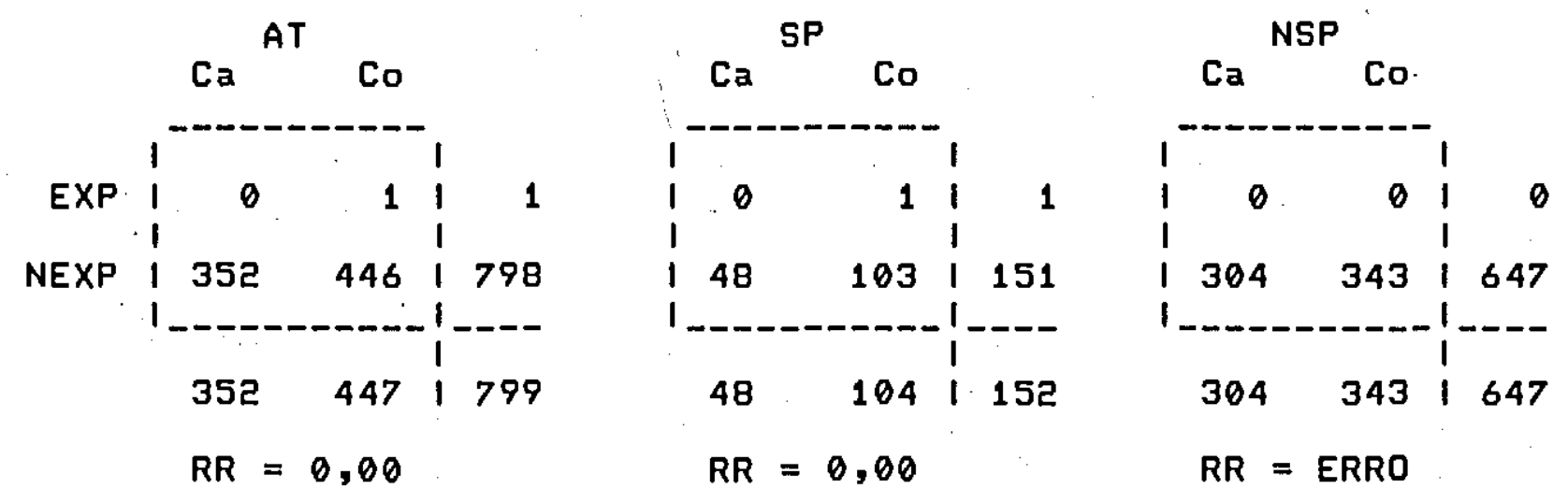

TABELA 14 - NÚMERO DE CASOS DE FISSURA LABIAL OU LÁBIO-PALATINA E DE CONTROLES SEgunḍo "MKE - RUBÉOLA NOS 4 PRIMEIROS MESES DE GESTACณO".
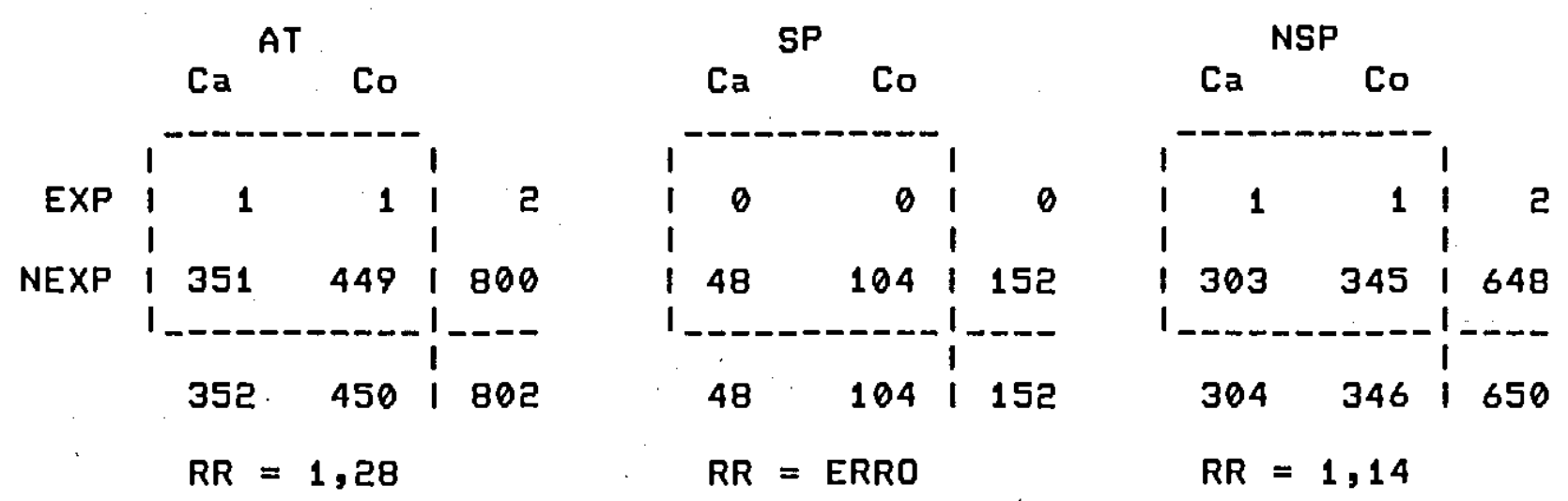
TABELA IS - NÚMERO DE CASOS DE FISSURA LABIAL OU LÁBIO-PALATINA E DE CONTROLES SEgUNDO "MXE - HIPERTENSZ̃o NOS 4 PRIMEIROS MESES DE GESTACZ̃".
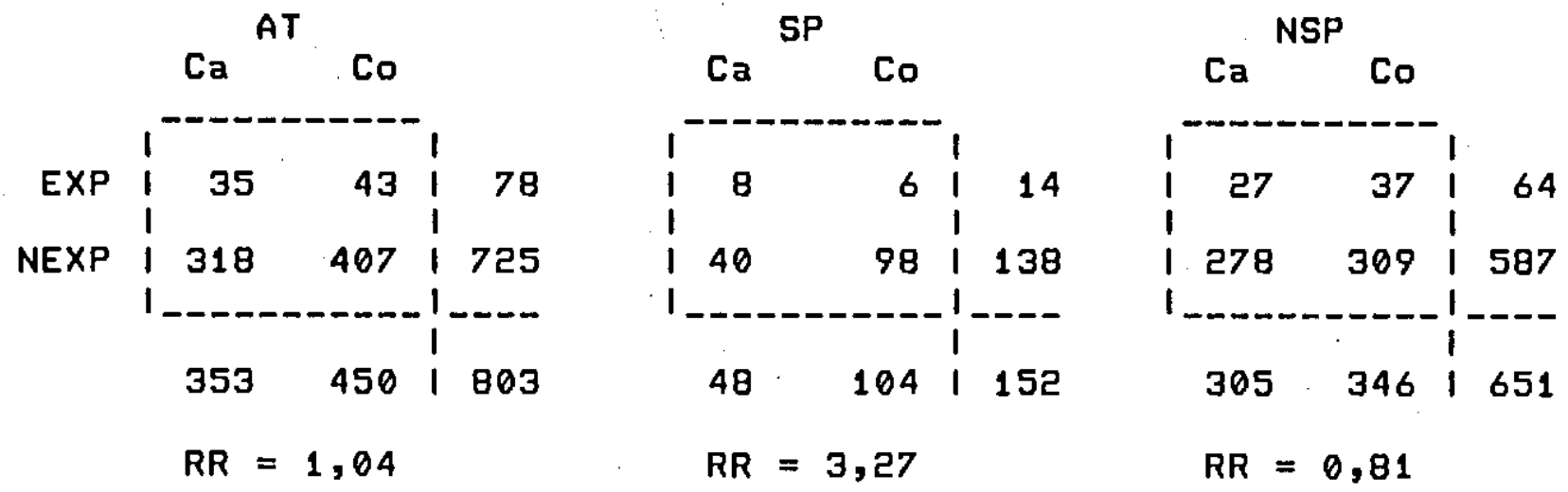

TABELA IG - NÚMERO DE CASOS DE FISSURA LABIAL OU LÁBIO-PALATINA E dE CONTROLES SEgUNDO "MXE - CONUULSX̃o NOS 4 PRIMEIROS MESES DE GESTACXO".
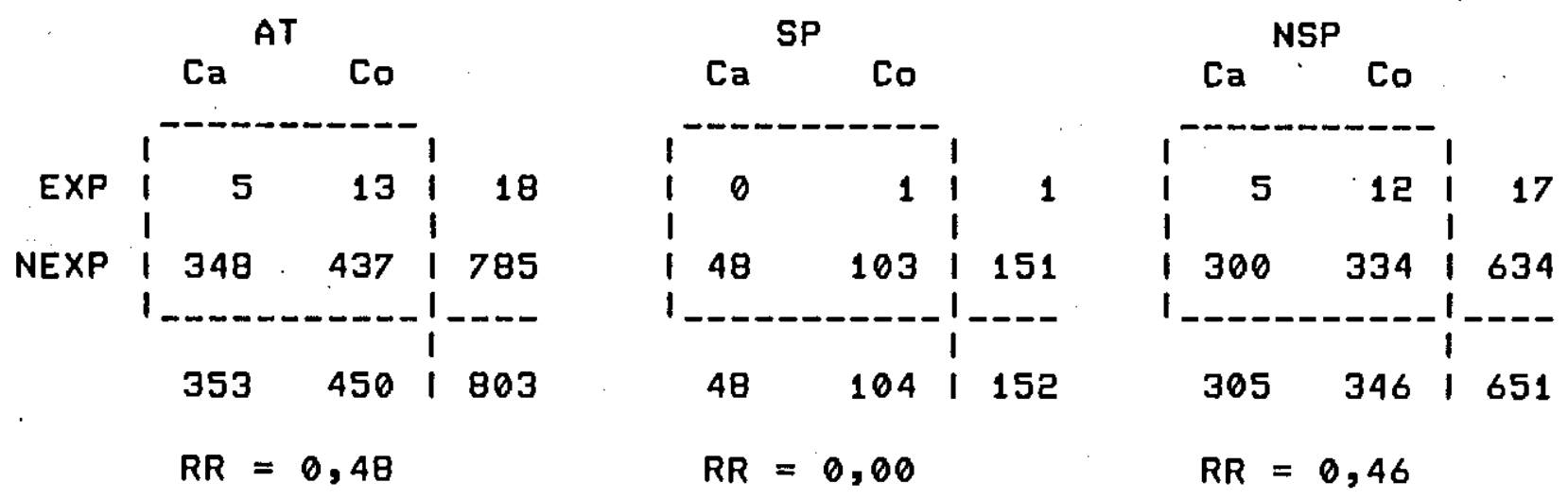
TABELA IT - NÚMERO DE CASOS DE FISSURA LABIAL OU LÁBIO-PALATINA E DE CONTROLES SEgUNDO "MXE - DIABETES NOS 4 PRIMEIROS .MESES DE GESTACXO".
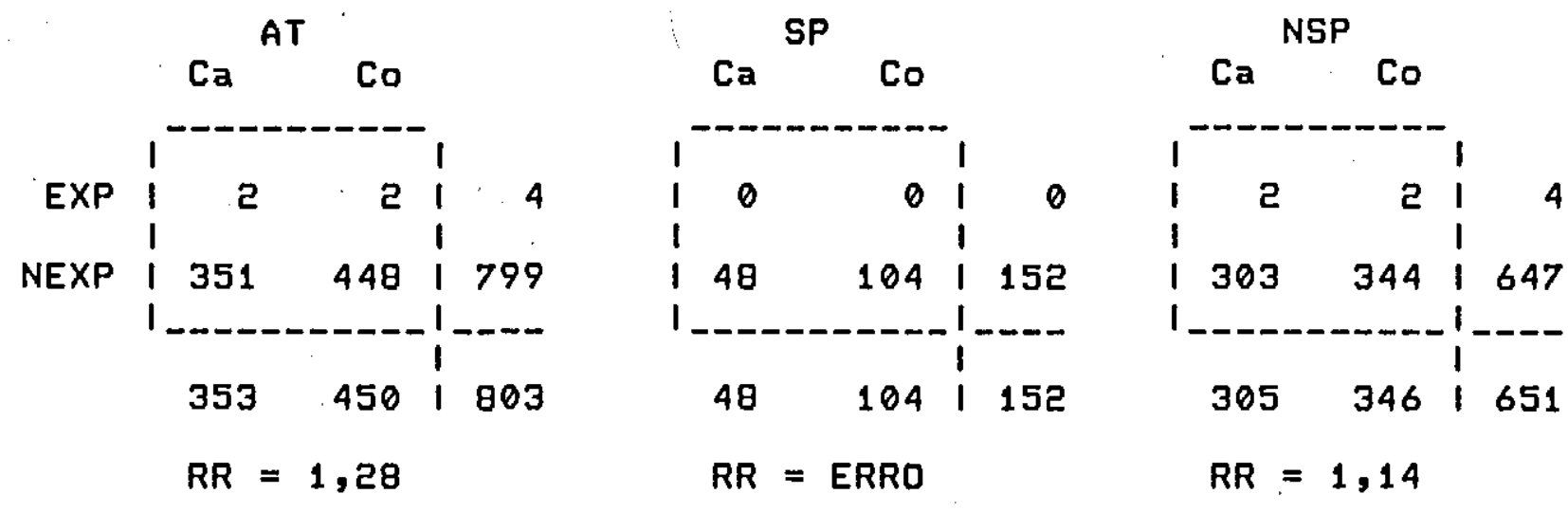

TABELA IS - NúMERO DE CASOS DE FISSURA LABIAL OU LÁBIO-PALATINA E DE CONTROLES SEgUNDO "MZE - INGESTZO DE ANTI-INFLAMATORIO NOS 4 PRIMEIROS MESES DE GESTACXO".
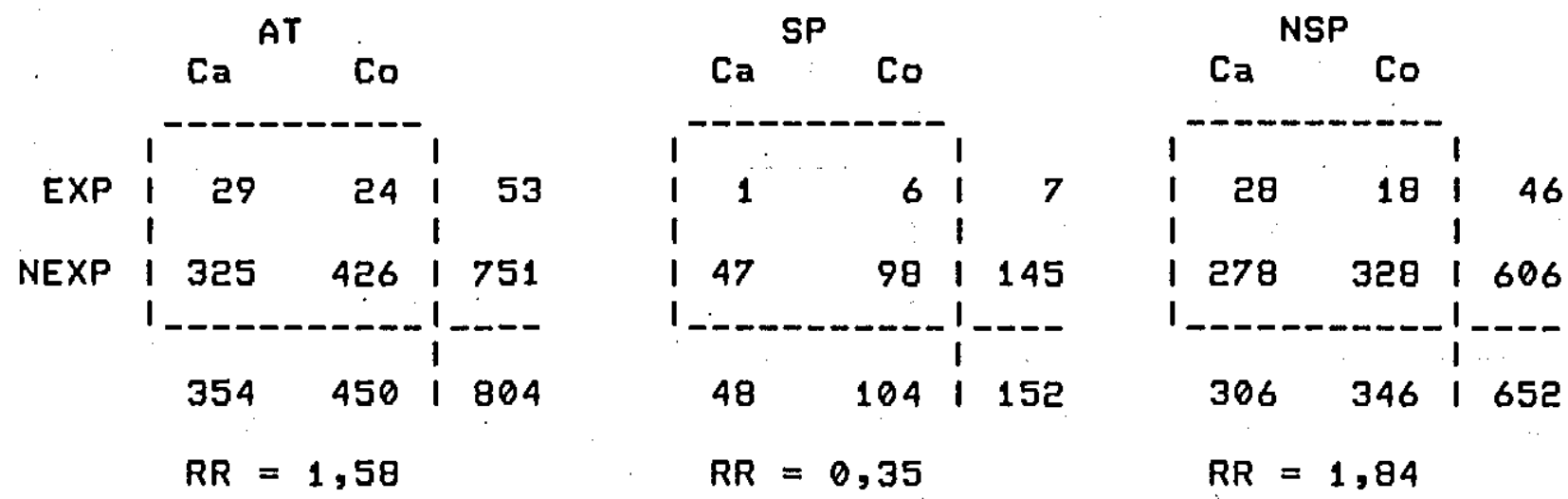
TABELA 15 - NÚMERO DE CASOS DE FISSURA LABIAL OU LÁBIO-PALATINA E DE CONTROLES SEgUNDO "MaE - INGEST\&O DE ANTI-EMÉTICO NOS 4 PRIMEIROS MESES DE GESTACXO".
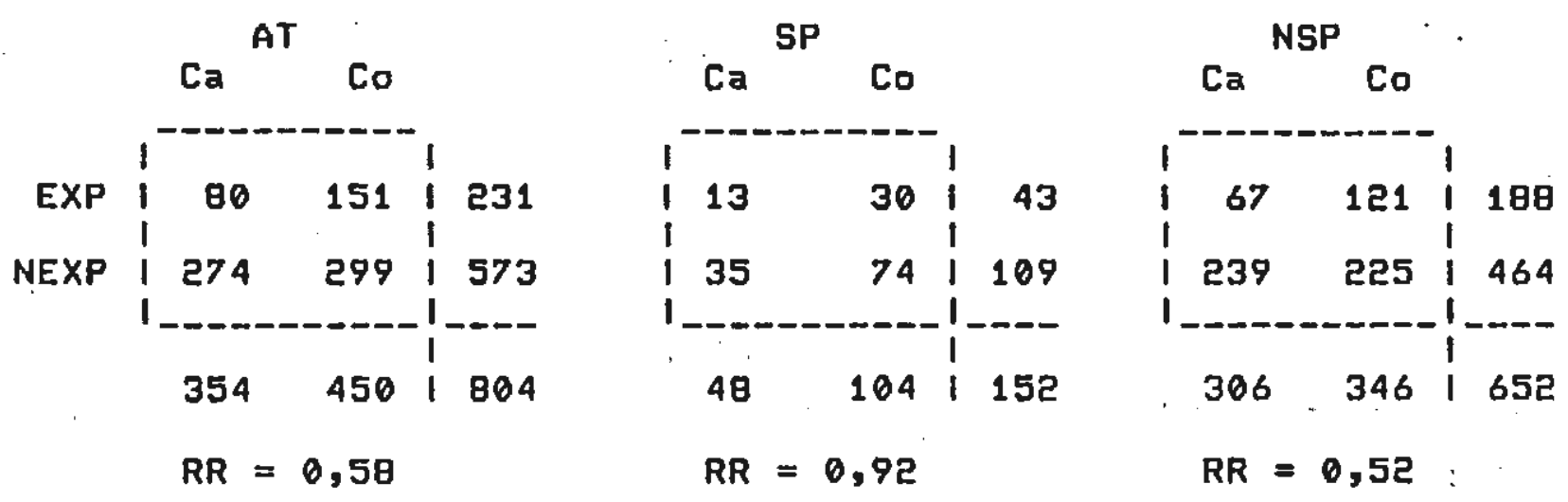

TABELA ZG - NUMERO DE CASOS DE FISSURA LABIAL OU LÁBIO-PALATINA E DE CONTROLES SEgUNDO "MKE - INGESTZO DE ANTI-CONUULSIVANTE NOS 4 PRIMEIROS MESES DE GESTACX̃".
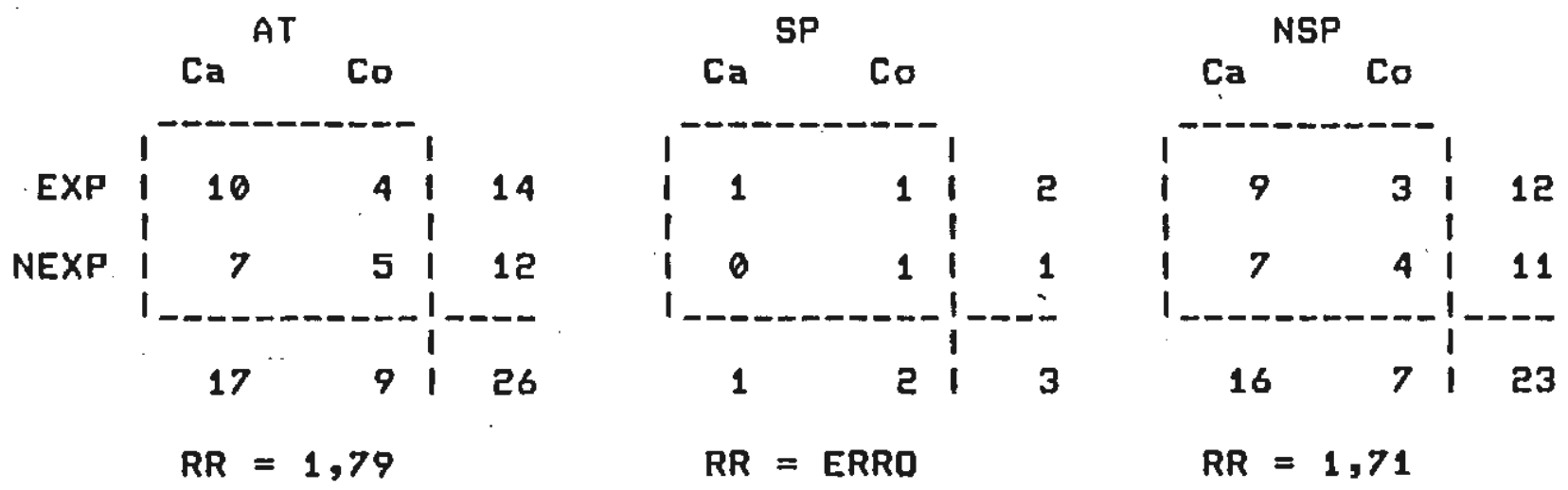
TABELA EL - Número de CASOS DE fISSURA LABIAL OU LÁBIO-PALATINA E DE CONTROLES SEgUNDO "MrE - INGESTrO DE ANTI-HIPERTENSIVO NOS 4 PRIMEIROS MESES DE GESTACZO".
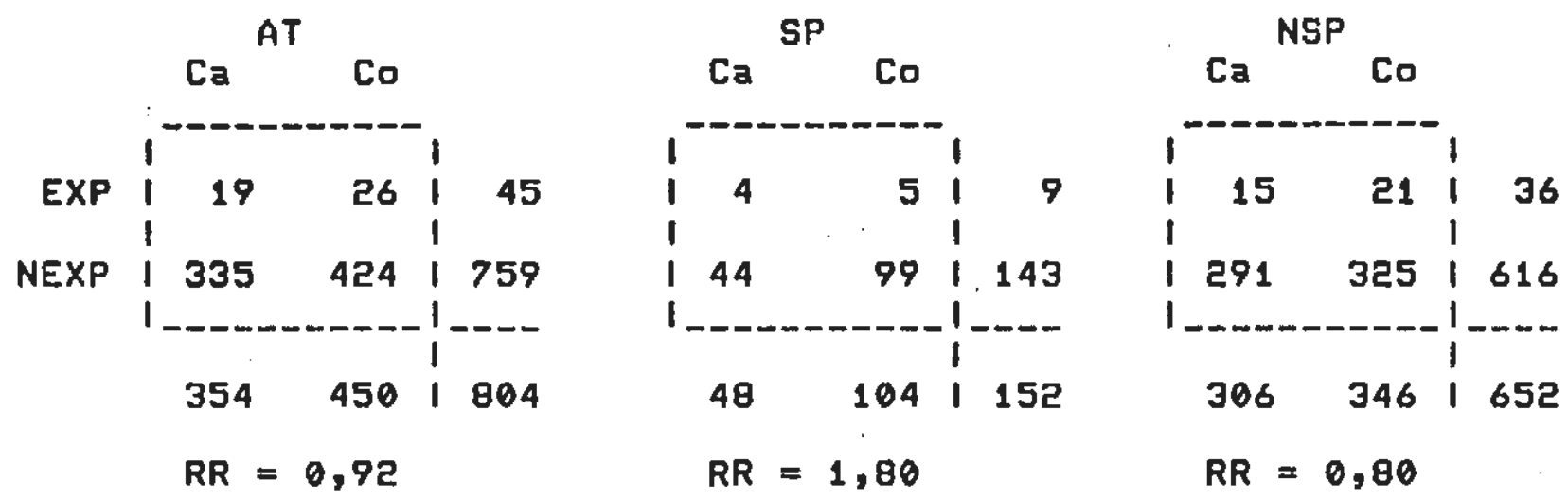

TABELA EZ - NÚMERO DE CASOS DE FISSURA LABIAL OU LABIO-PALATINA E DE CONTROLES SEGUNDO "MZE - INGESTצO DE ANTI-ALÉRGICO NOS 4 PRIMEIROS MESES DE GESTACXO".
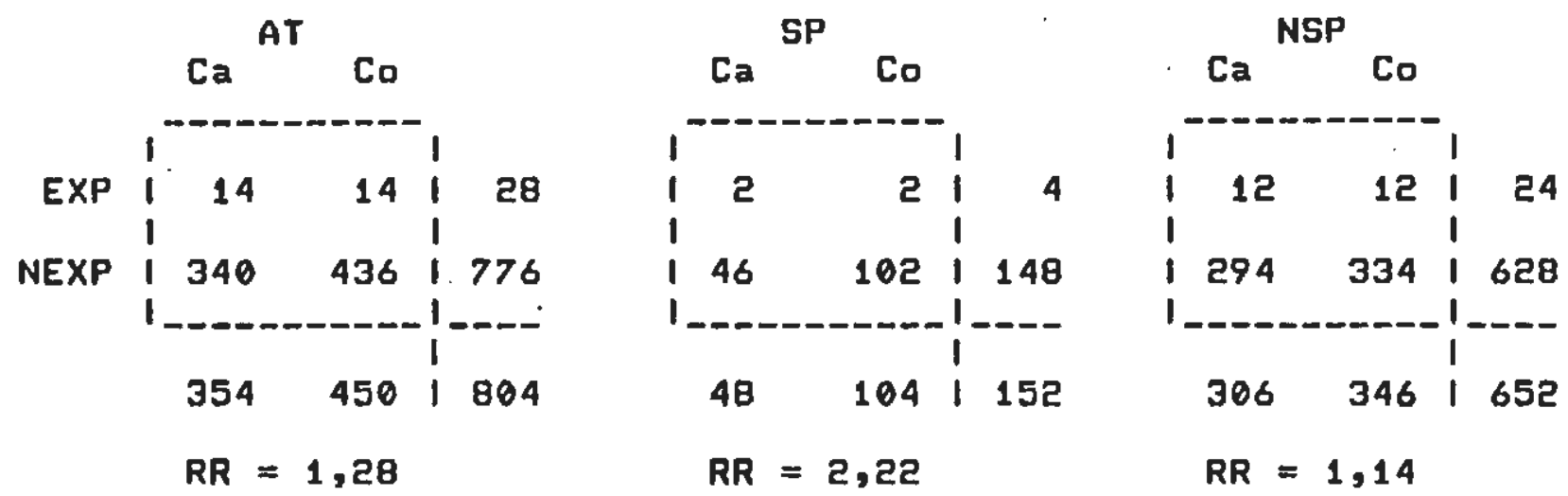
TAEELA ES - NÚMERO DE CASOS DE FISSURA LABIAL OU LABIO-PALATINA E de CONTROLES SEgundo "MKE - ingestro de andVULATório NOS 4 PRIMEIROS MESES DE GESTACXO".
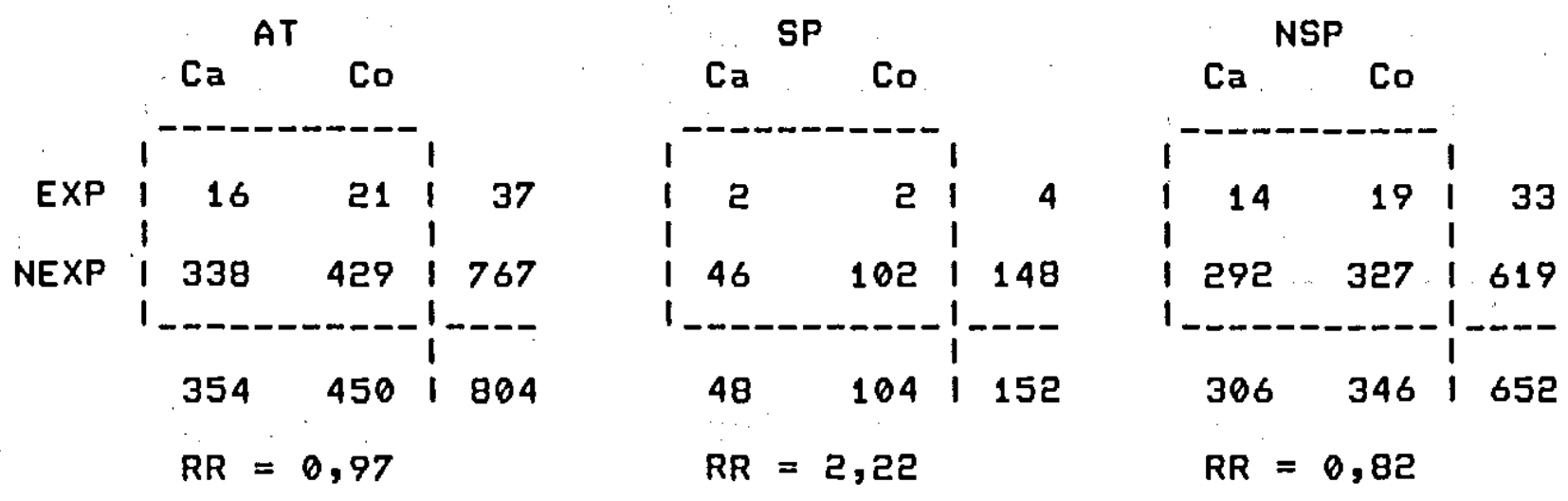

TABELA PA - NUMERO DE CASOS DE FISSURA LABIAL OU LABIO-PALATINA E de controles segundo "mZE - ingestzo de complexo viTAMINICO NOS 4 PRIMEIROS MESES DE GESTACXO".
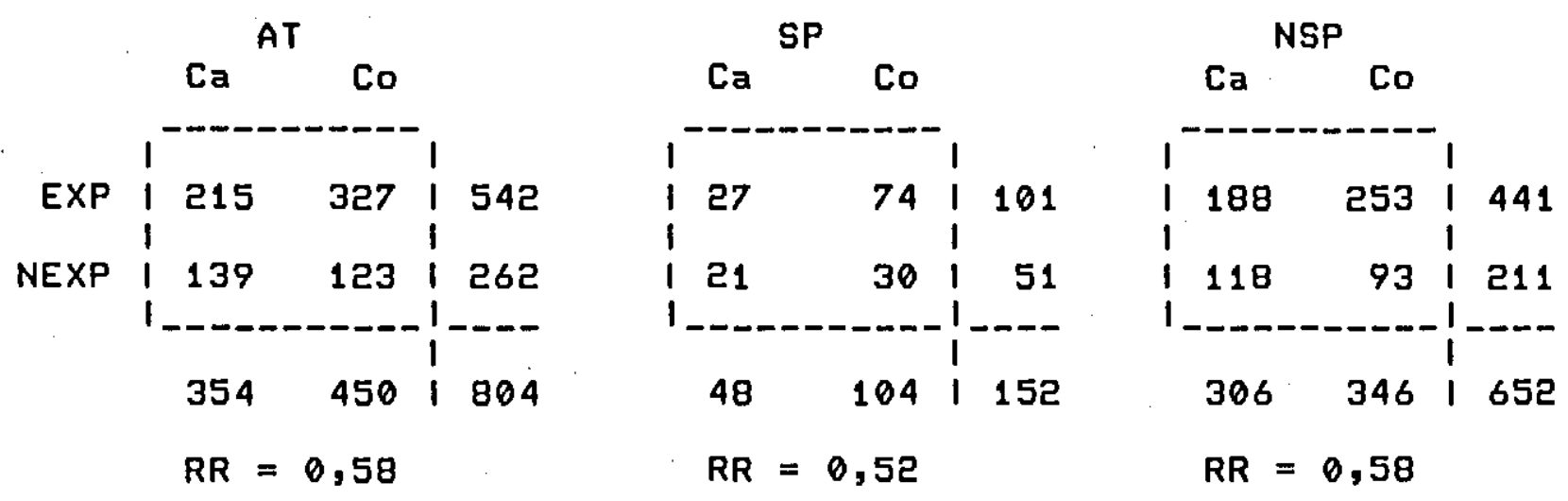
TABELA ES - NÜMERO DE CASOS DE FISSURA LABIAL OU LABIO-PALATINA E de controles segundo "MaE - fez tratamento para hanSEN NOS 4 PRIMEIROS MESES DE GESTACXO".
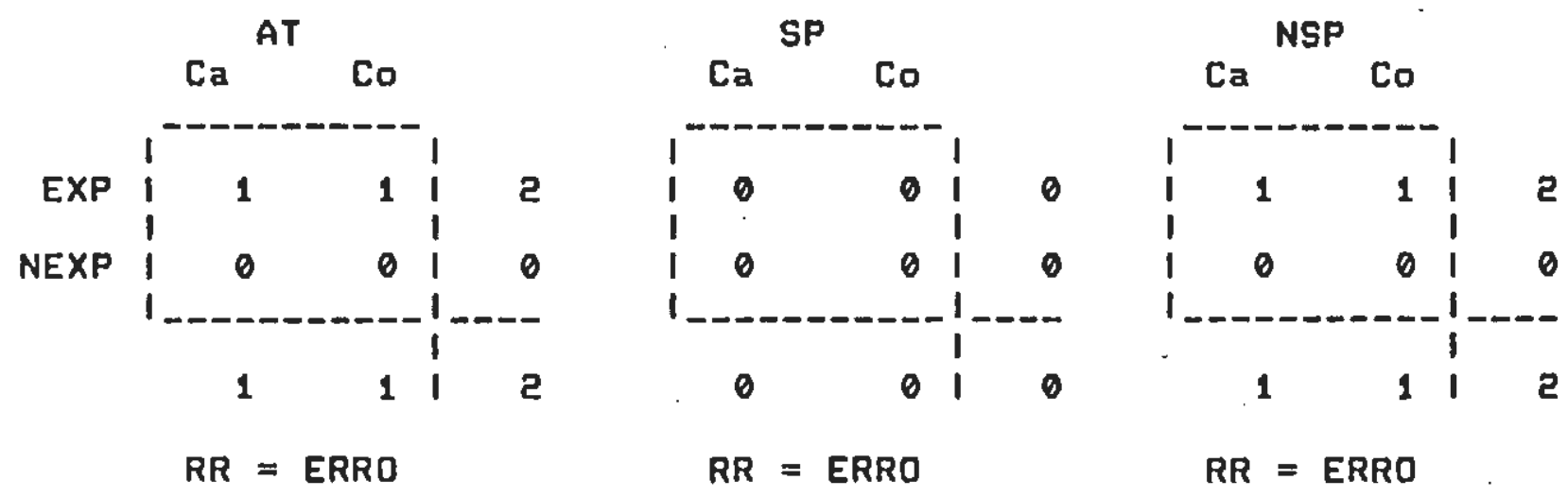

TABELA E6 - NUMMERO DE CASOS DE FISSURA LABIAL OU LABIO-PALATINA E de CONTROLES SEgundo "MaE - ingestăo de ABORTIUO NOS 4 PRIMEIROS MESES DE GESTACZO".
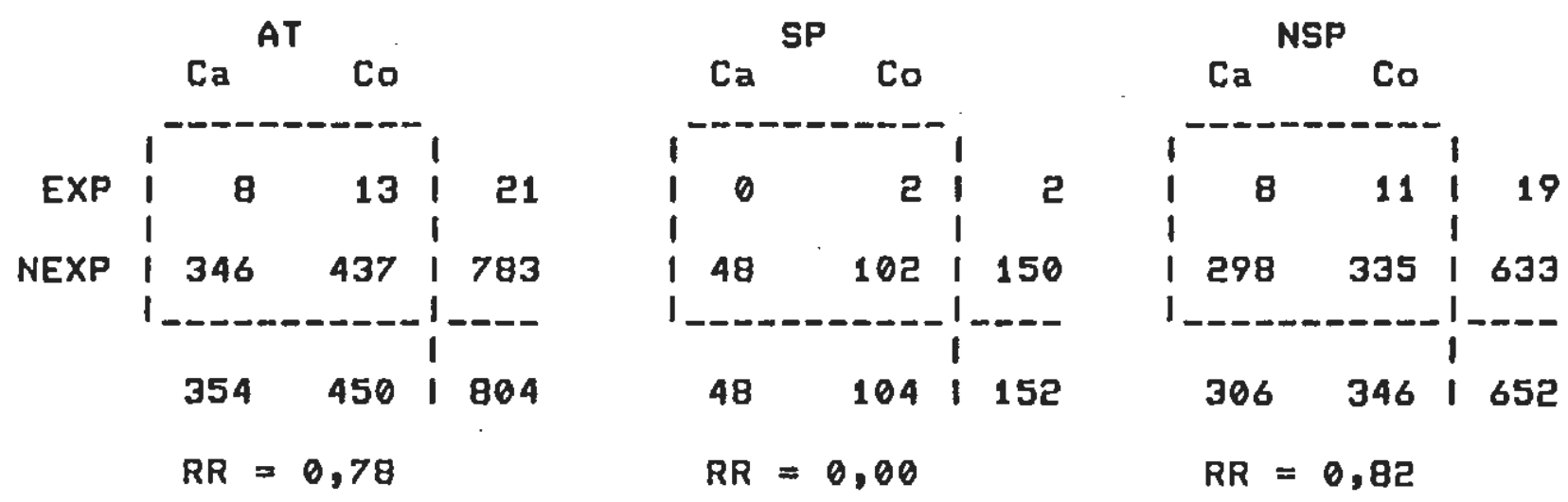
TABELA EF - NÚMERO DE CASOS DE FISSURA LABIAL DU LABIO-PALATINA E

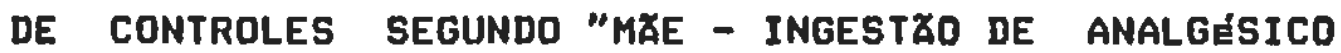
NOS 4 PRIMEIROS MESES DE GESTACXO".
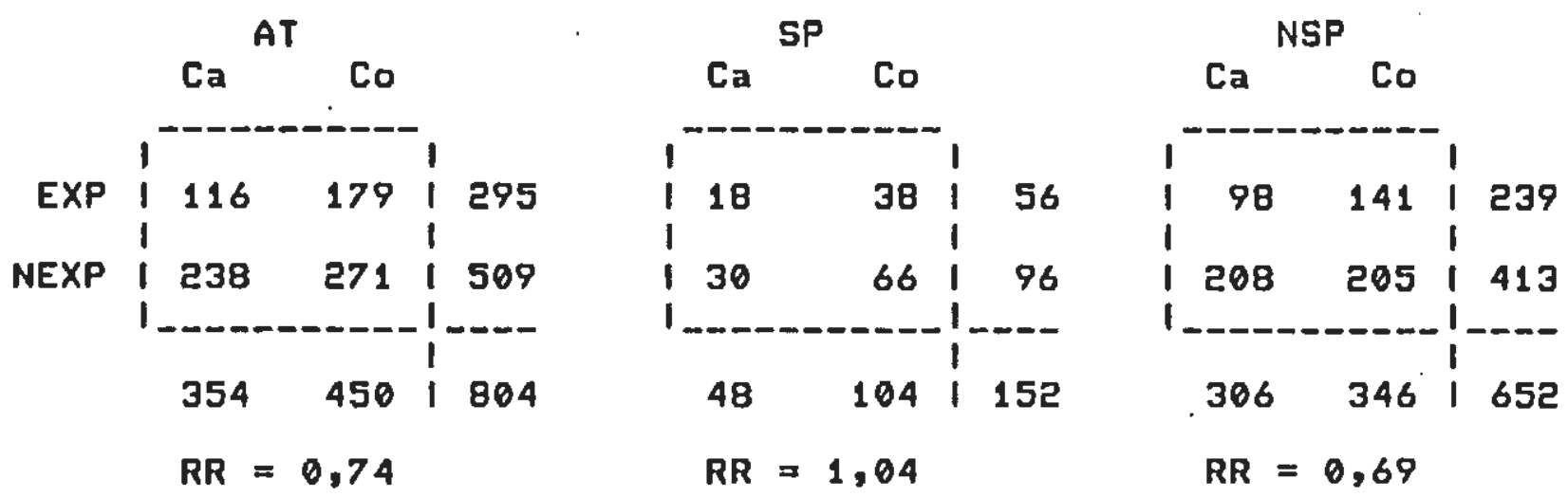

TABELA ZG - NÚMERO DE CASOS DE FISSURA LABIAL DU LABIO-PALATINA E DE CONTROLES SEgundo "Mä - INGESTád de ANTIBIótico NOS 4 PRIMEIROS MESES dE GESTACX̃o".
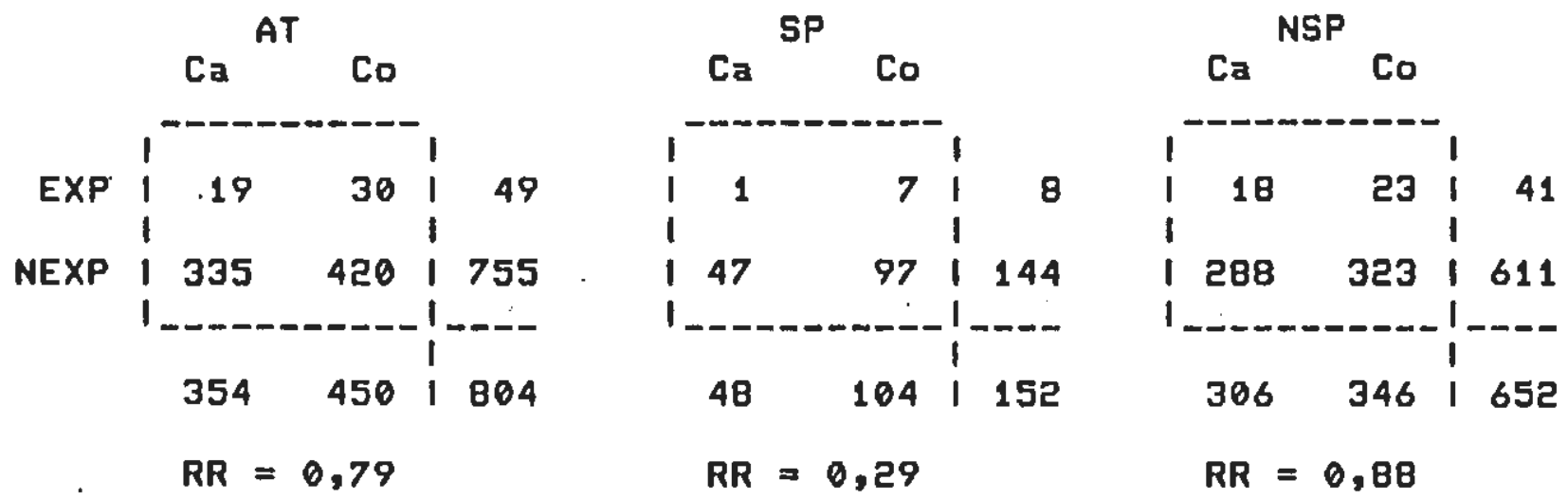
TABELA EF - NÚMERO DE CASOS DE FISSURA LAEIAL DU LÁBIO-PALATINA E DE CONTROLES SEGUNDO "MXE - EXPOSICXO AO RX NOS 4 PRIMEIROS MESES DE GESTACXO".
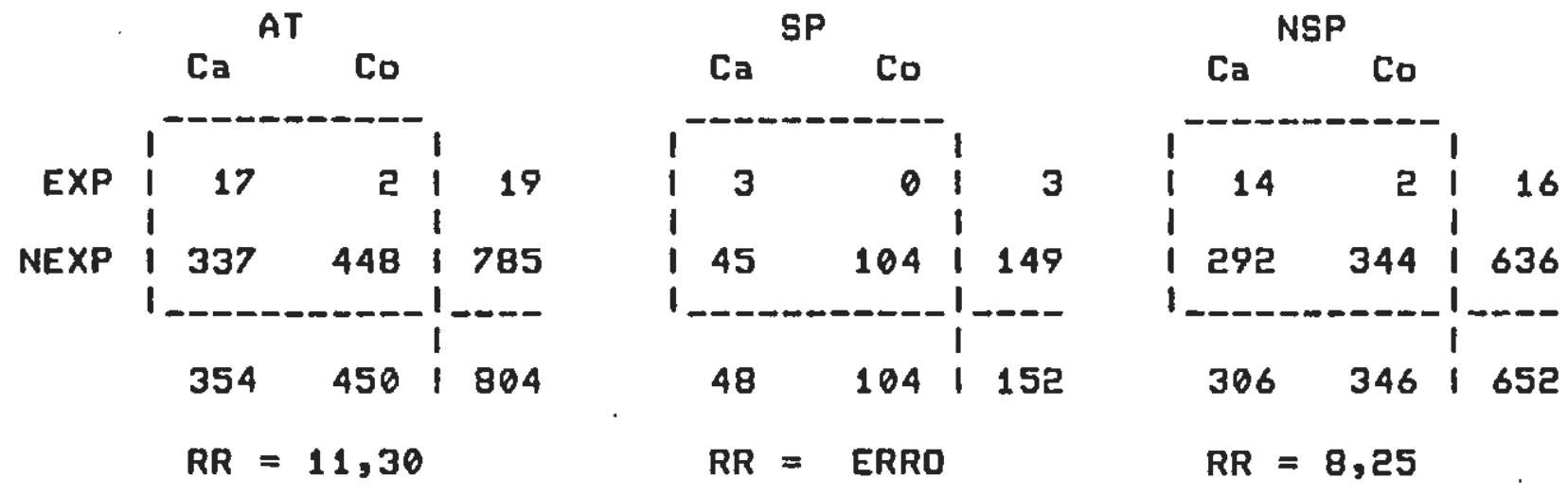

TABELA 30 - NÚMERO DE CASOS DE FISSURA LABIAL DU LABID-PALATINA E DE CONTROLES SEgUNDO "MX̃E - EXPOSICXO AO RX 1 ANO ANTES DA GESTACXั".
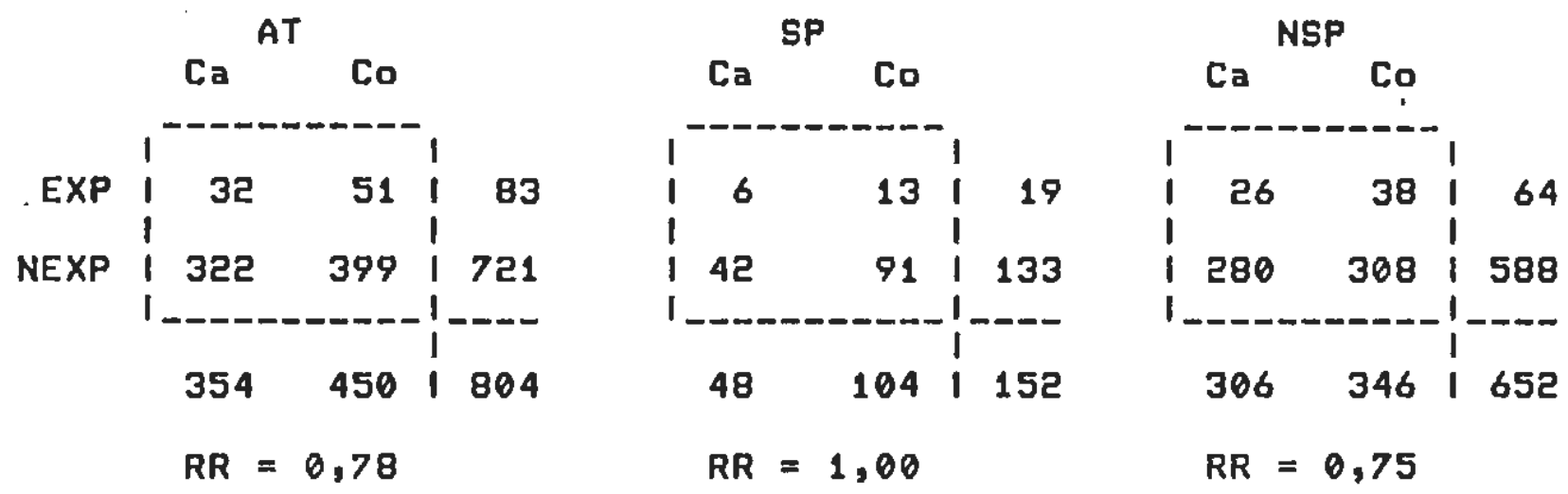
TABELA $3 L$ - NÚMERO DE CASOS DE FISSURA LABIAL OU LÁBIO-PALATINA E DE CONTROLES SEGUNDO "PAI - EXPOSICXO AO RX 1 ANO ANTES DA GESTACXO DA MXE".
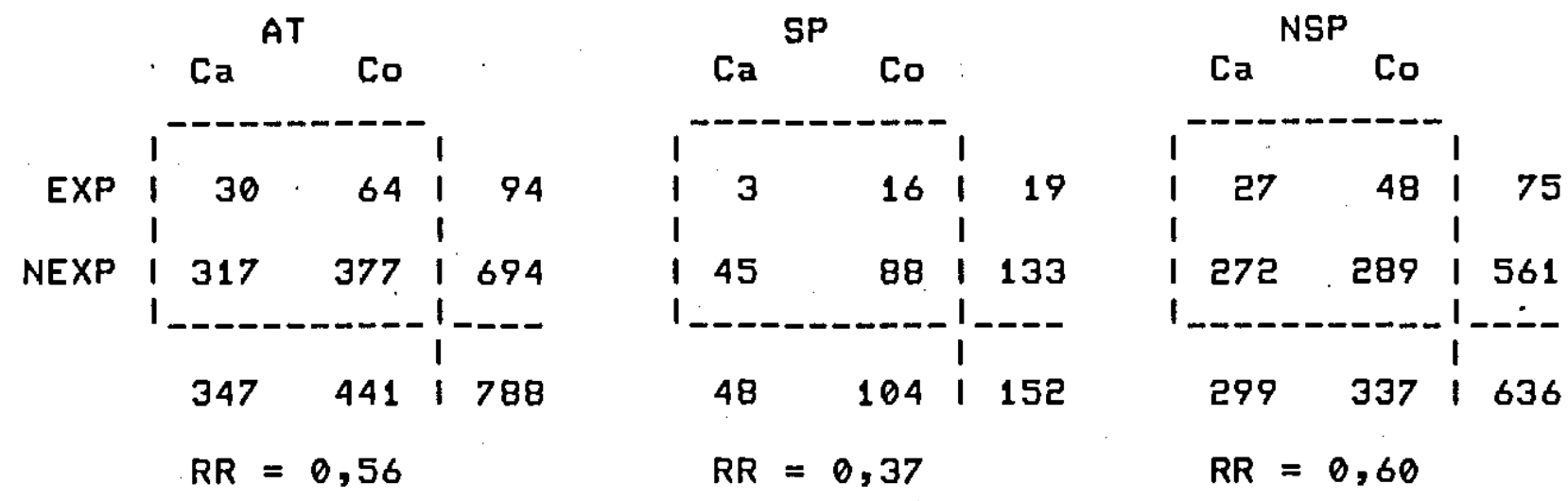

TABELA SEE - NÚMERO DE CASOS DE FISSURA LABIAL OU LÁBIO-PALATINA E DE CONTROLES SEgUNDO "MXE - HABITO DE FUMAR".
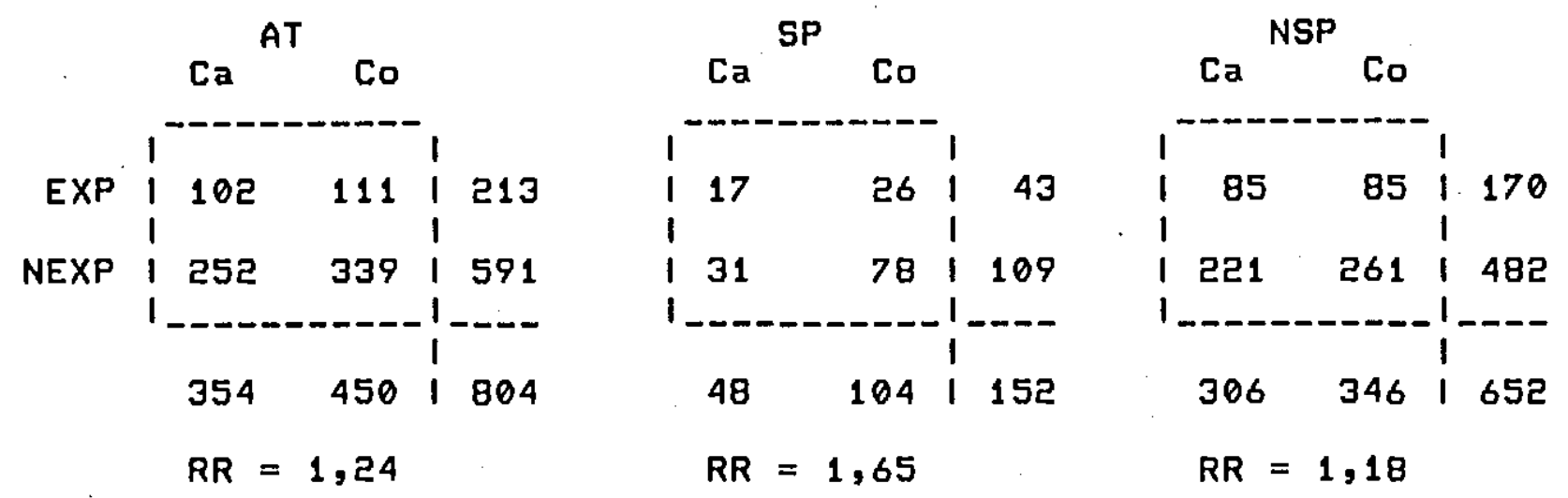
TABELA S3 - NúMERO DE CASOS DE FISSURA LABIAL OU LÁBIO-PALATINA E de CONTRdLes SEgundo "PAI - habitd de fumaR".
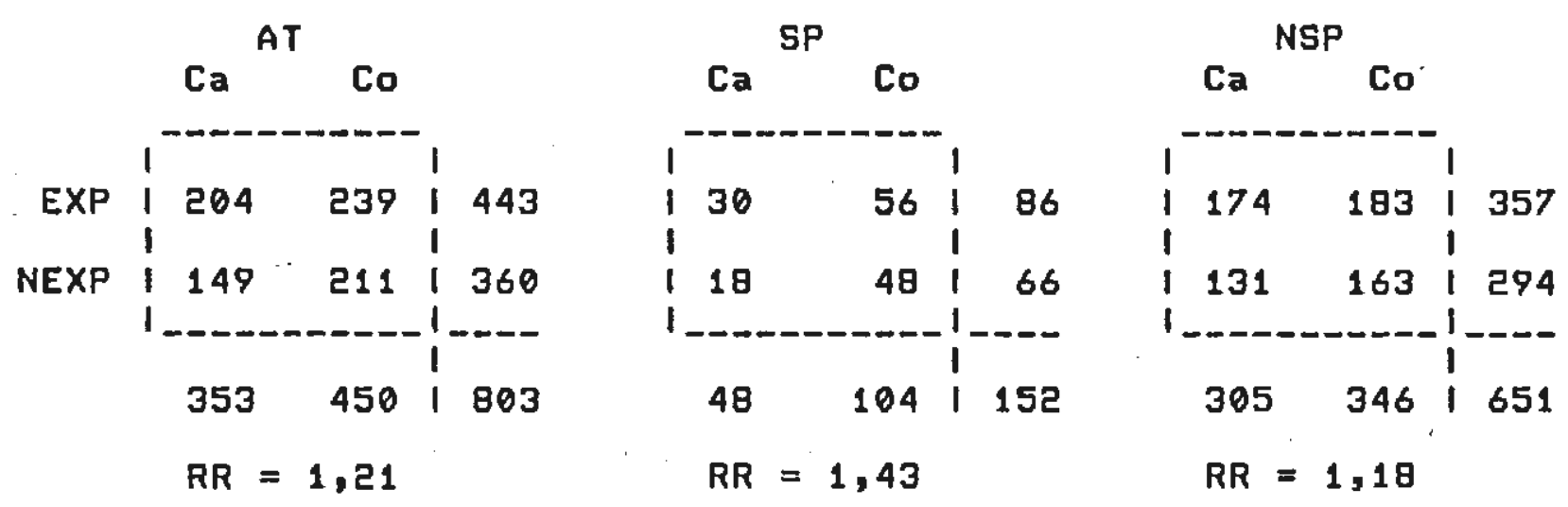

TABELA $\$ 34$ - NÚMERO DE CASDS DE fISSURA LABIAL OU LABIO-PALATINA E DE CONTROLES SEgUndo "MZE - INGEstzo DE BEBIDA ALCODLICA".
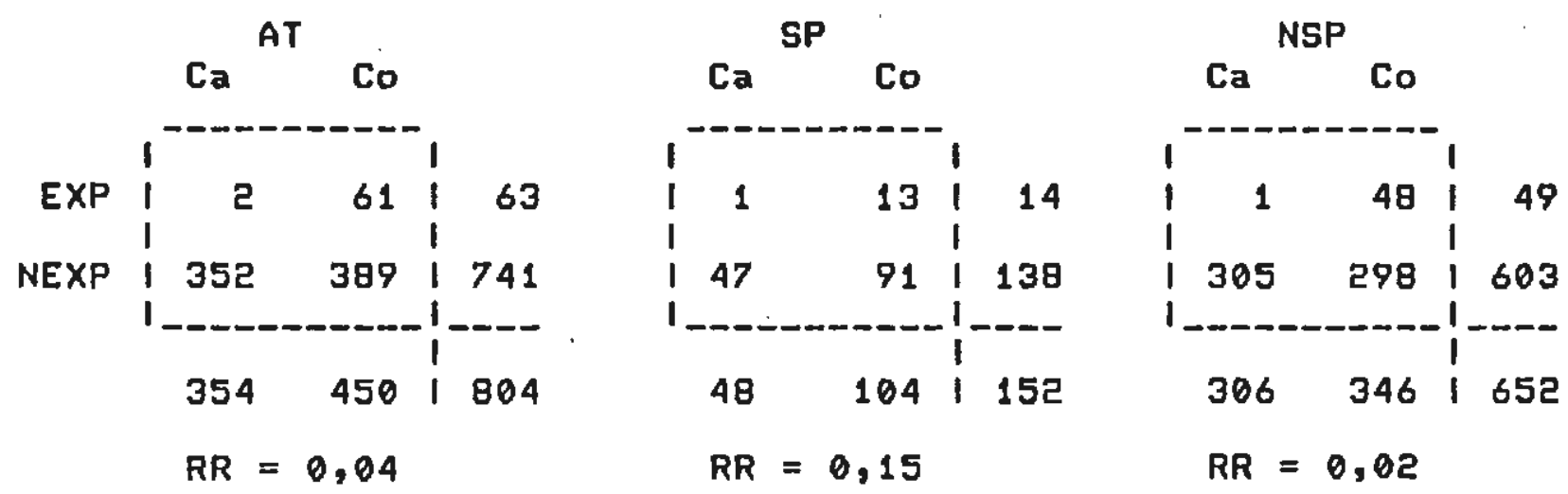


\section{ANEXO U}

\section{FISSURA PALATINA}

As tabelas de contingência a seguir referem-se aos atributos de estudo, quais sejam, caso (Ca) e controle (Co), dado que foram expostos (EXP) ou não-expostos (NEXP) aos possiveis fatores de risco.

Estes atributos foram analisados segundo o local de moradia da mãe do caso ou do controle nos 4 primeiros meses de gestacão e categorizados por : - amostra total (AT), quando o local de moradia se referia ao pais todo: - municipio de são Paulo (SP), quando o local era o municipio de São Paulo; - não-municiPio de São Paulo (NSP), quando o local era formado por qualquer municipio deste pais, com excefão do município de São Paulo.

Foi calculado o risco relativo (RR) para cada tabela de contingência. Não houve preocupafão en ajustes do risco relativo segundo os estratos porque pretendeu-se verificar se a cidade de são Paulo modificaria o comportamento da variável de análise.

Construiu-se a tabela a seguir para casose contrales da cidade de São Paulo e de fora dela e encontrou-se: 


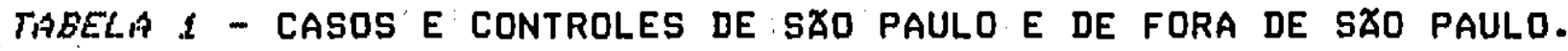

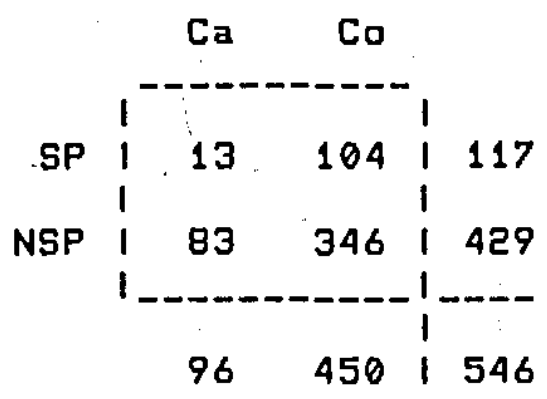

$\begin{aligned} \mathrm{SP} \times \mathrm{Ca}: \mathrm{OR} & =0,52 \\ \mathrm{NSP} \times \mathrm{Ca}: \mathrm{OR} & =1 / 0,52=1,92\end{aligned}$

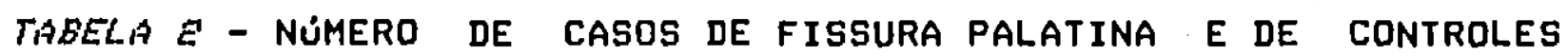
SEGUNDO "ZONA RURAL".
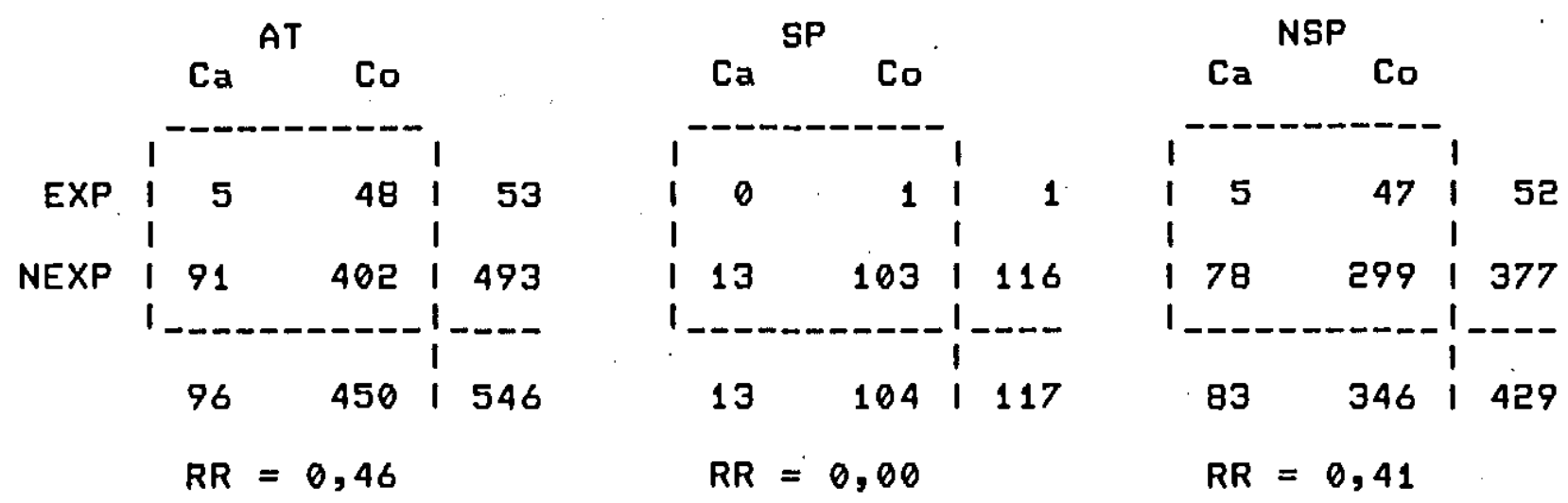
TABELA 3 - Número de CASOS DE fissura palatina E de CONTROLES SEGUNDO "POLUICðO".
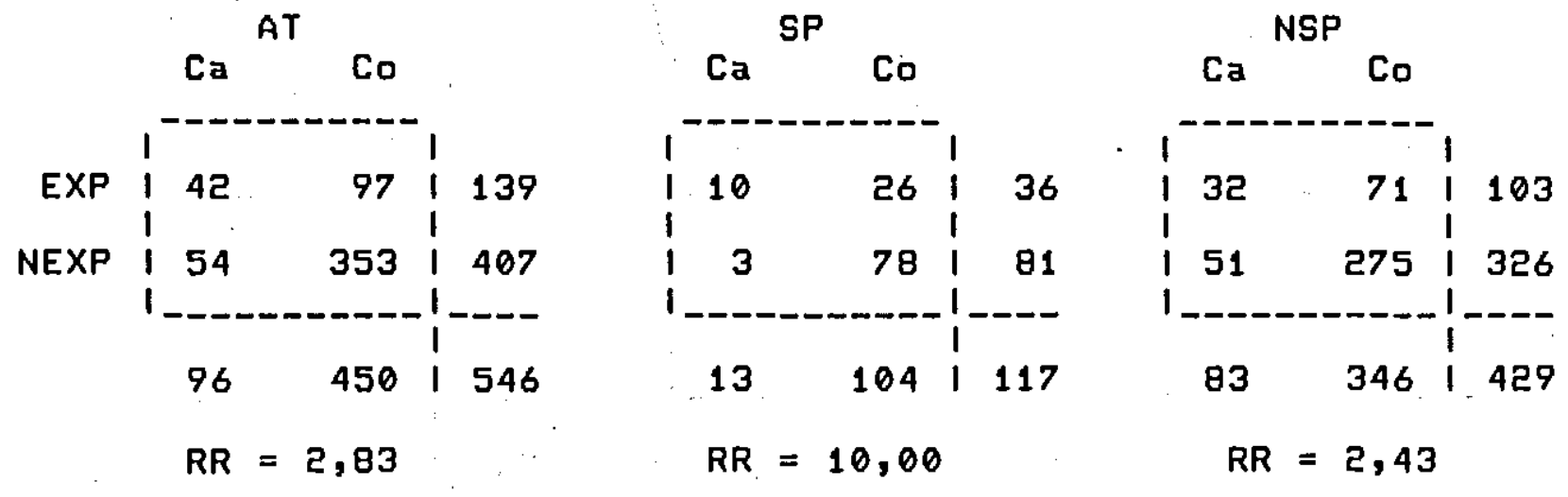

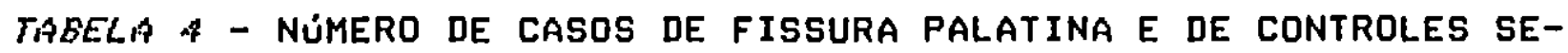
GUNDO "PAI-LAVOURA".
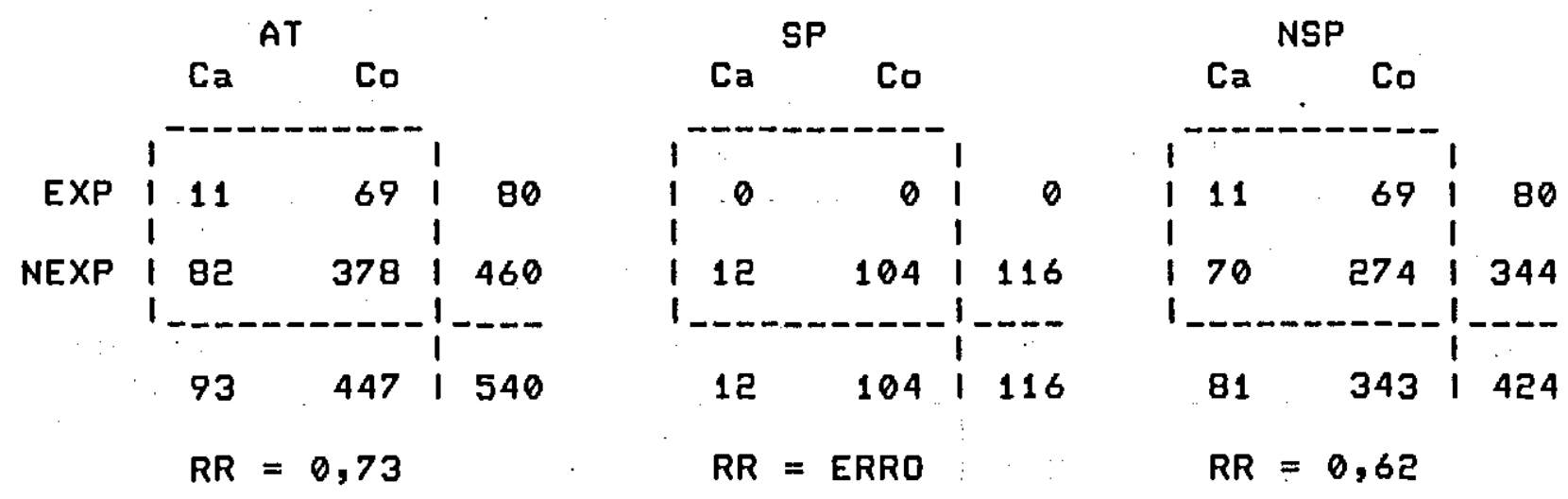
TABELA 5 - NÚMERO DE CASOS DE FISSURA PALATINA E DE CONTROLES 5EgUNDO "PAI - APLICACXO DE PESTICIDA OU HERBICIDA NA LAVOURA".
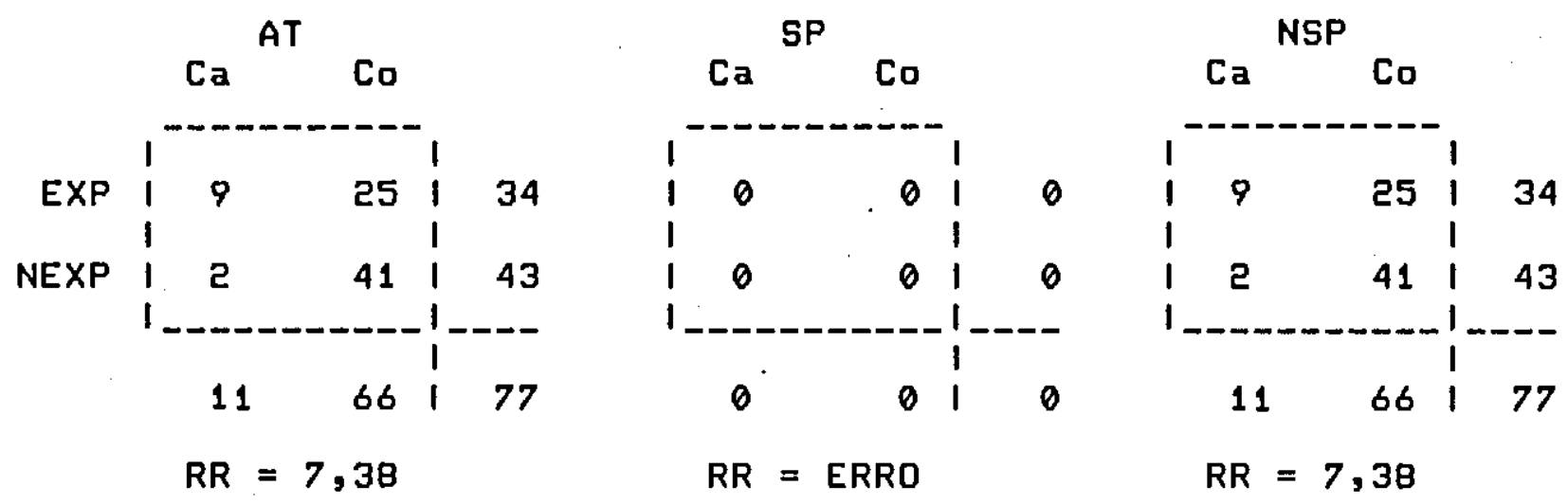

TABELA \& - NúMERO dE CASOS DE FISSURA PALATINA E DE CONTROLES SEGUNDO "MXE - LAVOURA".
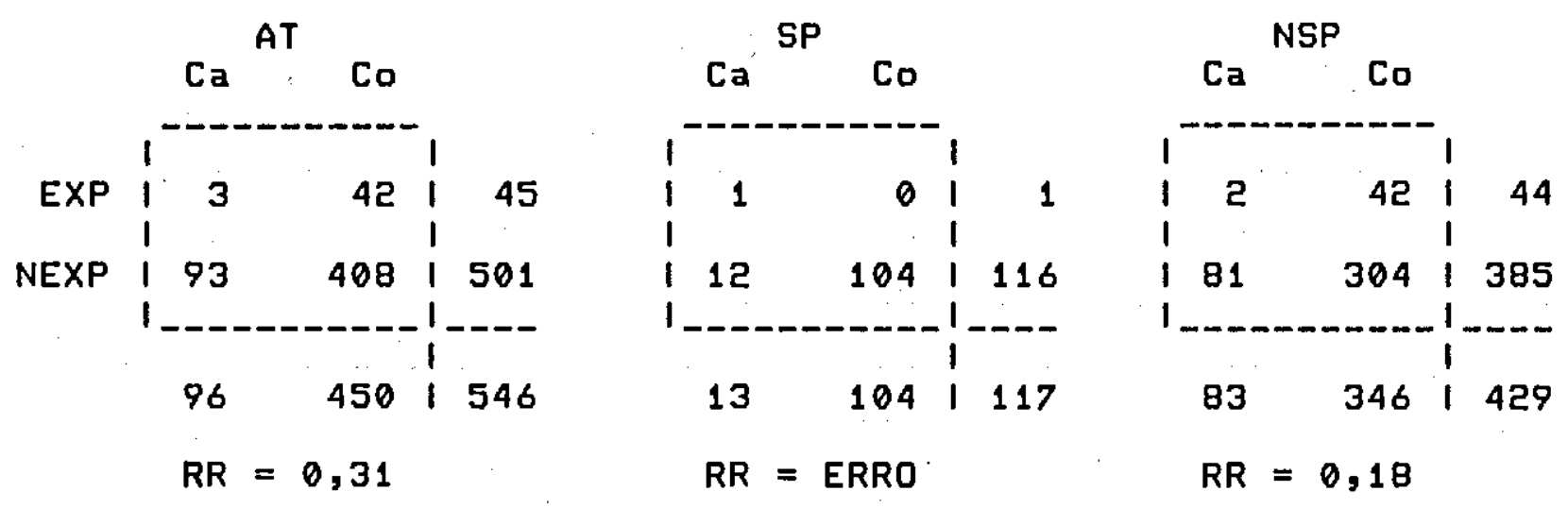
TABELA F - NÚMERO DE CASOS DE fISSURA PALATINA E DE CONTROLES SEGUNDO "MÃE - APLICACXO DE PESTICIDA OU HERBICIDA NA LAUOURA".
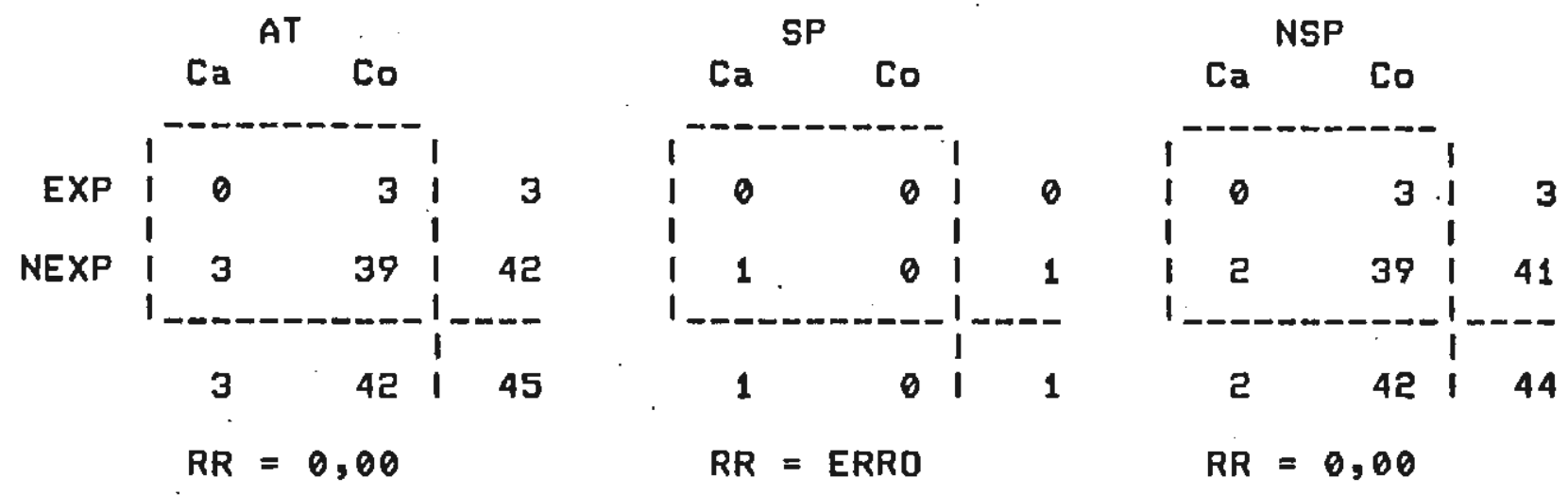

TABELA $B$ - NÚMERO DE CASOS DE FISSURA PALATINA E DE CONTROLES SEGUNDO "MAE - PARENTESCO ENTRE OS PAIS".
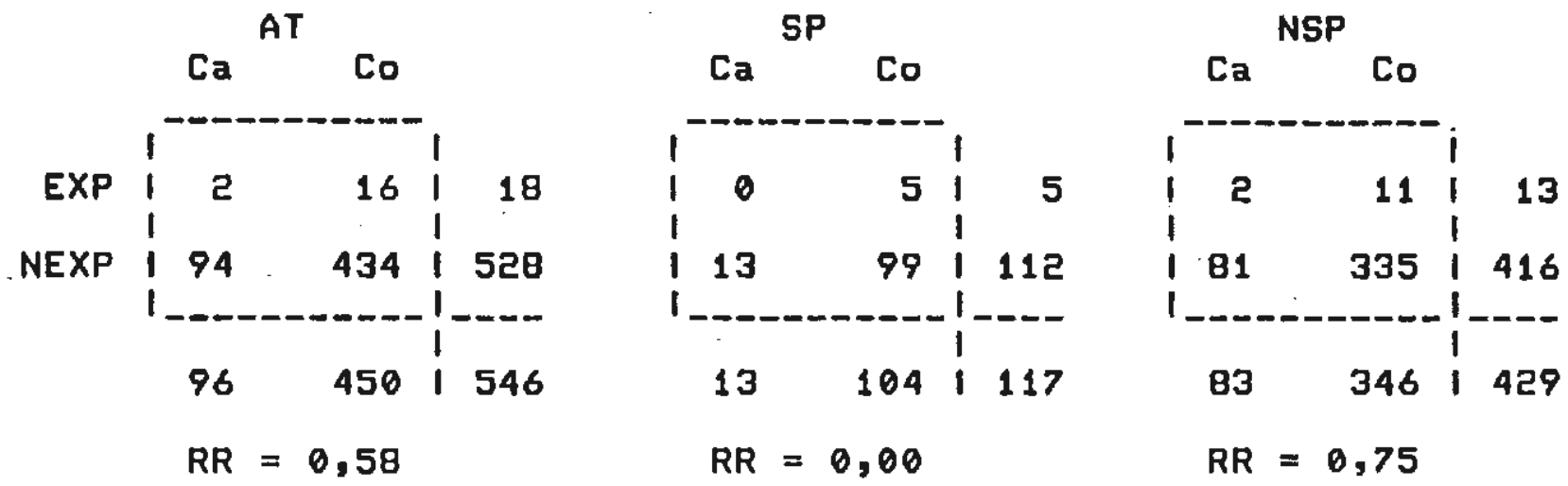
tabela - Número de casos de fissura palatina e de controles SegUNDO "TER PARENTE FissURADO".
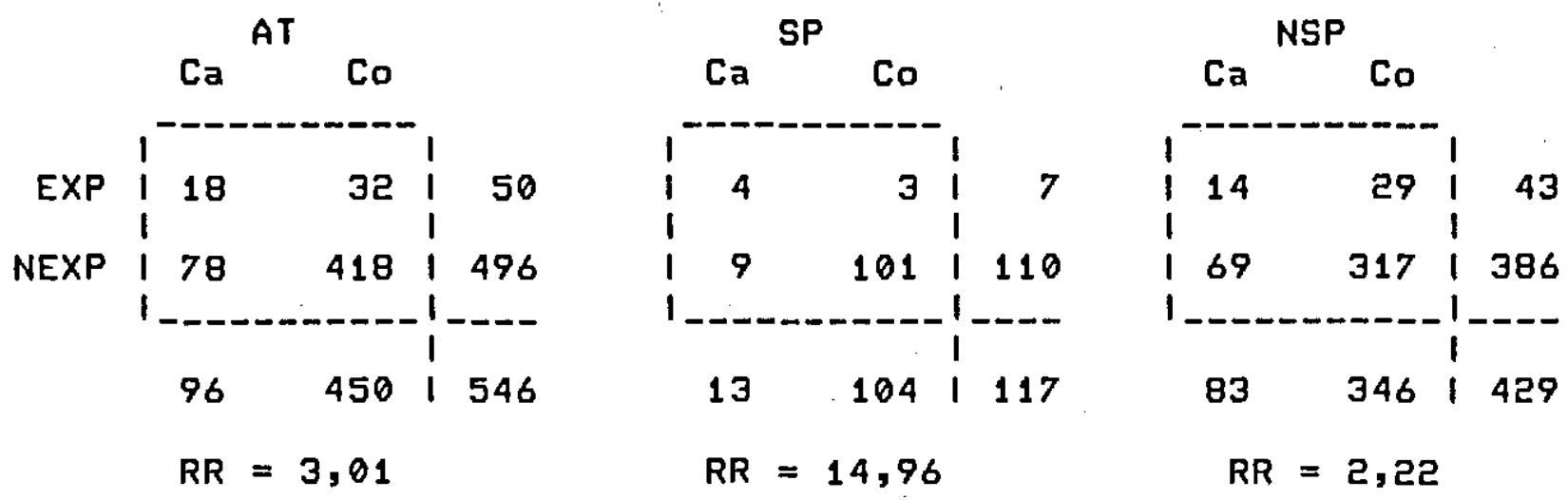

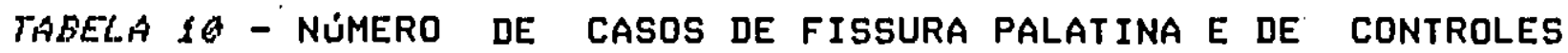
SEgUNDO "MZE COM EPILEPSIA".
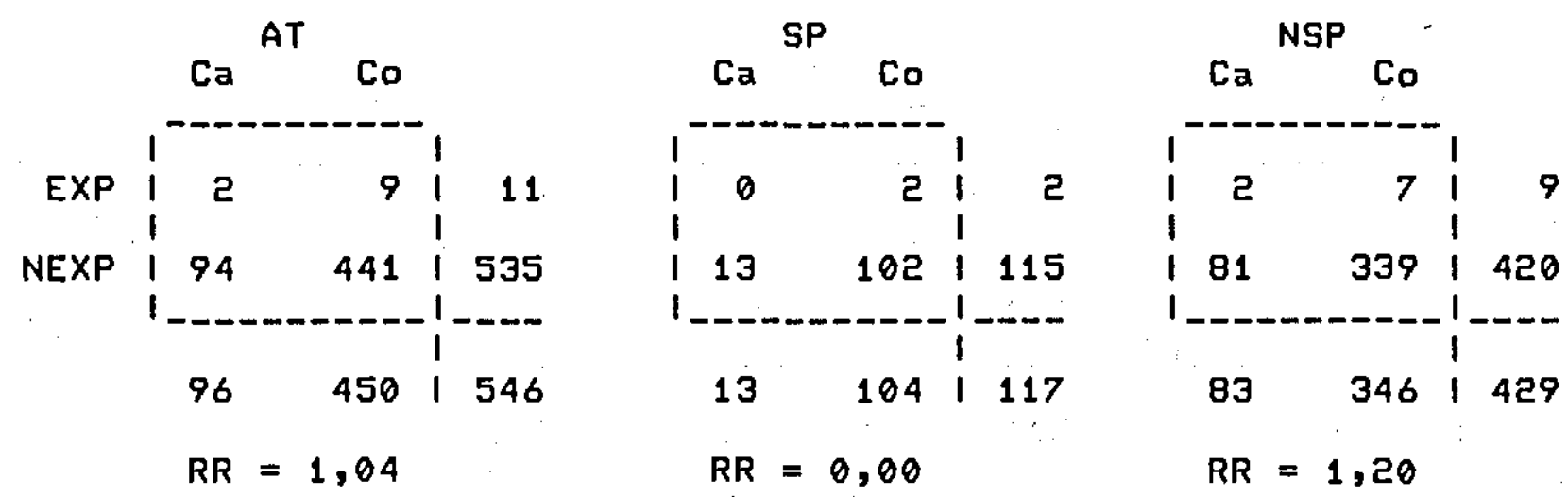
TABELA It - NÚMERO DE CASOS DE FISSURA PALATINA E DE CONTROLES SEGUNDO "PAI COM EPILEPSIA".
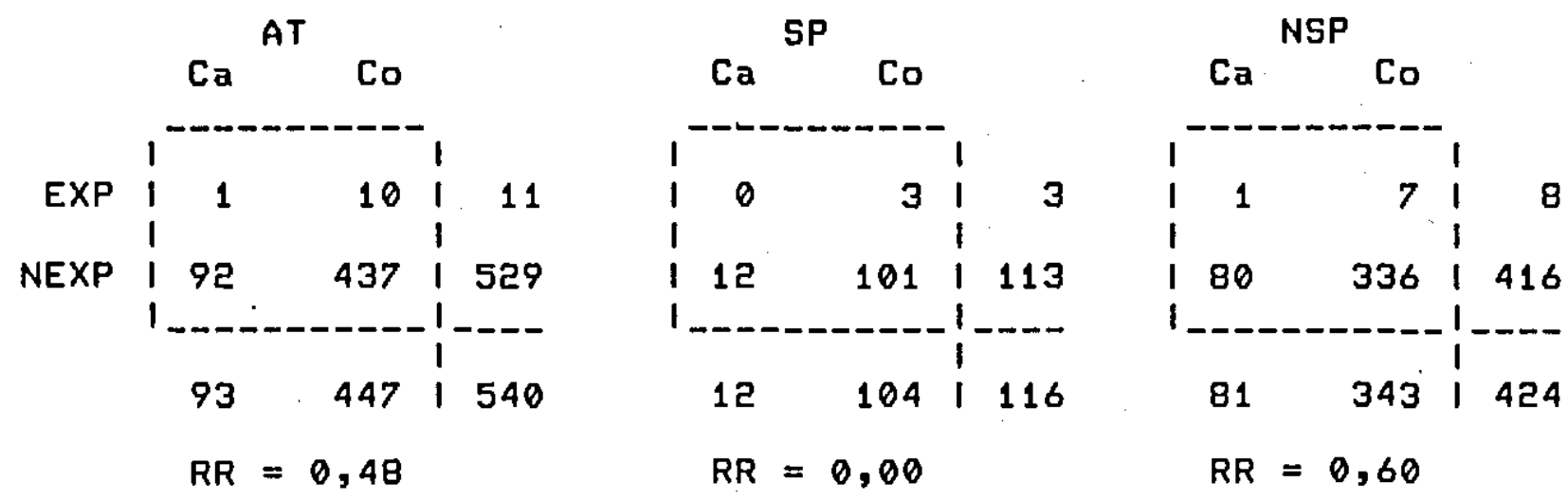

tabelaA IE - NúmERo dE CASOS DE fISSURA PALATINA E dE CONTROLES SEgUNDO "MaE COM haNSENiASE".
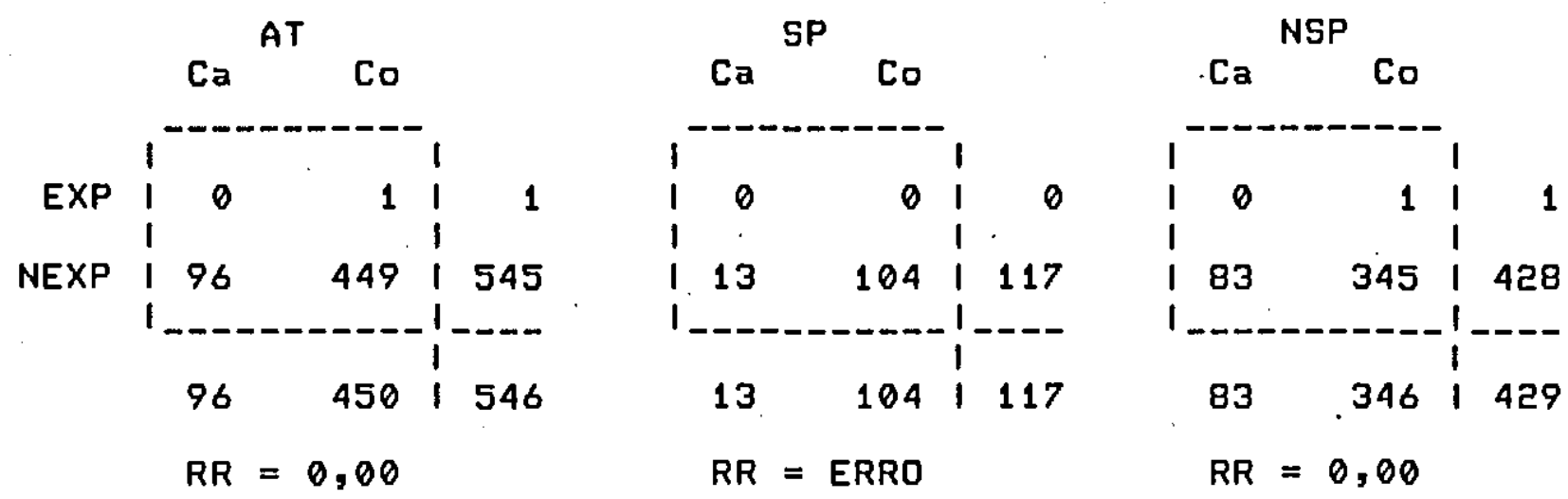


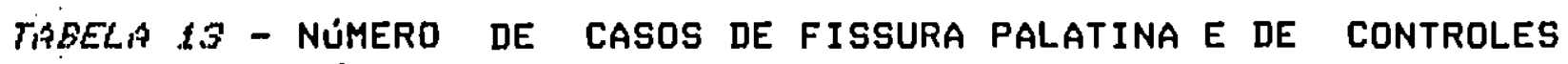
SEGUNDO "PAI COM HANSENIASE".
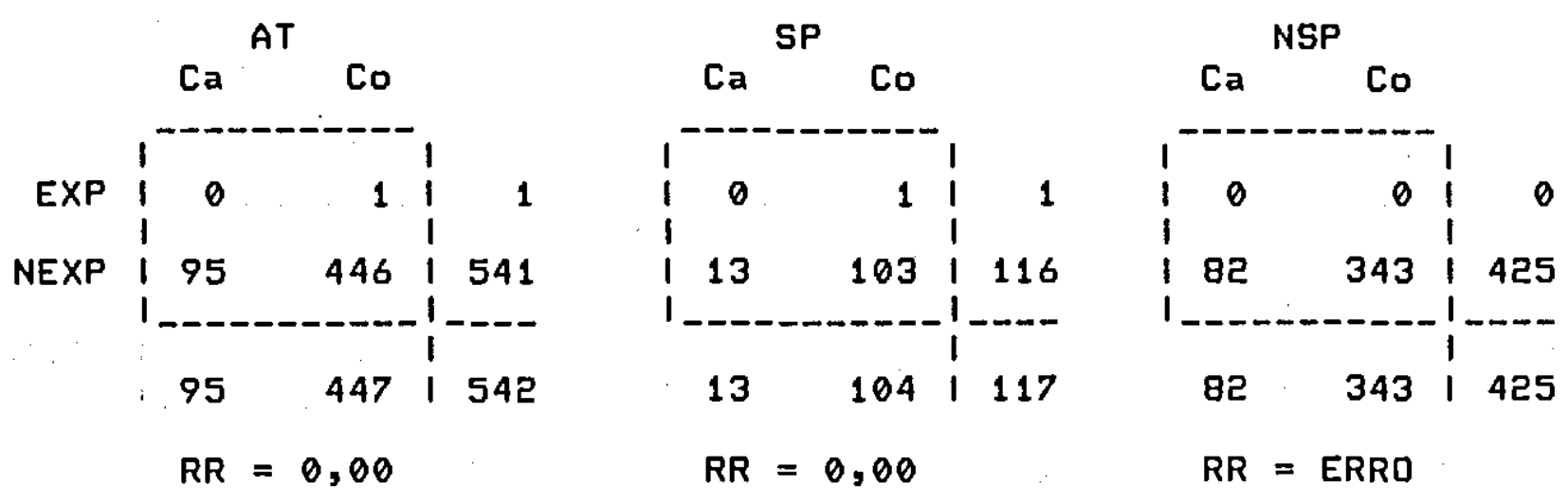

tabela 24 - Número dE CASOS dE fissura palatina e dE CONTROLES SEGUNDO "MXE - RUBEOLA".
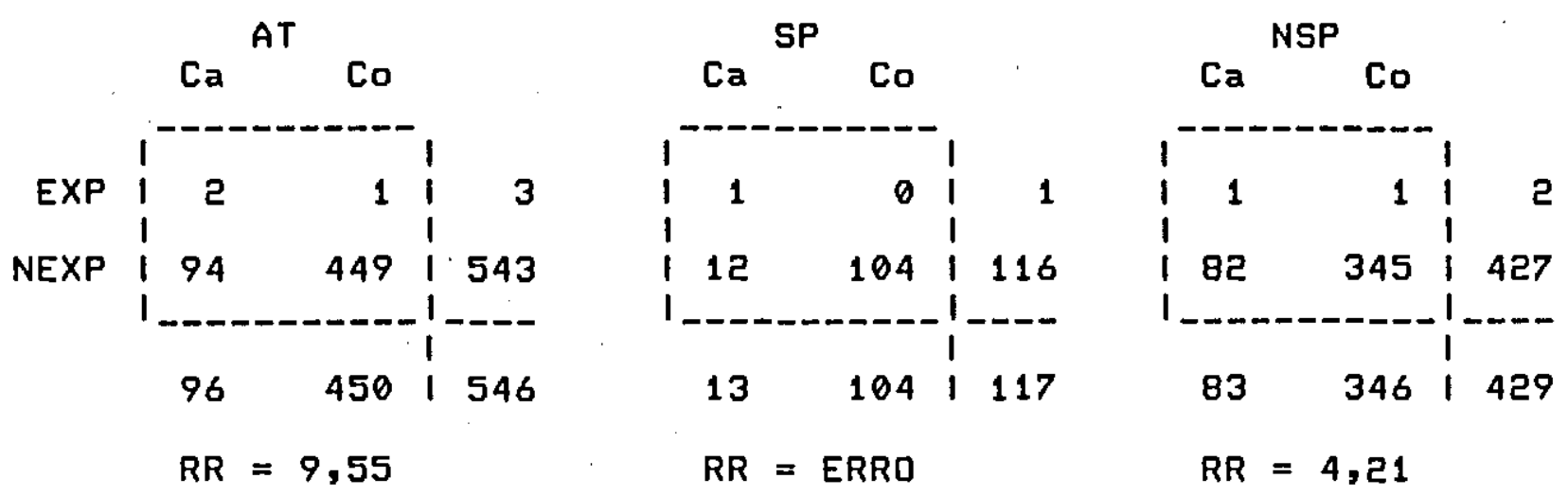
TABELA 15 - NúMERO DE CASOS DE FISSURA PALATINA E DE CONTROLES SEGUNDO "Mス̃ - HIPERTENSð̃o".
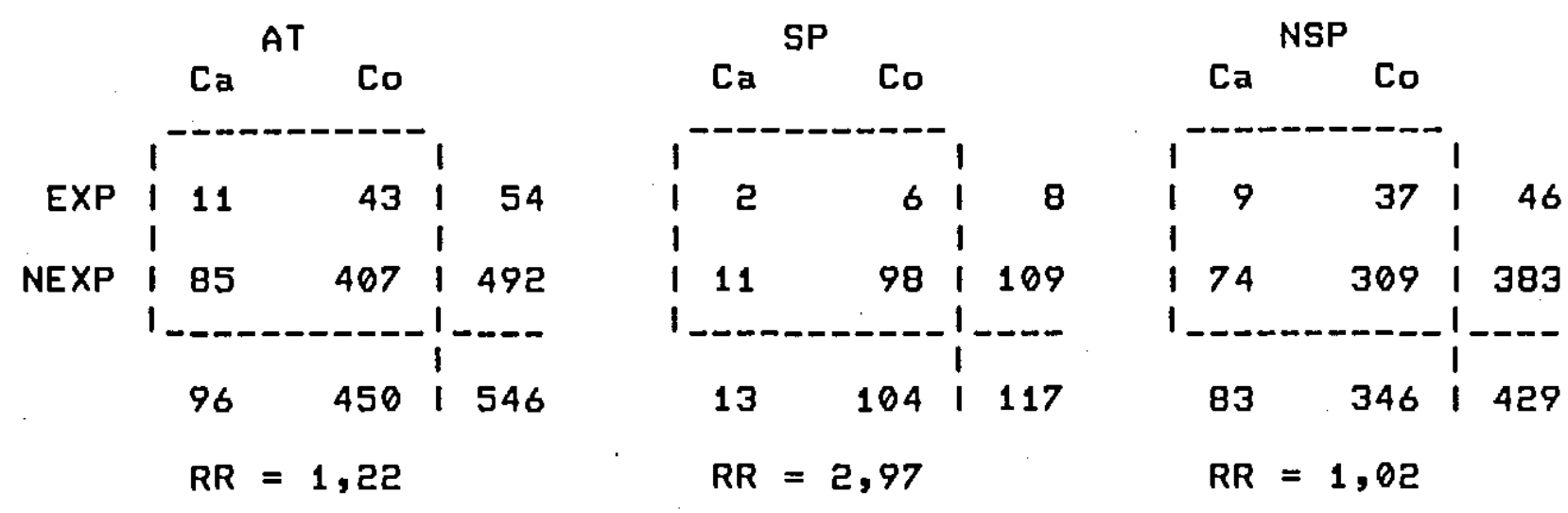

TABELA LG - NÚMERO DE CASOS DE FISSURA PALATINA E DE CONTROLES SEgUNDO "MðE - CONUULSХ̃".
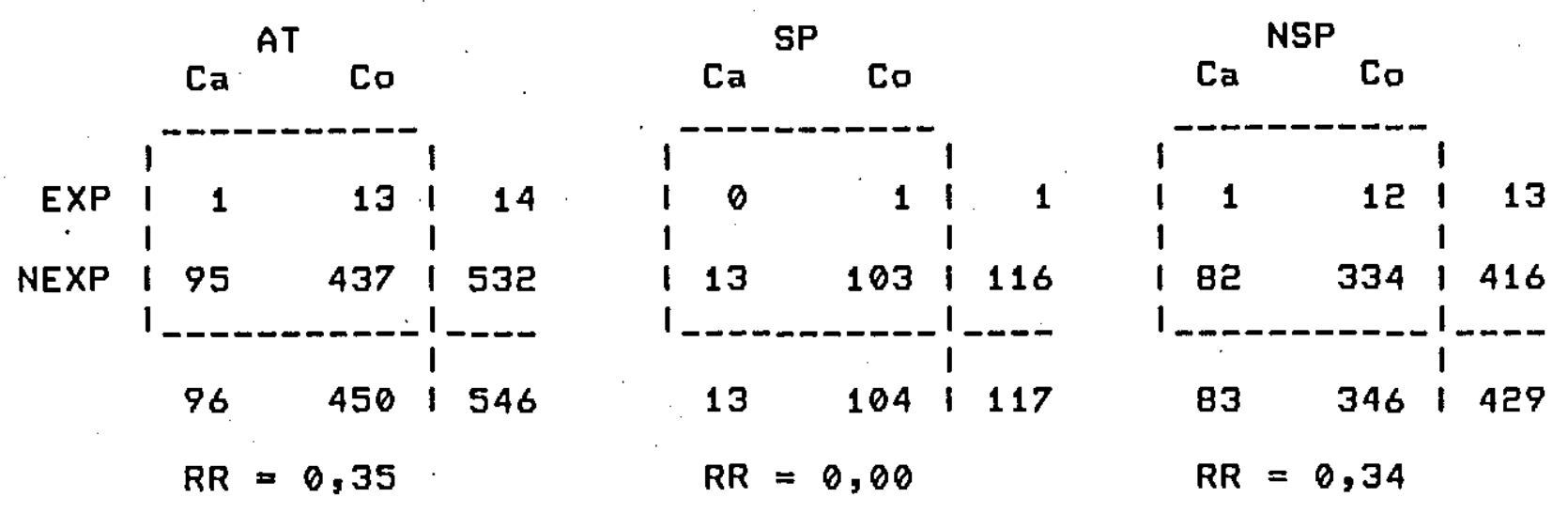
TABELA 17 - NúMERO DE CASOS DE FISSURA PALATINA E DE CONTROLES SEGUNDO "MAE - DIABETES".
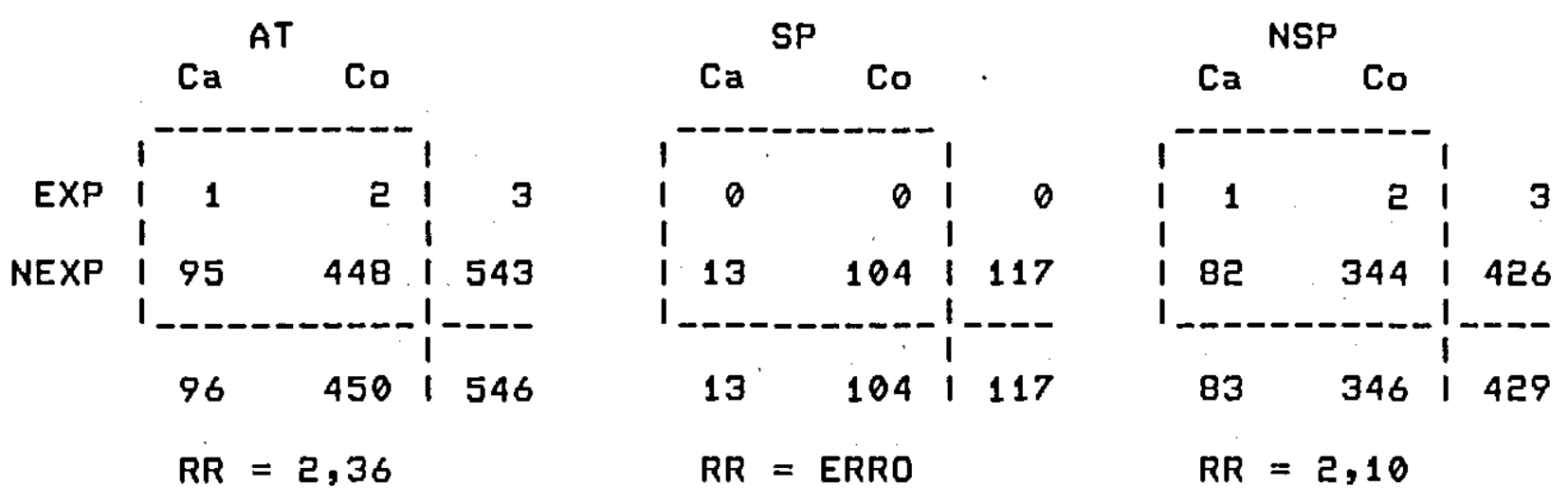

TABELA $2 B$ - NúmERO DE CASOS de fissura palatiNa E DE CONTROLES SEGUNDO " INGESTXO DE ANTI-INFLAMATóRIO NOS 4 PRIMEIROS MESES DE GESTACXO".
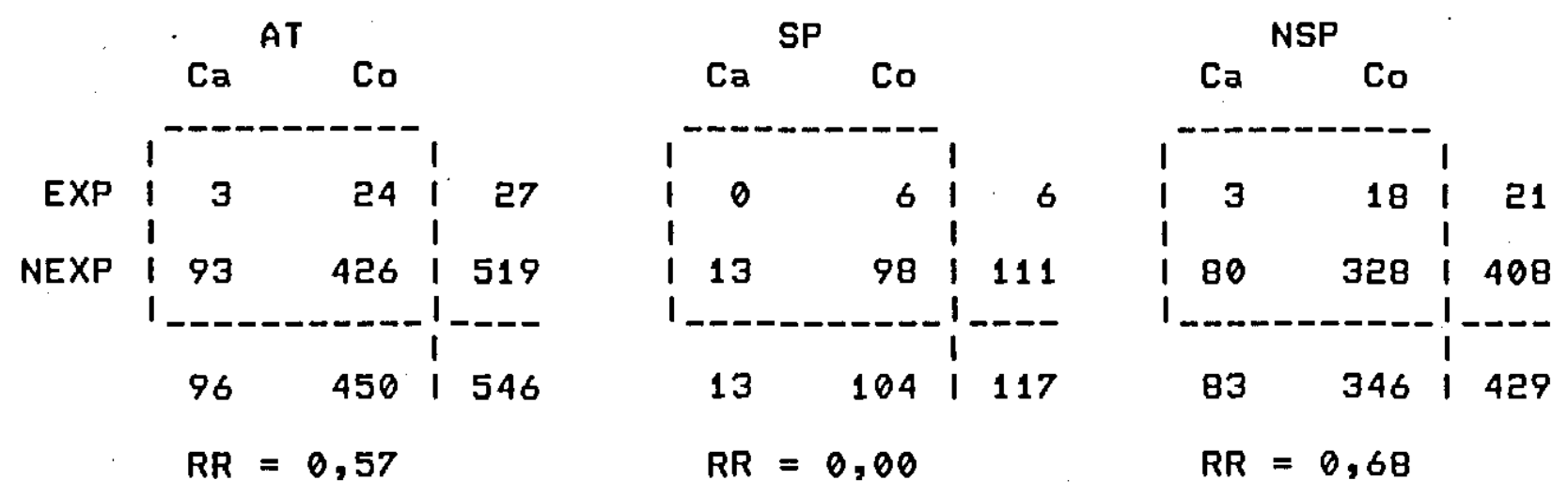
TABBELA 19 - NúMERo DE CASOS DE fISSURA PALATINA E DE CONTROLES SEgundo "INGESTro de ANTI-EMétICO NOS 4 PRIMEIROS MESES DE GESTACAO".
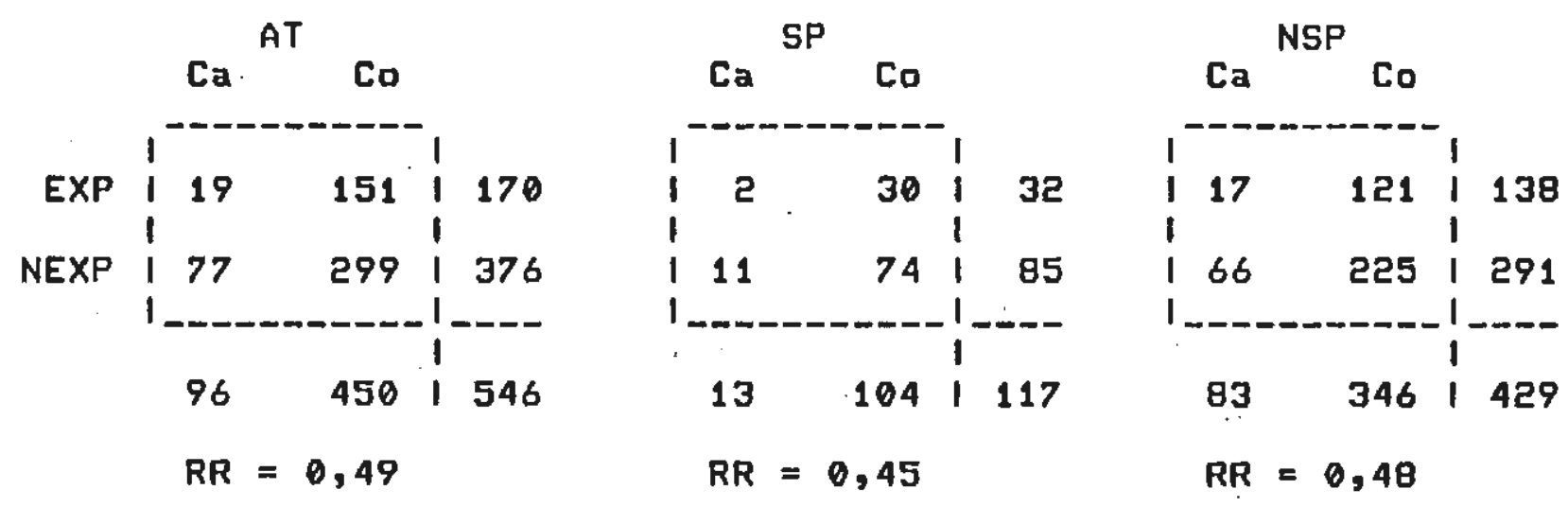

TABELA 20 - NúMERO DE CASOS dE fissura PALATINA E DE CONTROLES SEgUndo "INGESTro de ANTI-CONUULSIVANTE NOS 4 PRIMEIROS MESES DE GESTAČ̃".
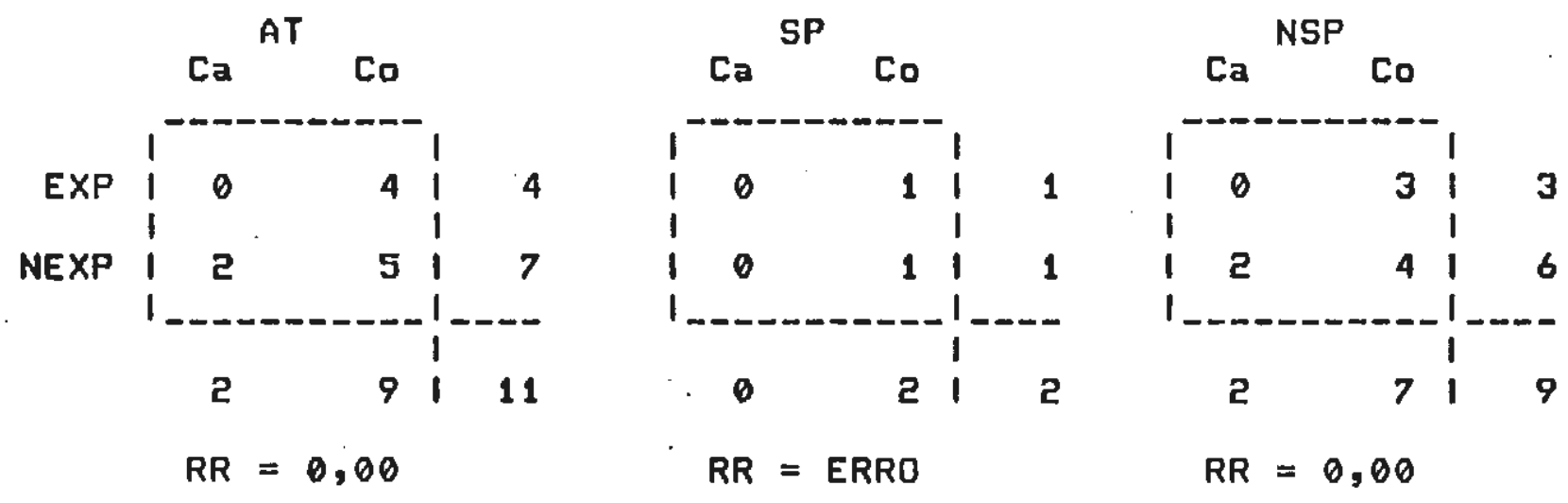


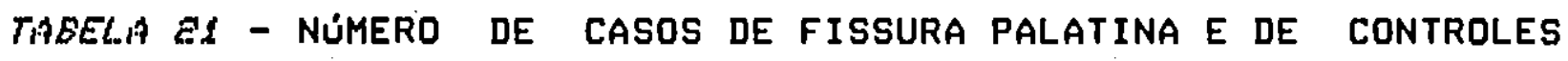
SEGUNDO "INGESTZO DE ANTI-HIPERTENSIVO NOS 4 PRIMEIROS MESES DE GESTACXO".
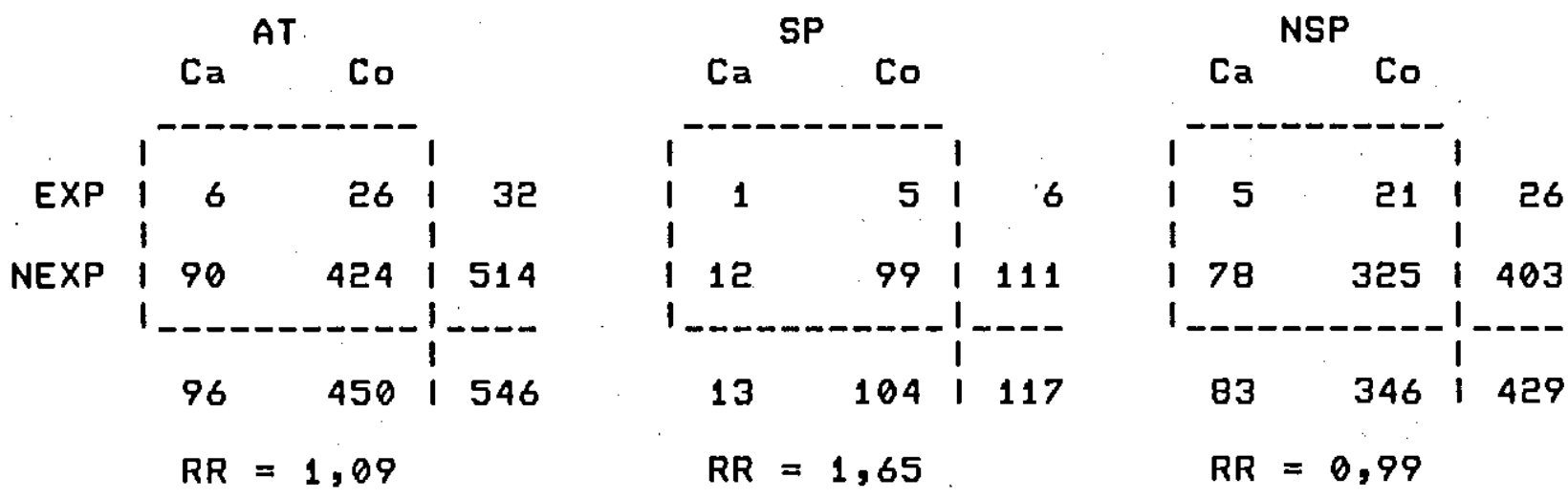

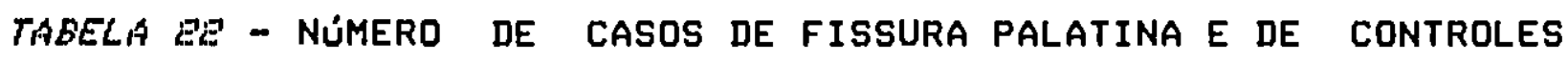
SEgUNDO "INGESTZO DE ANTI-ALÉRGICO NOS 4 PRIMEIROS MESES DE GESTACXO".
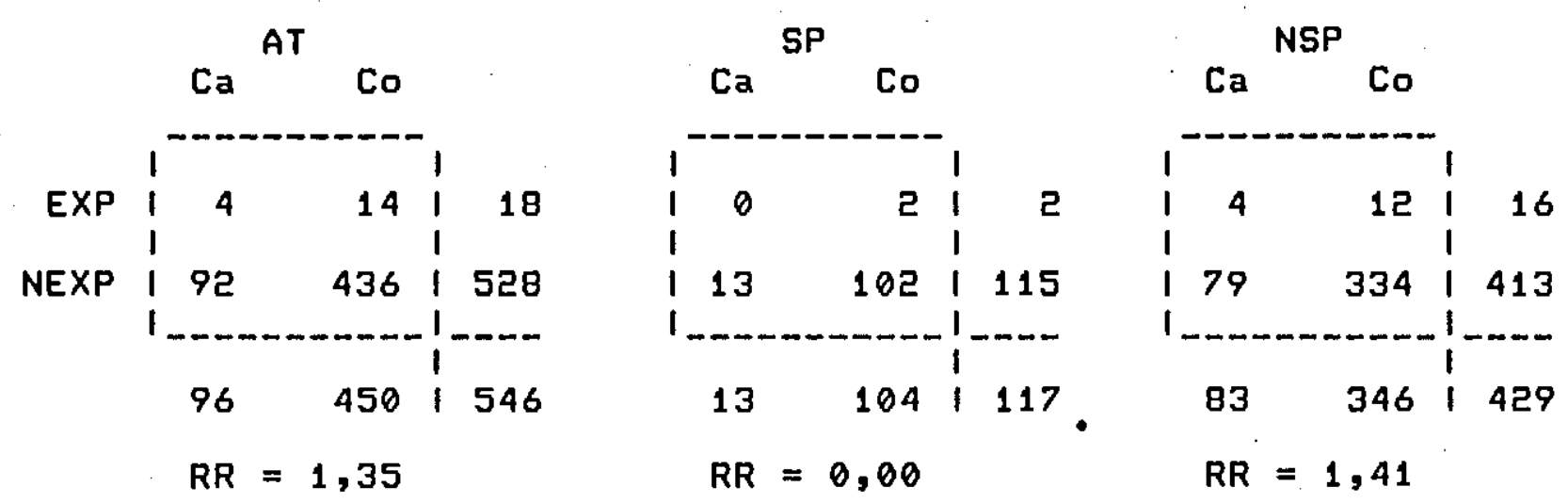
TABELA EIS - NúmERO DE CASOS DE fisSURA PALATINA E DE CONTROLES SEGUNDO "INGESTZO DE ANOVULATóRIO NOS 4 PRIMEIROS MESES DE GESTACXO".
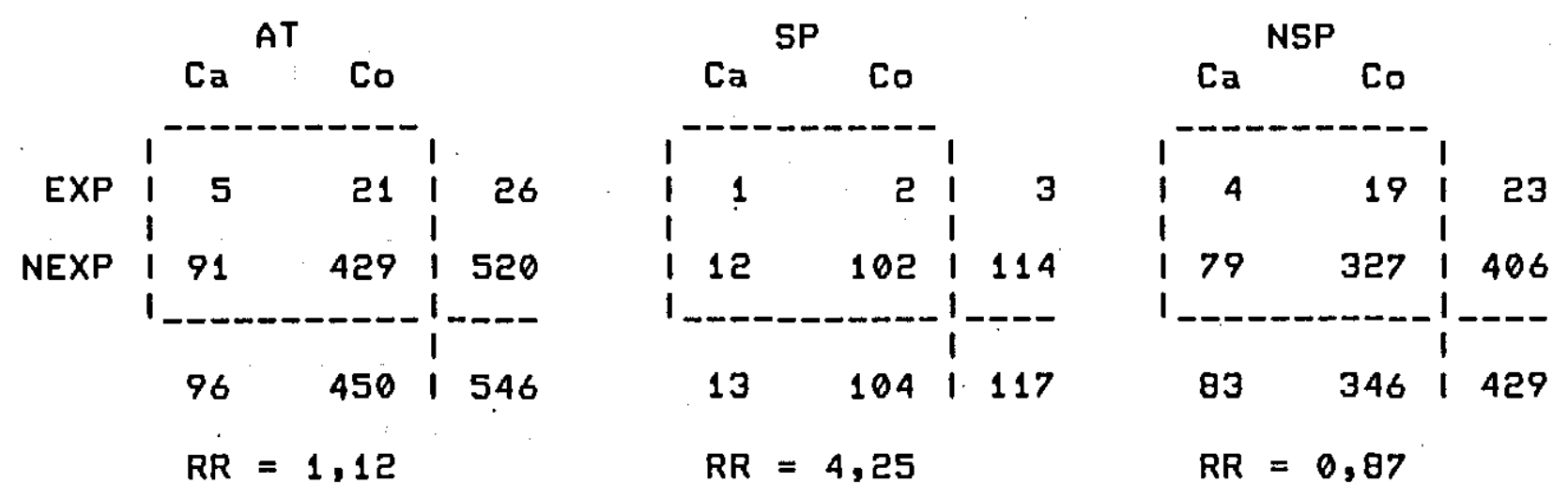

TABELA EA - NúMERO DE CASOS DE FISSURA PALATINA E DE CONTROLES SEGUNDO " INGESTZO DE COMPLEXO VITAMINICO NOS 4 PRIMEIROS MESES DE GESTACKO".
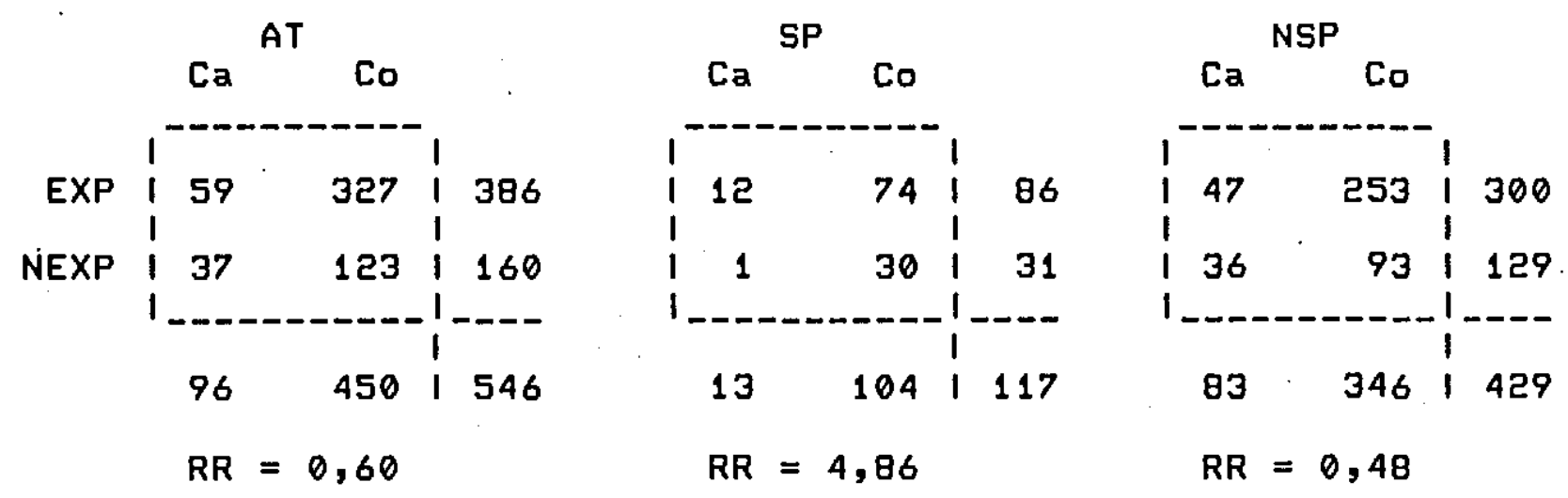
THSELA ESS - NÚMERO DE CASOS DE FISSURA PALATINA E DE CONTROLES SÉGUNDO "INGESTXO DE TALIDOMIDA NOS 4 PRIMEIROS MESES DE GESTACXO".
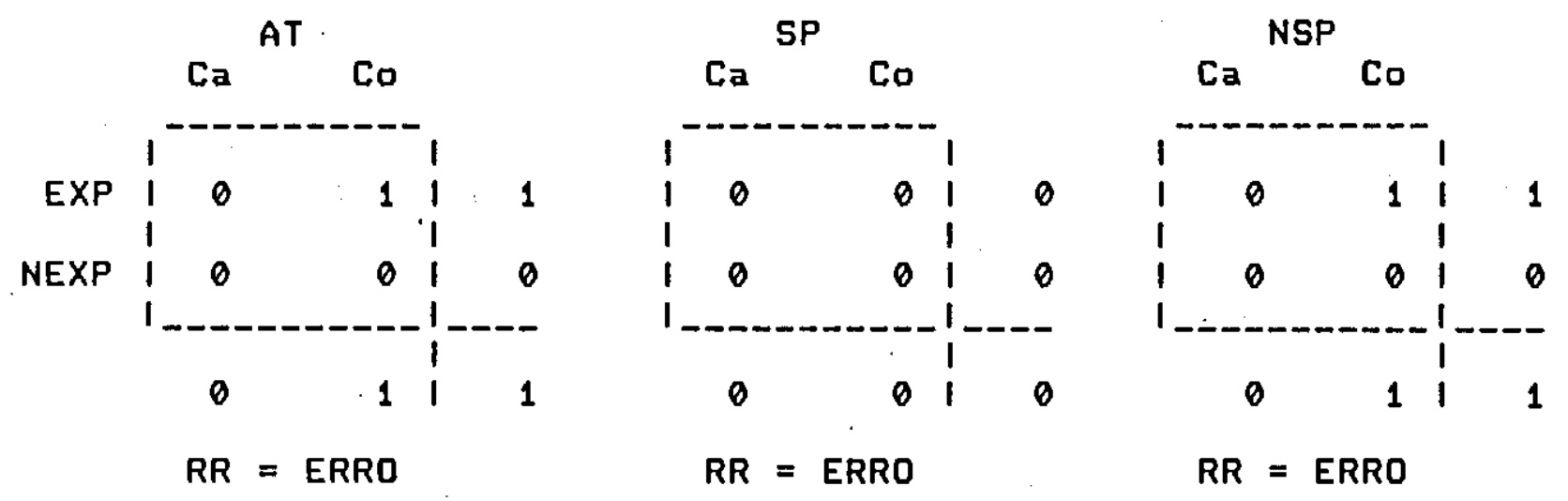

THaELA Ë' - NúMERO dE CASOS dE FISSURA PALATINA E DE CONTROLES SEgUNDO "INGESTKO DE ABORTIVO NOS 4 PRIMEIROS MESES DE GESTACXO".
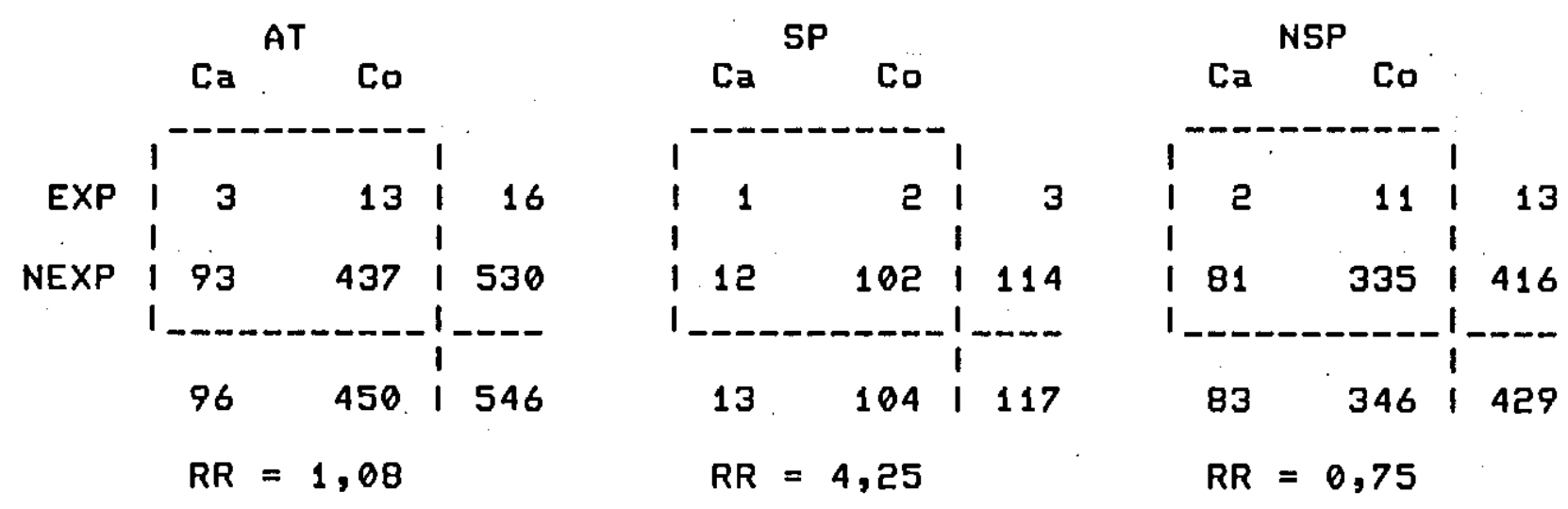
TABELA ET - NUMERO DE CASOS DE FISSURA PALATINA E DE CASOS CONTROLES SEGUNDO "INGESTฬO DE ANALGÉSICO NOS 4 PRIMEIROS MESES DE GESTACXO".
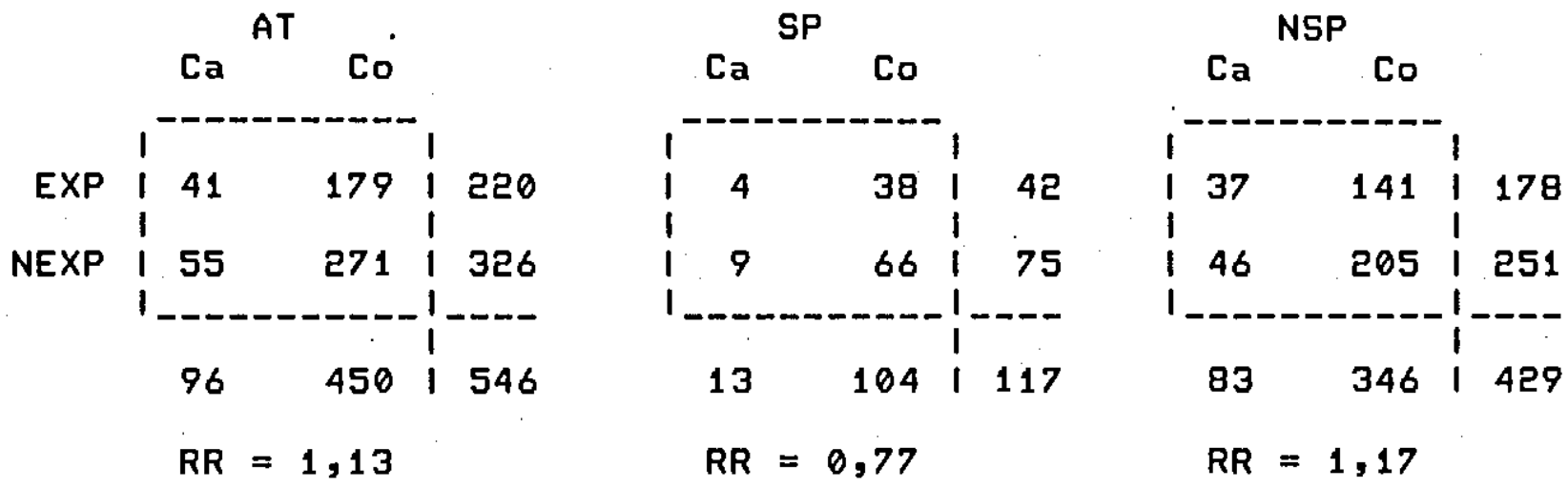

TABELA ES - NUMERO DE CASOS DE FISSURA PALATINA E DE CONTROLES SEGUNDO. "INGEST\&O DE ANTIBIÓTICO NOS 4 PRIMEIROS MESES DE GESTACXO".
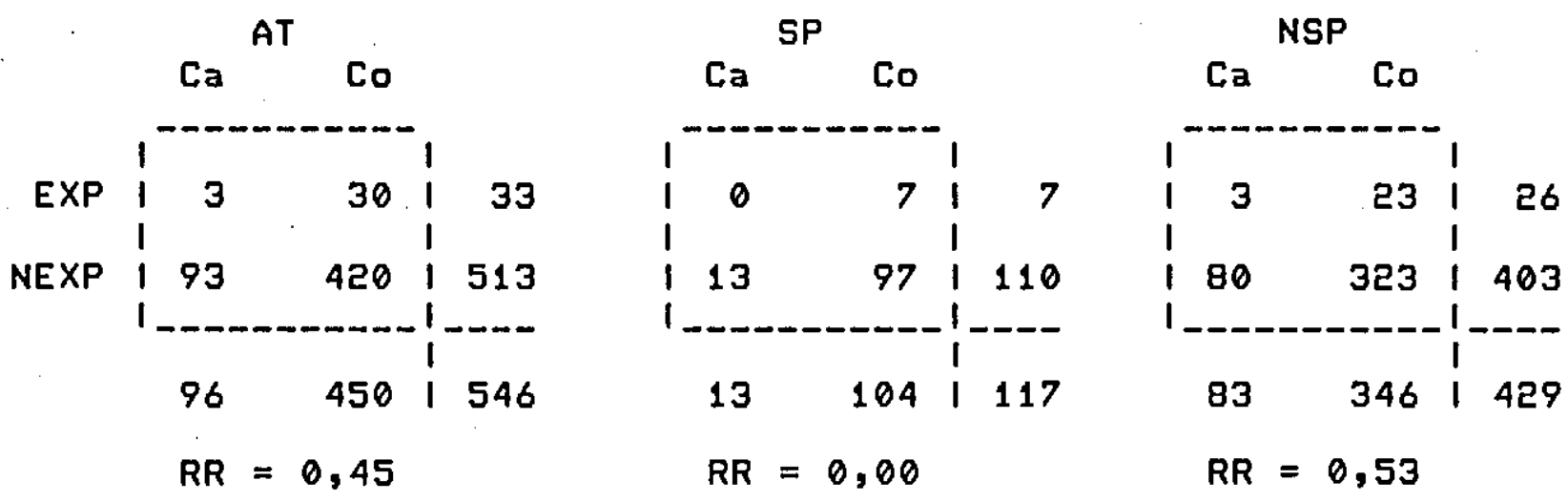
TABELAA ES - NúMERO DE CASOS DE FISSURA PALATINA E DE CONTROLES SEGUNDO "MZE - EXPOSICXO AO RX NOS 4 PRIMEIROS MESES DE GESTAEZO".
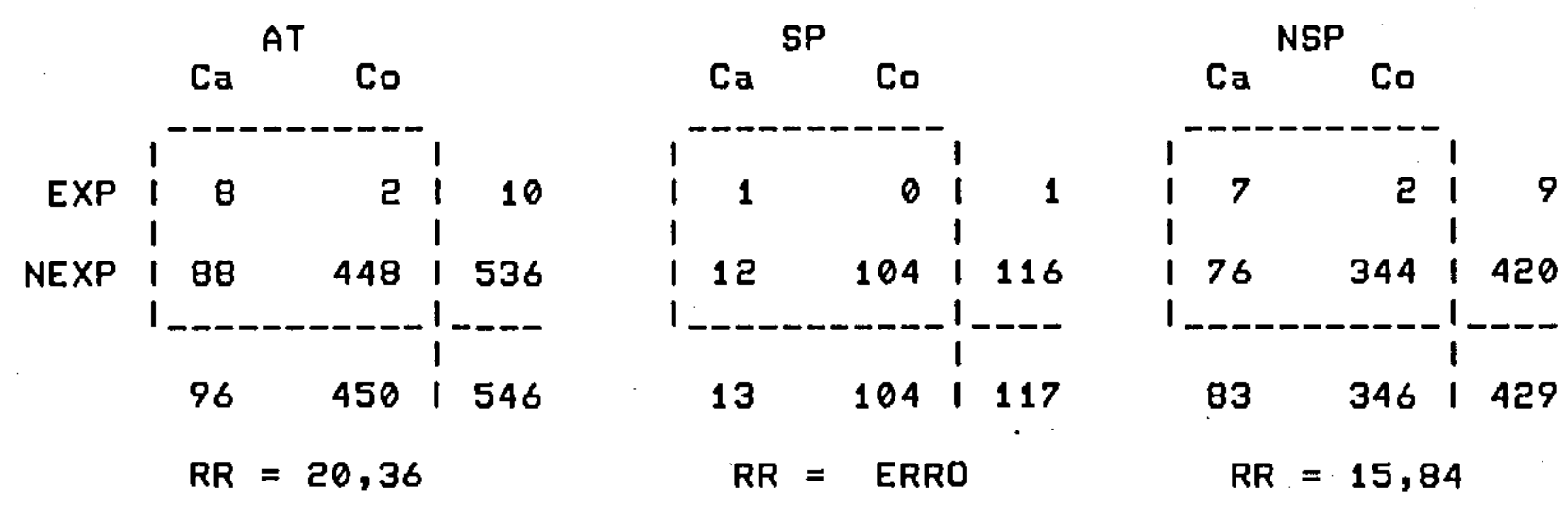

TABELA 30 - NúmERO DE CASOS DE fisSURA PALATINA E DE CONTROLES SEGUNDO "MZE - EXPOSICXO AO RX 1 ANO ANTES DA GESTAcxo".
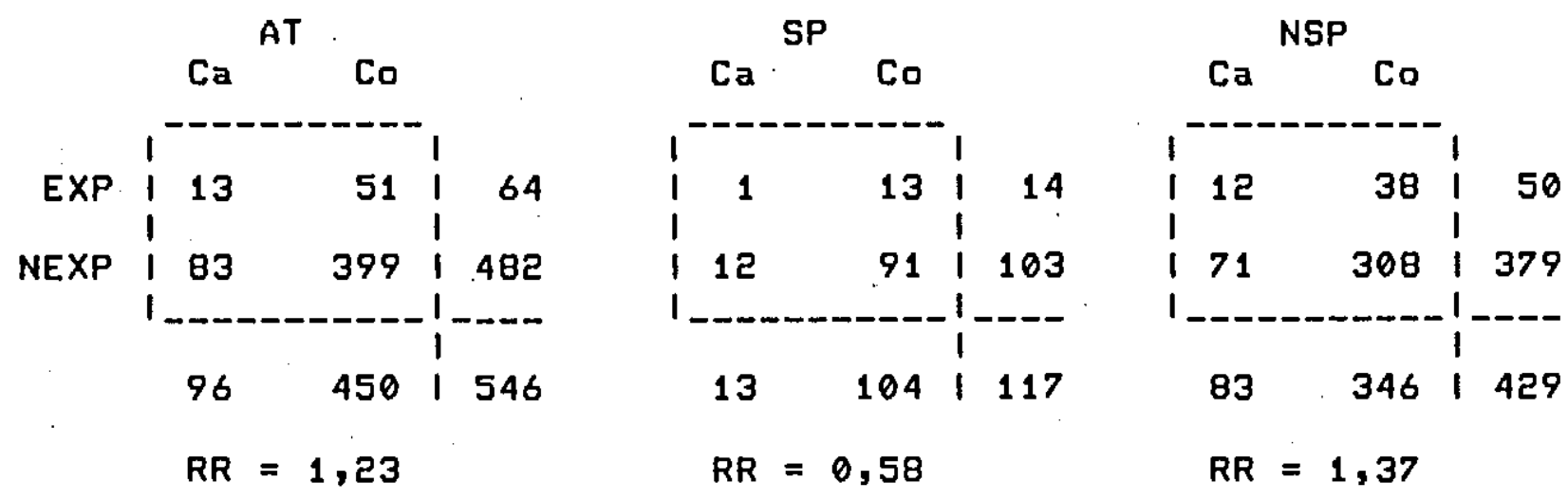
ThBELA Fit - NúMERo DE CASOS DE FISSURA PALATINA E DE CONTROLES SEGUNDO "PAI - EXPOSICZ̃O AO RX 1 ANO ANTES DA GESTACXO DA MXE".
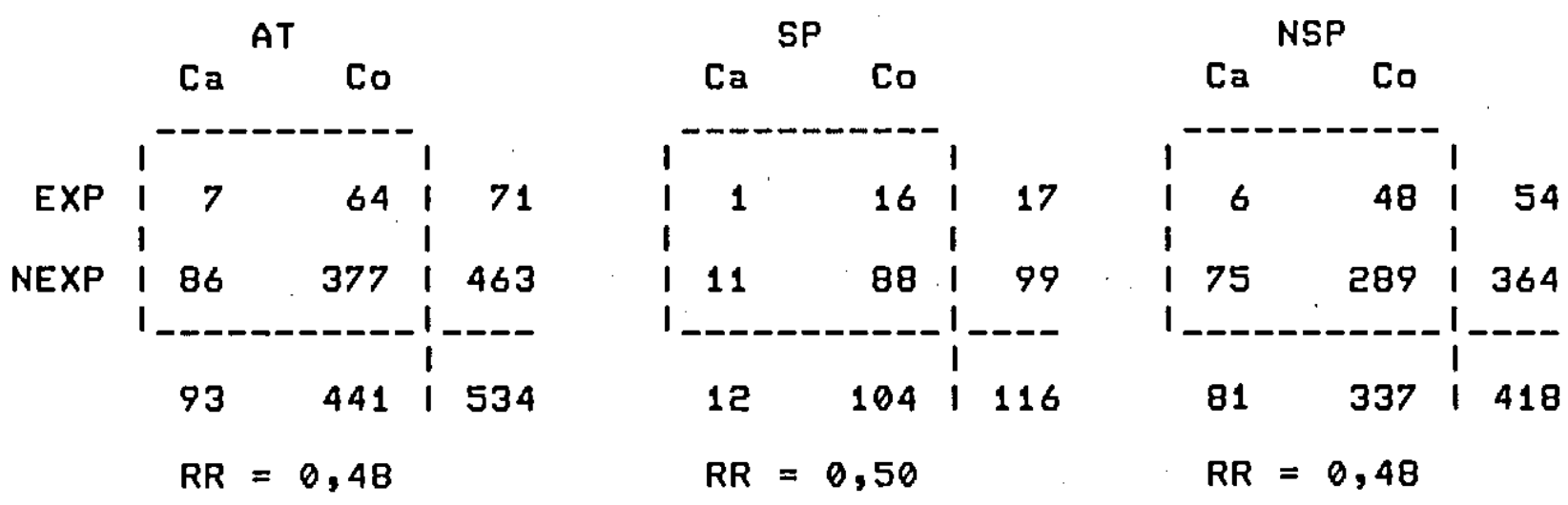

TABELA BZ - NÚMERO DE CASOS DE FISSURA PALATINA E DE CONTROLES SEGUNDO "MXE - HÁBITO DE FUMAR".
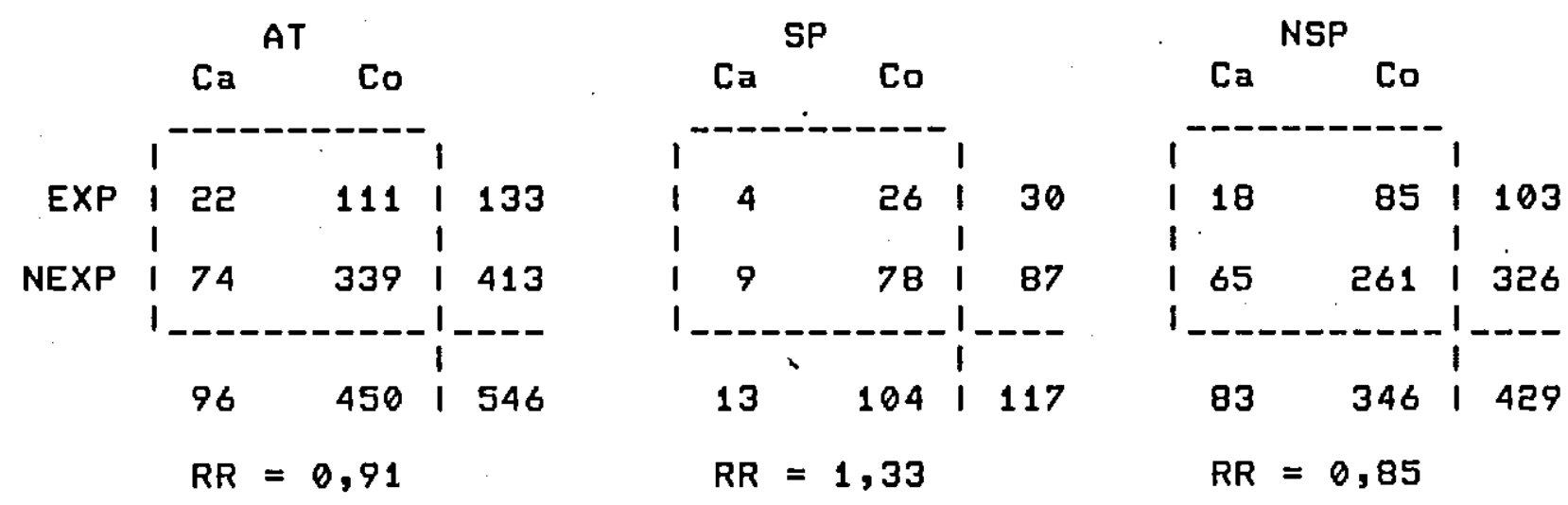
TABELA $3 \%$ - NÚMERO DE CASOS DE FISSURA PALATINA E DE CONTROLES SEGUNDO "PAI - HáBITO DE FUMAR".
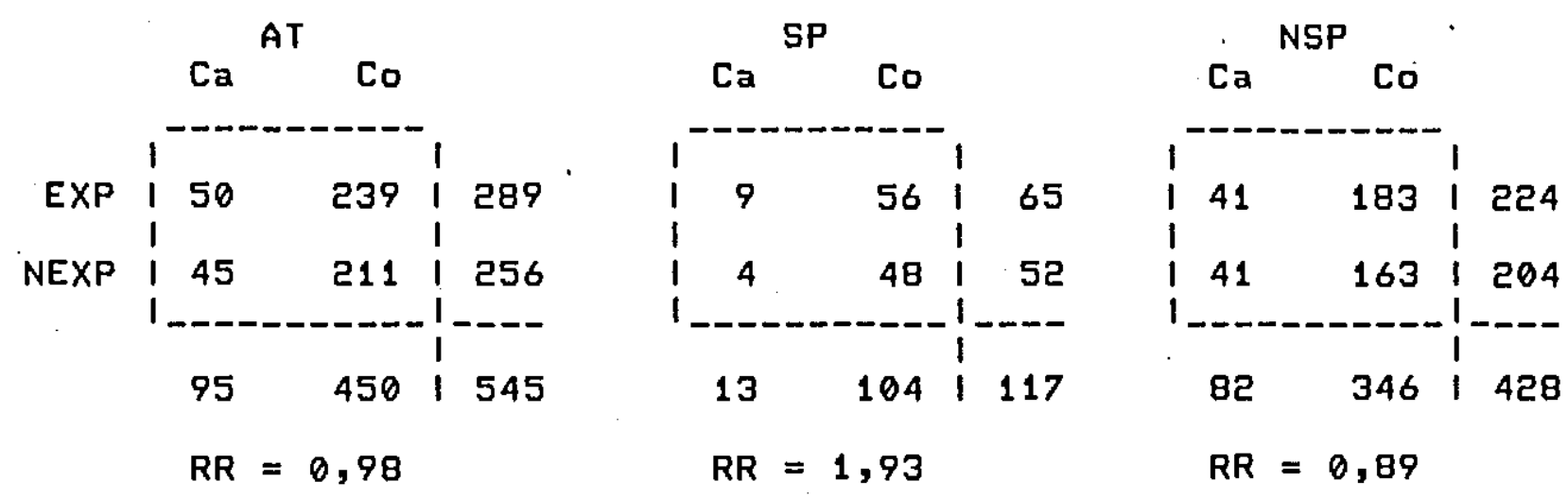

TABELA 34 - NúMERO DE CASOS DE FISSURA PALATINA E DE CONTROLES SEgUNDO "MKE - INGESTKO DE BEBIDA ALCOÓLICA NOS 4 PRIMEIROS MESES DE GESTACXO".
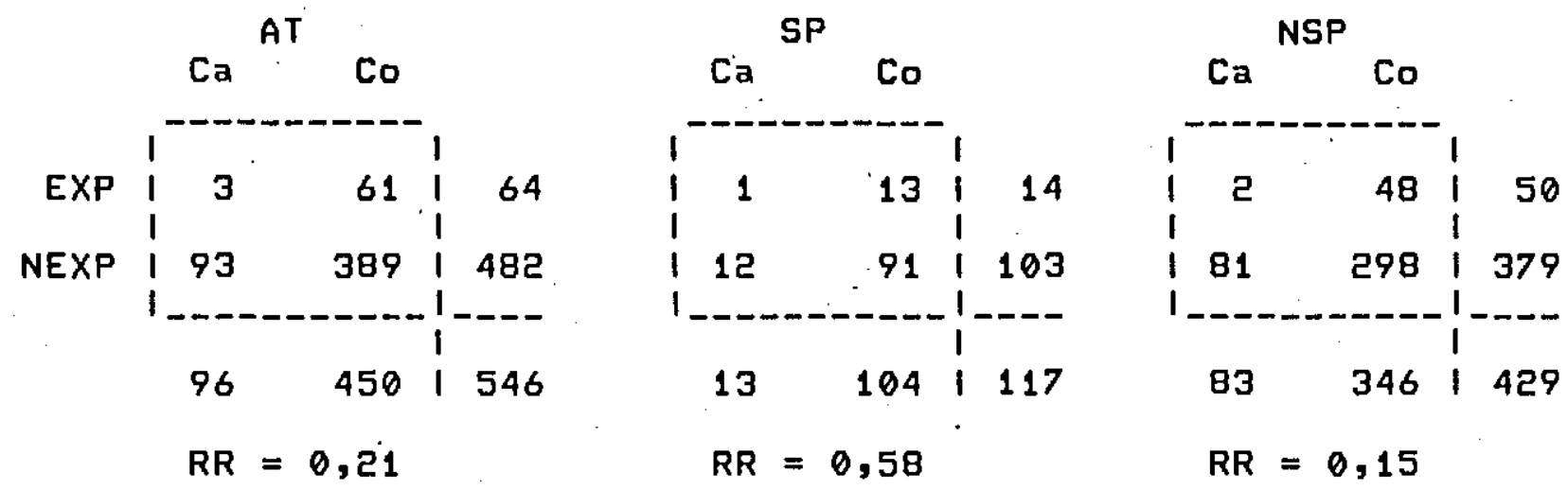